\title{
Research progress in nondoped lanthanoid silicate oxyapatites as new oxygen-ion conductors
}

\author{
Kiyoshi KOBAYASHI ${ }^{\dagger}$ and Yoshio SAKKA \\ Materials Processing Unit, National Institute for Materials Science, 1-2-1 Sengen, Tsukuba, Ibaraki 305-0047, Japan
}

\begin{abstract}
The discovery of oxygen-ion conductivity and changes in the crystal-structure model of nondoped lanthanum silicate oxyapatites are reviewed from the researches which led to the discovery to current work. The oxygen-ion conductivity of lanthanoid silicate oxyapatites was discovered by Nakayama et al., during development of new oxide lithium-ion conductors. Although samples with compositions of $\mathrm{LiRESiO}_{4}(\mathrm{RE}=\mathrm{La}, \mathrm{Nd}, \mathrm{Sm}, \mathrm{Gd}$, Dy) were initially reported to be single phases with the same crystal structure, the accurate crystal structure of $\mathrm{LiRESiO}_{4}$ was not clarified until later. The crystal structure determined from X-ray diffraction patterns of $\mathrm{LiLnSiO}_{4}$ was revised as oxyapatite by another group. The chemical composition of the crystal phases in $\mathrm{LiRESiO}_{4}$ was also revised to $\mathrm{RE}_{10} \mathrm{Si}_{6} \mathrm{O}_{25}$ and/or $\mathrm{RE}_{9.33} \mathrm{Si}_{6} \mathrm{O}_{24}$. The discovery of oxygen-ion conductivity in these materials was confirmed when researchers noted that samples of $\mathrm{RE}_{10} \mathrm{Si}_{6} \mathrm{O}_{25}$, specifically, the samples without lithium, are electrically conducting. Furthermore, very high oxygen-ion conductivity in the direction parallel to $c$-axis was discovered after single crystals of $\mathrm{RE}_{9.33}\left(\mathrm{SiO}_{4}\right)_{6} \mathrm{O}_{2}$ $(\mathrm{RE}=\mathrm{Nd}$, Pr, and $\mathrm{Sm})$ were successfully grown. The crystal structure and defect models were also altered after the discovery of oxygen-ion conductivity. Although numerous reports related to the electrical conductivity of $\mathrm{La}_{9.33+x}\left(\mathrm{SiO}_{4}\right)_{6} \mathrm{O}_{2+3 x / 2}$ ceramics have appeared in the literature, clear dependences of the total conductivity on the cation nonstoichiometry $(x)$ as well as the sintering temperature are still unclear because of large discrepancies in the reported data. Furthermore, the composition region, where the lanthanum silicate oxyapatite single phase is formed, is also still unclear because of the inconsistencies in the reported results. (O2014 The Ceramic Society of Japan. All rights reserved.
\end{abstract}

Key-words : Rare-earth silicate, Oxyapatite, Oxygen-ion conductivity, Crystal structure

[Received July 30, 2014; Accepted August 27, 2014]

\section{Introduction}

After the discovery of the oxygen-ion conductivity in lanthanoid silicate oxyapatites by Nakayama et al. in 1995, ${ }^{1,2)}$ numerous studies related to crystal structures, total conductivity, and applications in solid oxide fuel cells and chemical sensors of these oxyapatites have been published. In particular, many researchers have been interested in the lanthanum silicate oxyapatite after the Nakayama's report that the conductivity of the lanthanum-silicate-oxyapatite ceramics is higher than the conductivity of yttria stabilized zirconia ceramics below $873 \mathrm{~K}^{3}{ }^{3}$ In addition, the detection of oxygen-ion defects has been an important theme because oxygen-related point defects are necessary for oxygen-ion conduction in solid electrolytes. ${ }^{4)}$ Even though almost no reports concerning point defects related to the oxygen and the disorder of oxygen distribution in lanthanoid silicate oxyapatites were published before 1995. ${ }^{5)}$ Furthermore, the discovery of high oxygen-ion conductivity has opened new research areas for many researchers. As a result, the development direction of the research field related to lanthanoid silicate oxyapatites has drastically changed since 1995 .

As explained in our previous review, ${ }^{5}$ which summarized the progress regarding the research related to rare-earth silicate oxyapatites starting from its identification as a new compound (1959) until the discovery of its oxygen-ion conductivity (1993), the basic knowledge of the crystal structure and applications of rare-earth silicate oxyapatites gradually improved from a state of uncertainty caused by a discrepancies in understanding of underlying physical and chemical properties to a consistent and

$\uparrow$ Corresponding author: K. Kobayashi; E-mail: KOBAYASHI. kiyoshi@nims.go.jp reliable state. However, the knowledge acquired before 1993 was partially cast into doubt in 1995 because of the discovery of a new property, specifically, oxygen-ion conductivity. The acquired knowledge related to the crystal structure, point defects, and the phase relationships of these materials appeared to again return to a state with no consensus because consistent explanations could not be provided on the sole basis of the knowledge accumulated prior to 1993. Most current researchers in this field do not recognize this point, as reflected by the fact that many authors who published studies related to the solid-state electrochemical properties of rare-earth silicate oxyapatites after 1995 have not properly cited the previous related research. Furthermore, no review has been published regarding the initial discovery of oxygen-ion conductivity in lanthanoid silicate oxyapatites by Nakayama et al. or regarding the changes in the crystal-structure and point-defect models of rare-earth silicate oxyapatites after 1995.

In this review, we summarize the progress in nondoped lanthanoid silicate oxyapatite research, starting from the research trigger related to the discovery of the oxygen-ion conductivity to the present state.

\section{Research trigger for the discovery of oxygen-ion conductivity}

In 1992, Nakayama and Sakamoto reported the microstructure and electrical properties of $\mathrm{LiXSiO}_{4}(\mathrm{X}=\mathrm{Al}, \mathrm{Y}, \mathrm{La}, \mathrm{Nd}, \mathrm{Sm}, \mathrm{Gd}$, $\mathrm{Dy}, \mathrm{Ho}, \mathrm{Er}, \mathrm{Yb}$ ) ceramics with the aim of developing a new lithium-ion conductor suitable for use as a solid electrolyte in humidity sensors. ${ }^{6}$ ) Their reasoning for the selection of the $\mathrm{X}$ elements was explained as follow: $\mathrm{LiAlSiO}_{4}$ is known to be a stable lithium-ion conductor. They attempted to develop a new solid electrolyte by substitution of $\mathrm{Al}^{3+}$ ions with tri-valent 
lanthanoid ions. Because the ionic radii of lanthanoid ions are larger than that of $\mathrm{Al}^{3+}$, the saddle-position space for lithium-ion migration in the crystal could be expanded. On the basis of this strategy, they systematically synthesized the samples and measured their electrical conductivity. They reported that these samples could be classified into three groups on the basis of their crystal systems estimated from their X-ray diffraction patterns. The first group was the samples of $\mathrm{LiXSiO}_{4}$ with $\mathrm{X}=\mathrm{La}, \mathrm{Nd}$, $\mathrm{Sm}, \mathrm{Gd}$, or Dy, which belong to the hexagonal system. The second group was the samples with $\mathrm{X}=\mathrm{Y}, \mathrm{Ho}, \mathrm{Er}$, or $\mathrm{Yb}$, which belong to the orthorhombic system. The third one was the $\mathrm{LiAlSiO}_{4}$ sample, which belongs to a hexagonal system but possesses a crystal structure that differs from that of the first group. Although Nakayama and Sakamoto offered no explanation of the crystal structures of their samples, the powder X-ray diffraction (XRD) patterns of $\mathrm{LiLaSiO}_{4}, \mathrm{LiYSiO}_{4}$, and $\mathrm{LiAlSiO}_{4}$ showed good agreement with the data in the ICDD PDF-2 database (Nos. 20-0630, 20-0643, and 17-0533, respectively). ${ }^{7)}$ A comparison of the XRD patterns of Nakayama and Sakamoto ${ }^{6}$ with previously reported data reveals that the XRD pattern of $\mathrm{LiLaSiO}_{4}$ is similar to that of $\mathrm{LiLa}_{9}\left(\mathrm{SiO}_{4}\right)_{6} \mathrm{O}_{2}$ (PDF-2 No. 320567). With respect to $\mathrm{LiYSiO}_{4}$ and $\mathrm{LiAlSiO}_{4}$, the patterns were very similar to the patterns calculated from the crystal data reported by Blasse et al. ${ }^{8), 9)}$ and Pillars and Peacor, ${ }^{10)}$ respectively. The misidentification of the formed phases in $\mathrm{LiRESiO}_{4}$ $(\mathrm{RE}=\mathrm{La}, \mathrm{Nd}, \mathrm{Sm}, \mathrm{Gd}$, and Dy) might have occurred because Nakayama and Sakamoto relied on the results of Blasse et al. ${ }^{8), 9)}$

Initial structures based on the XRD patterns of $\mathrm{LiRESiO}_{4}$ $(\mathrm{RE}=\mathrm{La}, \mathrm{Nd}, \mathrm{Sm}, \mathrm{Gd}$, and Dy) were proposed by Sato et al. in $1994^{11)}$ and 1996. ${ }^{12)}$ They focused on the fact that the powder XRD patterns of $\mathrm{LiRESiO}_{4}(\mathrm{RE}=\mathrm{La}, \mathrm{Nd}, \mathrm{Sm}, \mathrm{Gd}$, and Dy) were very similar to the patterns of lithium-containing lanthanidesilicate oxyapatite. They attempted to fit the chemical composition of $\mathrm{LiRESiO}_{4}$ by Rietveld analysis using an apatite structure model with various site occupancies. After further combinations of microstructural and elemental distribution observations by secondary electron microscopy and electron probe microscope analysis, they concluded that amorphous phases such as $\mathrm{Li}_{2} \mathrm{O}$ and lithium silicate glass were contained in $\mathrm{LiRESiO}_{4}(\mathrm{RE}=\mathrm{La}$, $\mathrm{Nd}, \mathrm{Sm}, \mathrm{Gd}$, and Dy) samples. This research clarified that the chemical composition of the crystal phase in $\mathrm{LiRESiO}_{4}(\mathrm{RE}=$ $\mathrm{La}, \mathrm{Nd}, \mathrm{Sm}, \mathrm{Gd}$, and Dy) differed from the average sample compositions. In addition, $\mathrm{Li}_{2} \mathrm{O}$ was dissolved in the rare-earth silicate oxyapatite phases by substitution into the RE-ion sites.

As pointed out in our previous review, ${ }^{5)}$ the oxyapatite phase in many quasi-ternary systems were misidentified. ${ }^{13)}$ One reason for this misidentification was a lack of quasi-ternary phase diagrams that included rare-earth oxides and silica. In case of the $\mathrm{RE}_{2} \mathrm{O}_{3}-$ $\mathrm{SiO}_{2}$-alkali oxide systems, no phase diagram is listed in the database even at present. ${ }^{14)}$

With respect to conductivity, Nakayama and Sakamoto reported that $\mathrm{LiSmSiO}_{4}, \mathrm{LiLaSiO}_{4}$, and $\mathrm{LiNdSiO}_{4}$ exhibit high totalelectrical conductivities with relatively low activation energies $(0.8-0.9 \mathrm{eV})$. Impedance spectroscopy performed in the frequency region between $13 \mathrm{MHz}$ and $5 \mathrm{~Hz}$ indicated that grain and grain boundary resistance were observed at frequencies greater than $10 \mathrm{kHz}$. Although Nakayama and Sakamoto concluded that the charge carriers might be ions, on the basis of their observation of slow voltage relaxation after the steady-state polarization, they offered no explanation of the origin of the charge carrier species.

Sato et al. ${ }^{11), 12)}$ reported the bulk and grain boundary conductivities of $\mathrm{LiRESiO}_{4}(\mathrm{RE}=\mathrm{La}, \mathrm{Nd}, \mathrm{Sm}, \mathrm{Gd}, \mathrm{Eu}$, and Dy $)$ deduced from impedance spectra. They concluded that $\mathrm{LiLaSiO}_{4}$,
$\mathrm{LiNdSiO}_{4}$, and $\mathrm{LiEuSiO}_{4}$ exhibited higher conductivities, but this conductivity was that of the amorphous grain boundaries. The bulk conductivities of the oxyapatite phases were more than two orders of magnitude smaller than the grain-boundary conductivities. Although no clear description of the carrier species was reported, the conductive carrier was considered to be the lithium ions. At this time, the fact that some ions might be conducted in the $\mathrm{Li}_{2} \mathrm{O}$-doped rare-earth silicate oxyapatites was clear.

\section{Discovery of oxygen-ion conductivity}

In 1995, Nakayama et al. reported the oxygen-ion conductivity of $\mathrm{RE}_{10}\left(\mathrm{SiO}_{4}\right)_{6} \mathrm{O}_{3}(\mathrm{RE}=\mathrm{La}, \mathrm{Nd}, \mathrm{Sm}, \mathrm{Gd}, \mathrm{Dy}, \mathrm{Y}, \mathrm{Ho}, \mathrm{Er}$, and $\mathrm{Yb})$ and alkali-earth-doped neodymium silicate oxyapatites sintered at 1823 and $1873 \mathrm{~K}$ in two studies. ${ }^{1) 2}$ ) They explained their approach of focusing on rare-earth silicate oxyapatites by the following arguement: ${ }^{1)}$ "The lanthanoid-silicate has a suitable tunnel size in its three-dimensional network structure for migration of the large $\mathrm{K}^{+}$ions. It is expected that large oxygenions also easily migrate in the lanthanoid-silicate." According to the corresponding references, ${ }^{15), 16)} \mathrm{LiRESiO}_{4}$ was referred to as "lanthanoid-silicate", which was observed to be a mixture of oxyapatite and amorphous phases. With respect to the discussions by Sato et al., ${ }^{11), 12)}$ Nakayama seemed to have been unware of Sato's results. However, the important fact was that Nakayama et al. discovered that the lanthanoid silicate oxyapatite phase exhibited oxygen-ion conductivity.

A careful comparison of Nakayama's studies published in $1995^{1), 2)}$ reveals that their results were complicated. For example, the crystal structure parameters of $\mathrm{La}_{10}\left(\mathrm{SiO}_{4}\right)_{6} \mathrm{O}_{3}$ were calculated by Rietveld analysis using the oxyapatite structure model. ${ }^{2)}$ In this case, the chemical composition derived from the crystal structure should be $\mathrm{La}_{10}\left(\mathrm{SiO}_{4}\right)_{6} \mathrm{O}_{2}$, which differs from the actual chemical composition of $\mathrm{La}_{10}\left(\mathrm{SiO}_{4}\right)_{6} \mathrm{O}_{3}$ by one oxygen per unit cell. However, no explanation was found for this inconsistency. ${ }^{2)}$ Furthermore, they reported that the $\mathrm{Ln}_{10}\left(\mathrm{SiO}_{4}\right)_{6} \mathrm{O}_{3}(\mathrm{Ln}=\mathrm{La}, \mathrm{Nd}$, $\mathrm{Sm}, \mathrm{Gd}$, and Dy) samples appeared to be the single phase in one study ${ }^{1)}$ but explained that $\mathrm{La}_{10}\left(\mathrm{SiO}_{4}\right)_{6} \mathrm{O}_{3}$ was not a single phase but rather a two-phase mixture of $\mathrm{La}_{4.67}\left(\mathrm{SiO}_{4}\right)_{6} \mathrm{O}$ and a small amount of $\mathrm{La}_{2} \mathrm{SiO}_{5}$ in the other study. ${ }^{2)}$ With respect to the total conductivity $\left(\sigma_{t}\right)$ data, a comparison of the conductivity values among these two studies was difficult because of the different vertical axes: the vertical axis was presented as $\log \sigma_{\mathrm{t}} T$ in one study ${ }^{1)}$ and $\log \sigma_{\mathrm{t}}$ in the other study. ${ }^{2)}$ To compare the $\sigma_{\mathrm{t}}$ values in these two studies, we plotted the relationship between the $\log \sigma_{\mathrm{t}}$ and reciprocal temperature on the same axis, as shown in Fig. 1. A comparison of the $\sigma_{\mathrm{t}}$ values of $\mathrm{Nd}_{10}\left(\mathrm{SiO}_{4}\right)_{6} \mathrm{O}_{3}$ in Table 3 and Fig. 5 in the reference ${ }^{2)}$ reveals that the $\sigma_{\mathrm{t}}$ values slightly differ from each other. With respect to the activation energy, we could not obtain the same value for the $\mathrm{Nd}_{10}\left(\mathrm{SiO}_{4}\right)_{6} \mathrm{O}_{3}$ when using the $\sigma_{\mathrm{t}}$ values listed in the table.

One important proof of oxygen-ion conduction in $\mathrm{Ln}_{10^{-}}$ $\left(\mathrm{SiO}_{4}\right)_{6} \mathrm{O}_{3}$ was the electromotive force $(E M F)$ of an oxygen concentration cell fabricated using $\mathrm{Nd}_{10}\left(\mathrm{SiO}_{4}\right)_{6} \mathrm{O}_{3}$ and $\mathrm{Sm}_{10^{-}}$ $\left(\mathrm{SiO}_{4}\right)_{6} \mathrm{O}_{3}$ ceramics as solid electrolytes and operated between 873 and $1073 \mathrm{~K}$. The detail cell construction has not been explained in their study, and therefore it is necessary to predict the Nernst equation they described. From the Nernst equation, the cell construction they used was

Reference gas (air, $p_{\mathrm{O}_{2}}^{\mathrm{ref}}$ ),

$\mathrm{Pt}(-) \mid \mathrm{Ln}_{10}\left(\mathrm{SiO}_{4}\right)_{6} \mathrm{O}_{3}$ ceramics $\mid \mathrm{Pt}(+)$, Sample gas $\left(p_{\mathrm{O}_{2}}\right)$, where $p_{\mathrm{O}_{2}}^{\text {ref }}$ and $p_{\mathrm{O}_{2}}$ are the normalized oxygen partial pressures around the reference electrode and working electrode, respec- 


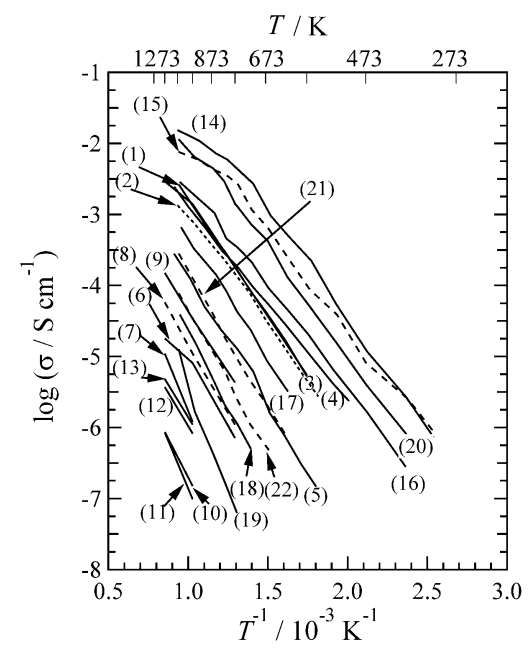

Fig. 1. Relationship between the total conductivity $\left(\sigma_{t}\right)$ for $\mathrm{RE}_{10^{-}}$ $\left(\mathrm{SiO}_{4}\right)_{6} \mathrm{O}_{3}$ ceramics and the reciprocal temperature, as reported in $1995^{1), 2)}$ and 1998. ${ }^{3)}$ Labels indicate the data for $\mathrm{La}_{10}\left(\mathrm{SiO}_{4}\right)_{6} \mathrm{O}_{3}(1)$ and $\mathrm{Nd}_{10}\left(\mathrm{SiO}_{4}\right)_{6} \mathrm{O}_{3}$ (2) reported in reference, ${ }^{1)}$ for $\mathrm{La}_{10}\left(\mathrm{SiO}_{4}\right)_{6} \mathrm{O}_{3}(3), \mathrm{Nd}_{10^{-}}$ $\left(\mathrm{SiO}_{4}\right)_{6} \mathrm{O}_{3}(4), \mathrm{Sm}_{10}\left(\mathrm{SiO}_{4}\right)_{6} \mathrm{O}_{3}(5), \mathrm{Gd}_{10}\left(\mathrm{SiO}_{4}\right)_{6} \mathrm{O}_{3}(6), \mathrm{Dy}_{10}\left(\mathrm{SiO}_{4}\right)_{6} \mathrm{O}_{3}(7)$, $\mathrm{Nd}_{8}\left(\mathrm{SiO}_{4}\right)_{6}(8), \mathrm{Nd}_{9}\left(\mathrm{SiO}_{4}\right)_{6} \mathrm{O}_{1.5}$ (9), $\mathrm{Nd}_{8} \mathrm{Ca}_{2}\left(\mathrm{SiO}_{4}\right)_{6} \mathrm{O}_{2}$ (10), $\mathrm{Nd}_{8} \mathrm{Sr}_{2-}$ $\left(\mathrm{SiO}_{4}\right)_{6} \mathrm{O}_{2}$ (11), $\mathrm{Nd}_{6} \mathrm{Ba}_{4}\left(\mathrm{SiO}_{4}\right)_{6} \mathrm{O}$ (12), and $\mathrm{Nd}_{5} \mathrm{Ba}_{5}\left(\mathrm{SiO}_{4}\right)_{6} \mathrm{O}_{0.5} \quad$ (13) reported in reference, ${ }^{2)}$ and for $\mathrm{La}_{10}\left(\mathrm{SiO}_{4}\right)_{6} \mathrm{O}_{3}(14), \mathrm{Pr}_{10}\left(\mathrm{SiO}_{4}\right)_{6} \mathrm{O}_{3}$ (15), $\mathrm{Nd}_{10}\left(\mathrm{SiO}_{4}\right)_{6} \mathrm{O}_{3}(16), \mathrm{Sm}_{10}\left(\mathrm{SiO}_{4}\right)_{6} \mathrm{O}_{3}(17), \mathrm{Gd}_{10}\left(\mathrm{SiO}_{4}\right)_{6} \mathrm{O}_{3}$ (18), $\mathrm{Dy}_{10^{-}}$ $\left(\mathrm{SiO}_{4}\right)_{6} \mathrm{O}_{3}(19), \mathrm{La}_{11}\left(\mathrm{SiO}_{4}\right)_{6} \mathrm{O}_{4.5}(20), \mathrm{La}_{9.33}\left(\mathrm{SiO}_{4}\right)_{6} \mathrm{O}_{2}(21)$, and $\mathrm{La}_{8}-$ $\left(\mathrm{SiO}_{4}\right)_{6}(22)$ reported in reference. ${ }^{3)}$ We use the $\sigma_{\mathrm{t}}$ of $\mathrm{Nd}_{10}(\mathrm{SiO} 4)_{6} \mathrm{O}_{3}$ (4) presented as Fig. 5 in reference ${ }^{2)}$ because the $\sigma_{\mathrm{t}}$ values listed in the table appeared to differ from those listed in the figure. With respect to the values in the table, the $\sigma_{\mathrm{t}}$ of $\mathrm{Nd}_{10}(\mathrm{SiO} 4)_{6} \mathrm{O}_{3}$ is approximately the same as the $\sigma_{\mathrm{t}}$ of $\mathrm{Nd}_{10}(\mathrm{SiO} 4)_{6} \mathrm{O}_{3}(2)$ in reference. ${ }^{1)}$

tively. The normalized oxygen partial pressure $\left(p_{\mathrm{O}_{2}}\right)$ is expressed using the oxygen partial pressure in units of $\mathrm{Pa}\left(p_{\mathrm{O}_{2}}\right)$ and the standard oxygen partial pressure $\left(p_{\mathrm{O}_{2}}^{\circ}=1.013 \times 10^{5} \mathrm{~Pa}\right)$ as

$$
p_{\mathrm{O}_{2}}=p_{\mathrm{O}_{2}} / p_{\mathrm{O}_{2}}^{\circ} \text {. }
$$

The actual $p_{\mathrm{O}_{2}}$ value was not described in either study. ${ }^{1), 2)}$ With this information set, we could not determine whether the $E M F$ values were adequate. On the basis of a reverse calculation of the $p_{\mathrm{O}_{2}}$ from the theoretical $E M F$ values they reported, they appeared to use a sample gas with $p_{\mathrm{O}_{2}}=0.56$. The relative densities of the samples were also a point of confusion. The relative density of the $\mathrm{Nd}_{10}\left(\mathrm{SiO}_{4}\right)_{6} \mathrm{O}_{3}$ ceramics was reported as $74 \%$ in their study. ${ }^{1)}$ However, EMF measurements are usually impossible with such low-relative-density ceramics because it is impossible to maintain the oxygen partial pressure difference by low-relative-density ceramics due to mechanical oxygen-gas leaks through the lowrelative-density ceramics. In another study, ${ }^{2)}$ they reported that highly dense ceramics were obtained for the $\mathrm{Nd}_{10}\left(\mathrm{SiO}_{4}\right)_{6} \mathrm{O}_{10}$ and $\mathrm{Sm}_{10}\left(\mathrm{SiO}_{4}\right)_{6} \mathrm{O}_{3}$ samples. ${ }^{2)}$ With respect to the $E M F$ measurements in their study, ${ }^{2)}$ they suggested that the $E M F$ of $\mathrm{Nd}_{10}\left(\mathrm{SiO}_{4}\right)_{6} \mathrm{O}_{3}$ and $\mathrm{Sm}_{10}\left(\mathrm{SiO}_{4}\right)_{6} \mathrm{O}_{10}$ ceramics were measured by varying the $p_{\mathrm{O}_{2}}$ between 0.01 and 1 . However, no data was provided except the $E M F$ values at $p_{\mathrm{O}_{2}}=0.56$. EMF measurements and the determination of the mobile carriers are one of the most delicate problems for solid electrolyte researchers; ${ }^{4)}$ careful experiments and measured data sets are therefore usually reported for the discovery of new solid electrolytes. In this regard, the initial two studies did not present sufficient data to allow for a wide consensus among researchers who investigate solid electrolytes.

Nakayama et al. ${ }^{1), 2)}$ did not discuss the phase relationships in comparison to those reported in several studies published prior to

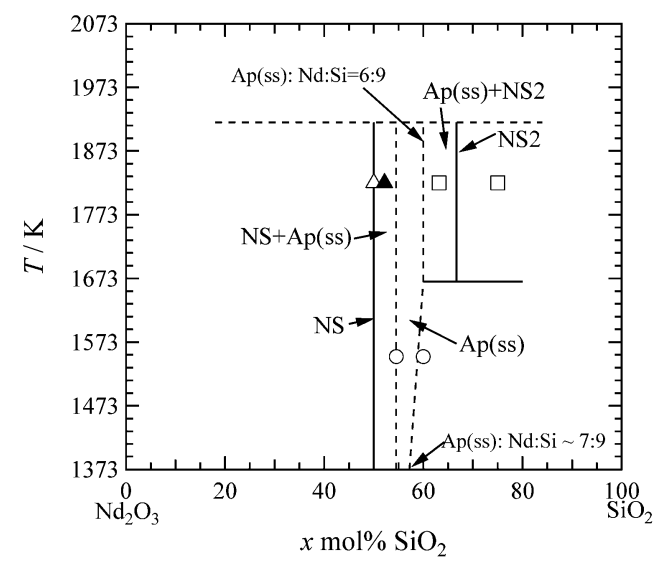

Fig. 2. Comparison of the phase relationship of $\mathrm{Nd}_{2} \mathrm{O}_{3}-\mathrm{SiO}_{2}$ quasibinary system by Toropov et al. ${ }^{17)}$ with the phase reported by Nakayama et al. ${ }^{2)}$ The NS, Ap(ss), NS2 in the diagram represent the $\mathrm{Nd}_{2} \mathrm{SiO}_{5}$ phase, the oxyapatite solid-solution phase, and the $\mathrm{Nd}_{2} \mathrm{Si}_{2} \mathrm{O}_{7}$ phase, respectively. The chemical compositions of $\mathrm{Nd}_{8}\left(\mathrm{SiO}_{4}\right)_{6}$ and $\mathrm{Nd}_{9.33}\left(\mathrm{SiO}_{4}\right)_{6} \mathrm{O}_{2}$ are presented at $\mathrm{Nd}: \mathrm{Si}=6: 9$ and $\mathrm{Nd}: \mathrm{Si}=7: 9$, respectively. The marks indicate oxyapatite single phase (open circles), $\mathrm{Nd}_{2} \mathrm{SiO}_{5}$ single phase (open triangles), an $\mathrm{Nd}_{2} \mathrm{SiO}_{5}$ and oxyapatite mixture (closed triangle), and an oxyapatite and $\mathrm{Nd}_{2} \mathrm{Si}_{2} \mathrm{O}_{7}$ mixture (open squares).

1993. With respect to the $\mathrm{Nd}_{2} \mathrm{O}_{3}-\mathrm{SiO}_{2}$ quasi-binary system, they did describe the relation between the composition and the formed phase. ${ }^{2)}$ Herein, we compare Nakayama's results with those of Toropov $^{17)}$ (Fig. 2). The formed phases are observed to be consistent with the Toropov's phase diagram, with the exception of the samples with $75 \mathrm{~mol} \% \mathrm{SiO}_{2}(\mathrm{Nd}: \mathrm{Si}=4: 6)$ and $63.2 \mathrm{~mol} \%$ $\mathrm{SiO}_{2}(\mathrm{Nd}: \mathrm{Si}=7: 6)$ in the $\mathrm{Nd}_{2} \mathrm{O}_{3}-\mathrm{SiO}_{2}$ quasi-binary system. Although Nakayama et al. explained that the these samples were tetragonal phase, the equilibrium phases, according Toropov's phase diagram, comprised $\mathrm{Nd}_{8}\left(\mathrm{SiO}_{4}\right)_{6}$ and $\mathrm{Nd}_{2} \mathrm{Si}_{2} \mathrm{O}_{7}$ at $75 \mathrm{~mol} \%$ $\mathrm{SiO}_{2}(\mathrm{Nd}: \mathrm{Si}=4: 6)$ and $\mathrm{Nd}_{2} \mathrm{Si}_{2} \mathrm{O}_{7}$ and $\mathrm{SiO}_{2}$ (cristobalite) at the $63.2 \mathrm{~mol} \% \mathrm{SiO}_{2}(\mathrm{Nd}: \mathrm{Si}=7: 6)$. Further comparison with the qualitative phase relation close to the melting point of neodymium silicate oxyapatite phase reported by Higuchi et al. in $2000^{18)}$ reveals that the single-phase composition of the neodymium silicate oxyapatite appeared to differ from both of the aforementioned compositions. Other results that the oxyapatite phase could not be obtained in the samples with $\mathrm{Ln}_{10}\left(\mathrm{SiO}_{4}\right)_{6} \mathrm{O}_{3}$ $(\mathrm{Ln}=\mathrm{Y}, \mathrm{Er}$, and $\mathrm{Yb})$ were consistent with the phase diagrams reported by Toropov et al. ${ }^{19)-24)}$ because the oxyapatite were not formed below $1923 \mathrm{~K}^{25), 26)}$

Another important result of the 1995 study was that dense ceramics of $\mathrm{La}_{10}\left(\mathrm{SiO}_{4}\right)_{6} \mathrm{O}_{3}$ could not be obtained at sintering temperatures of 1823 and $1873 \mathrm{~K}^{1), 2)}$ Related to the oxygenion conduction mechanism, Nakayama et al. explained that the relationship between the constituent lanthanoid ion radius and the oxygen-ion conductivity at a fixed temperature could be qualitatively understood on the basis of the effect on the electrostatic contribution model proposed by Anderson and Stuart. ${ }^{27)}$ This explanation corresponds to the assumption that the strong dependence of the oxygen-ion conductivity on the constituent lanthanoid species is a consequence of the difference in the oxygen-ion mobility.

In 1998, Nakayama and Sakamoto reported that dense $\mathrm{Ln}_{10^{-}}$ $\left(\mathrm{SiO}_{4}\right)_{6} \mathrm{O}_{3}(\mathrm{Ln}=\mathrm{La}, \mathrm{Pr}, \mathrm{Nd}, \mathrm{Sm}, \mathrm{Gd}$, and Dy) ceramics could be fabricated by heating the samples at temperatures above $1973 \mathrm{~K}^{3}{ }^{3)}$ One important factor related to their success was the use of magnesia-stabilized zirconia (MSZ) as the setter material during 


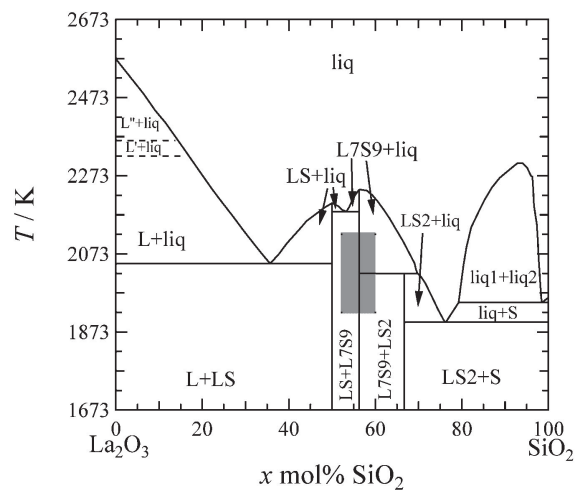

Fig. 3. Comparison of the $\mathrm{La}_{2} \mathrm{O}_{3}-\mathrm{SiO}_{2}$ quasi-binary phase diagram ${ }^{28)}$ and the results of Nakayama's study. ${ }^{3)}$ The gray area corresponds to the region where the oxyapatite and a small amount of $\mathrm{La}_{2} \mathrm{SiO}_{5}$ were reported by Nakayama et al. ${ }^{3)}$

the sintering because alumina setter material reacted with the $\mathrm{Ln}_{10}\left(\mathrm{SiO}_{4}\right)_{6} \mathrm{O}_{3}$ samples at temperatures above $1873 \mathrm{~K}$. In contrast, they observed that MSZ did not react with the $\mathrm{Ln}_{10^{-}}$ $\left(\mathrm{SiO}_{4}\right)_{6} \mathrm{O}_{3}$ at temperatures below $2073 \mathrm{~K}$. The sample composition was given as $\mathrm{Ln}_{10}\left(\mathrm{SiO}_{4}\right)_{6} \mathrm{O}_{3}$ on the basis of the explanation provided this study; however, these samples contained $\mathrm{Ln}_{2} \mathrm{SiO}_{5}$ as an impurity phase.

Nakayama and Sakamoto's explanation of the microstructure and crystal structure of lanthanoid silicate oxyapatites was also difficult to understand from the viewpoint of the phase equilibria. Nakayama and Sakamoto reported that "A hexagonal apatite structure phase was also confirmed as a major phase for $\mathrm{La}_{x} \mathrm{Si}_{6} \mathrm{O}_{12+1.5 x}(x=8-11)$ and very weak peaks assignable to $\mathrm{La}_{2} \mathrm{SiO}_{5}$ were observed in their XRD patterns, indicating that these samples are not also a single phase. In $\mathrm{La}_{x} \mathrm{Si}_{6} \mathrm{O}_{12+1.5 x}$ $(x=8-11)$, the lattice constants were little changed by an increase in the $x$ value." Here, we compare this explanation and the $\mathrm{La}_{2} \mathrm{O}_{3}-$ $\mathrm{SiO}_{2}$ quasi-binary phase diagram proposed by Bondar ${ }^{28)}$ (Fig. 3). The gray area corresponds to $\mathrm{La}_{x} \mathrm{Si}_{6} \mathrm{O}_{12+1.5 x}(x=8-11)$ at $1823-$ $2123 \mathrm{~K}$. The composition region reported by Nakayama et al. was in a region of overlap between the two-phase region of oxyapatite and $\mathrm{La}_{2} \mathrm{SiO}_{5}$ phases and the other two-phase region of $\mathrm{La}_{2} \mathrm{Si}_{2} \mathrm{O}_{7}$ and oxyapatite phases. If the explanation by Nakayama et al. was correct that the formed phases in the samples of composition $\mathrm{La}_{x} \mathrm{Si}_{6} \mathrm{O}_{12+1.5 x}(x=8-11)$ were the two phases constructed by the oxyapatite and $\mathrm{La}_{2} \mathrm{SiO}_{5}$ phases, then the chemical composition of the oxyapatite phase in the $\mathrm{La}_{2} \mathrm{O}_{3}-\mathrm{SiO}_{2}$ quasibinary system should be located at a higher $\mathrm{SiO}_{2}$ concentration than $\mathrm{La}_{8} \mathrm{Si}_{6} \mathrm{O}_{24}$. With respect to the $\sigma_{\mathrm{t}}$ value, we extracted the data from Figure 6 in the reference ${ }^{3)}$ and plotted the data, as shown in Fig. 1.

Nakayama et al. provided an unclear description regarding the EMF data. ${ }^{3)}$ Although they reported the cell construction as $\mathrm{O}_{2}+\mathrm{N}_{2}, \mathrm{Pt}\left|\mathrm{La}_{10} \mathrm{Si}_{6} \mathrm{O}_{27}\right| \mathrm{Pt}$, Air $\left(2.1 \times 10^{4} \mathrm{~Pa}-\mathrm{O}_{2}\right)$ in the experimental section, if we assume that configuration in the experimental section was consistent with international conventions, the electrode configuration appeared to be reversed in the Nernst equation given in the results and discussion section. ${ }^{29)}$ They calculated the $E M F$ using the Nernst equation given by the following:

$$
E M F=\frac{R T}{n F} \ln \frac{p_{\mathrm{O}_{2}}}{p_{\mathrm{O}_{2}}^{\prime}},
$$

where $R, T, \mathrm{n}, F$ are the gas constant, absolute temperature, electron transfer number (if we employ their explanation; see
Appendix A), and Faraday constant, respectively. The variables $p_{\mathrm{O}_{2}}$ and $p_{\mathrm{O}_{2}}^{\prime}$ are the oxygen partial pressure at the sample gas side and reference gas side, respectively. The $p_{\mathrm{O}_{2}}^{\prime}$ was fixed at 0.21 using air. In this study, they propose the possibility of oxygen-ion conduction by comparison of the Nernst slopes with units of $\mathrm{mV} /$ decade. ${ }^{3)}$ However, this unit is difficult to understand because a "decade" was not defined. By recalculation from the theoretical Nernst slope values, we determined that the Nernst slope appeared to be calculated from Eq. (1) using the following equation:

$$
\frac{\partial E M F}{\partial \log p_{\mathrm{O}_{2}}}=\frac{R T \ln 10}{n F}=\frac{2.303 R T}{n F} .
$$

In this case, the unit of $\partial E / \partial \log p_{\mathrm{O}_{2}}$ is given as volts. Given these relationships, we surmised that the description of "decade" appeared to indicate that they calculated the slope values from the $E M F$ vs. $\log p_{\mathrm{O}_{2}}$ plots. Although they calculated the $n$ value by comparing the theoretical Nernst slope values with the measured values, they did not report each $E M F$ value they measured. As a result, insufficient information was provided for other researchers to verify whether the $E M F$ values they measured were correct. Nakayama et al. reported that the $n$ values were close to 4 between 773 and $973 \mathrm{~K}$. Accurately, the slope of $\partial E M F / \partial \log p_{\mathrm{O}_{2}}$ is a function of the transference number of oxygen ions; it is not a suitable basis for determining the value of $n .4$ )

In summary, solid electrolyte researchers could not reach a strong consensus of which $\mathrm{La}_{10} \mathrm{Si}_{6} \mathrm{O}_{27}$ was the oxygen-ion conducting phase on the basis of these three studies ${ }^{1)-3)}$ because of the lack of sufficient information. In addition, the sintering temperature of $1973 \mathrm{~K}$ dissuaded solid electrolyte researchers and fuel cell engineers because such high temperatures are unusual in the fabrication of solid-electrolyte ceramics and preclude their use in solid oxide fuel cells. However, the usefulness of the very high sintering temperature was recognized by other researchers who are interested in lanthanoid silicate oxyapatites and, as a result, sintering temperatures greater than $1923 \mathrm{~K}$ are commonly used today.

\section{Single crystal growth and discovery of high conductivity}

Higuchi et al. reported the successful growth of a large single crystal of $\mathrm{Nd}_{9.33-x} \mathrm{Si}_{6} \mathrm{O}_{6-1.5 x}$ in $\left.1999 .{ }^{30}\right)$ The size of the neodymium silicate oxyapatite crystal was $6 \mathrm{~mm}$ in diameter and 15$25 \mathrm{~mm}$ in length. This was the first study on the growth of a single crystal of $\mathrm{Nd}_{9.33-x} \mathrm{Si}_{6} \mathrm{O}_{6-1.5 x}$; however, it was the third study on the growth of a large single crystal of a rare-earth silicate oxyapatite because Hopkins et al. reported the growth of a single crystal of $\mathrm{La}_{8} \mathrm{Ca}_{2}\left(\mathrm{SiO}_{4}\right)_{6} \mathrm{O}_{2}$ by the Czochralski method in $1971^{31)}$ and de la Fuente et al. reported the growth of a single crystal of $\left(\mathrm{La}_{1-x} \mathrm{Nd}_{x}\right)_{9.33}\left(\mathrm{SiO}_{4}\right)_{6} \mathrm{O}_{2}$ by the $\mathrm{CO}_{2}$-laser floating zone method in 1989. ${ }^{32)}$ Higuchi's crystal was of a very high quality because it was not contaminated by an impurity phase. Higuchi et al. explained that their rationale for selecting $\mathrm{Nd}_{9.33}\left(\mathrm{SiO}_{4}\right)_{6} \mathrm{O}_{2}$ for single-crystal growth was that the $\mathrm{Nd}_{10}\left(\mathrm{SiO}_{4}\right)_{6} \mathrm{O}_{3}$ ceramics exhibited high oxygen-ion conductivity and that the neodymium silicate system effectively absorbed the near-infrared radiation of their heat source.

In the same year (1999), Nakayama et al. reported the oxygenion conductivity of a $\mathrm{Nd}_{9.33}\left(\mathrm{SiO}_{4}\right)_{6} \mathrm{O}_{2}$ single crystal. ${ }^{33)}$ This work represented the first report of the oxygen-ion conductivity along the $c$-axis $\left(\sigma_{\|}\right)$being much greater than the conductivity vertical to the $c$-axis $\left(\sigma_{\perp}\right)$. An impressive result was that the $\sigma_{\|}$value was approximately two orders of magnitude greater than the bulk con- 


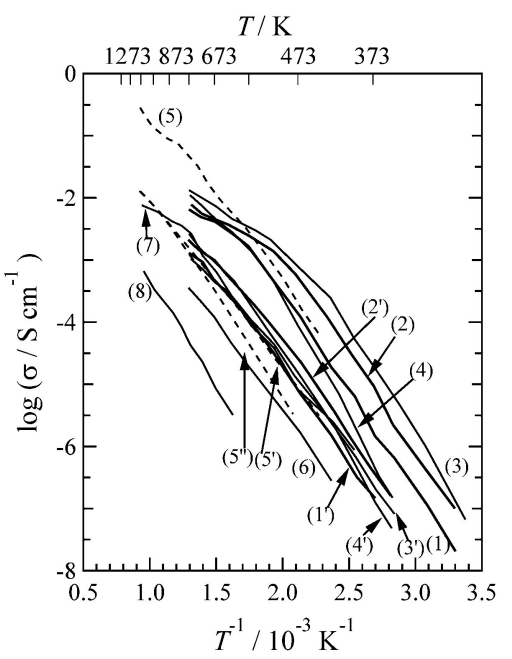

Fig. 4. Relationship between the total conductivities parallel to the $c$-axis $\left(\sigma_{\|}\right)$, those vertical to the $c$-axis $\left(\sigma_{\perp}\right)$, and the reciprocal temperature. The labels are defined as follows: (1) $\sigma_{\|}$and (1') $\sigma_{\perp}$ of $\mathrm{Nd}_{9.33^{-}}$ $\left(\mathrm{SiO}_{4}\right)_{6} \mathrm{O}_{2} ;$; $(2) \sigma_{\|}$and $\left(2^{\prime}\right) \sigma_{\perp}$ of $\mathrm{Nd}_{9.2}\left(\mathrm{SiO}_{4}\right)_{6} \mathrm{O}_{1.8},{ }^{37)}$ (3) $\sigma_{\|}$and $\left(3^{\prime}\right) \sigma_{\perp}$ of $\mathrm{Pr}_{9.33}\left(\mathrm{SiO}_{4}\right)_{6} \mathrm{O}_{2}$; (4) $\sigma_{\|}$and $\left(4^{\prime}\right) \sigma_{\perp}$ of $\mathrm{Sm}_{9.33}\left(\mathrm{SiO}_{4}\right)_{6} \mathrm{O}_{2},{ }^{36)}$ and (5) $\sigma_{\|}$ and $\left(5^{\prime}\right) \sigma_{\perp}$ of as-grown $\mathrm{Nd}_{9.33}\left(\mathrm{SiO}_{4}\right)_{6} \mathrm{O}_{2}$ and $\left(5^{\prime \prime}\right) \sigma_{\|}$of $\mathrm{Nd}_{9.33}\left(\mathrm{SiO}_{4}\right)_{6} \mathrm{O}_{2}$ after annealing at $950^{\circ} \mathrm{C}$ for 3 months. ${ }^{40)}$ The total conductivities of ceramic samples of $\mathrm{Nd}_{10}\left(\mathrm{SiO}_{4}\right)_{6} \mathrm{O}_{3}(6), \mathrm{Pr}_{10}\left(\mathrm{SiO}_{4}\right)_{6} \mathrm{O}_{3}$ (7), and $\mathrm{Sm}_{10^{-}}$ $\left(\mathrm{SiO}_{4}\right)_{6} \mathrm{O}_{2}(8)$ are plotted for comparison. ${ }^{3), 33)}$

ductivity of the $\mathrm{Nd}_{10}\left(\mathrm{SiO}_{4}\right)_{6} \mathrm{O}_{3}$ ceramics (Fig. 4). The temperature dependence of $\sigma_{\|}$changed at approximately $573 \mathrm{~K}$. Nakayama et al. speculated that this phenomenon was related to an order-disorder transition of oxygen vacancies. Moreover, the conductivity was independent of moisture surrounding their sample. From this fact, they concluded that the major carrier was not protons. Although the proof of oxygen-ion conduction in a $\mathrm{Nd}_{9.33}\left(\mathrm{SiO}_{4}\right)_{6} \mathrm{O}_{2}$ single crystal is the $E M F$ analysis, only the Nernst slope values were shown for the temperature range from 523 and $773 \mathrm{~K}$, similar to the study published in 1998 . $^{3)}$ Moreover, the descriptions of the cell construction and the Nernst equation, as previously discussed, were confusing. They concluded that the $E M F$ values measured along the $c$-axis of the $\mathrm{Nd}_{9.33}\left(\mathrm{SiO}_{4}\right)_{6} \mathrm{O}_{2}$ single crystal showed good agreement with the theoretical $E M F$ values of an ideal oxygen-ion conductor in the temperature range between 773 and $623 \mathrm{~K}$ and in the $p_{\mathrm{O}_{2}}$ range between 0.8 and 0.01 . However, no data were presented concerning the relationship between the $p_{\mathrm{O}_{2}}$ and $E M F$, including the measured $E M F$ values.

From 2000 to 2002, Higuchi and Nakayama's group reported the successful single crystal growth of $\mathrm{Sm}_{9.33}\left(\mathrm{SiO}_{4}\right)_{6} \mathrm{O}_{2}, \mathrm{Pr}_{9.33^{-}}$ $\left(\mathrm{SiO}_{4}\right)_{6} \mathrm{O}_{2}$, and $\mathrm{Nd}_{9.33-x}\left(\mathrm{SiO}_{4}\right)_{6} \mathrm{O}_{2-1.5 x}(0 \leq x \leq 0.7)$ and their total electrical conductivity ${ }^{18), 34)-36}$ (Fig. 4). They concluded that $\mathrm{Nd}_{9.2}\left(\mathrm{SiO}_{4}\right)_{6} \mathrm{O}_{1.8}$ was close to the congruent composition on the basis of careful observation of the macroscopic defects in their single crystal. ${ }^{18)}$ In addition, the total conductivity of the $\mathrm{Nd}_{9.2^{-}}$ $\left(\mathrm{SiO}_{4}\right)_{6} \mathrm{O}_{1.8}$ single crystal between 873 and $573 \mathrm{~K}$ was slightly higher than the conductivity of $\mathrm{Nd}_{9.33}\left(\mathrm{SiO}_{4}\right)_{6} \mathrm{O}_{2}$ in both the parallel and vertical directions relative to the $c$-axis. With respect to the growth of single crystals of $\operatorname{Pr}_{9.33}\left(\mathrm{SiO}_{4}\right)_{6} \mathrm{O}_{2}$ and $\mathrm{Sm}_{9.33^{-}}$ $\left(\mathrm{SiO}_{4}\right)_{6} \mathrm{O}_{2}$, the single crystal growth of $\mathrm{Sm}_{9.33}(\mathrm{SiO} 4)_{6} \mathrm{O}_{2}$ was reported to be difficult because of the formation of cracks parallel to the growth direction during the growth process and the formation of numerous microcracks within the crystal. ${ }^{34)}$ In contrast, a large $\operatorname{Pr}_{9.33}\left(\mathrm{SiO}_{4}\right)_{6} \mathrm{O}_{2}$ single crystal more than $30 \mathrm{~mm}$ long was reported to be easily grown. A comparison of the total

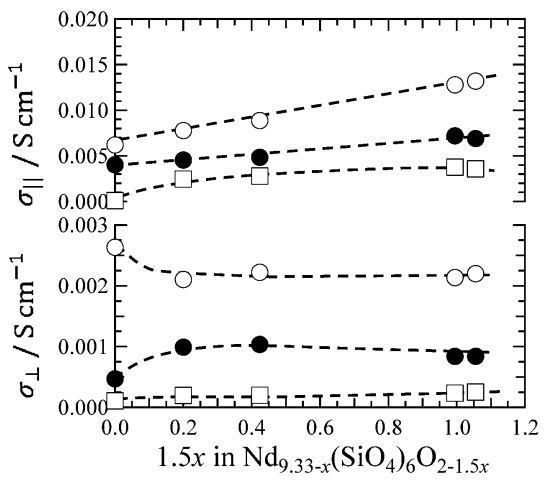

Fig. 5. Relationships between the total conductivity parallel to the $c$-axis $\left(\sigma_{\|}\right)$, vertical to the $c$-axis $\left(\sigma_{\perp}\right)$, and $1.5 x$ in $\mathrm{Nd}_{9.33-x}\left(\mathrm{SiO}_{4}\right)_{6} \mathrm{O}_{2-1.5 x}$ single crystals at $773 \mathrm{~K}$ (open circles), $673 \mathrm{~K}$ (closed circles), and $573 \mathrm{~K}$ (open squares). ${ }^{35), 37)}$

electrical conductivity among $\mathrm{Pr}_{9.33}\left(\mathrm{SiO}_{4}\right)_{6} \mathrm{O}_{2}, \mathrm{Sm}_{9.33}\left(\mathrm{SiO}_{4}\right)_{6} \mathrm{O}_{2}$, and $\mathrm{Nd}_{9.33}\left(\mathrm{SiO}_{4}\right)_{6} \mathrm{O}_{2}$ single crystals (Fig. 4) reveals that the $\sigma_{\|}$ of $\mathrm{Pr}_{9.33}\left(\mathrm{SiO}_{4}\right)_{6} \mathrm{O}_{2}$ was slightly higher than the conductivities of $\mathrm{Nd}_{9.33}\left(\mathrm{SiO}_{4}\right)_{6} \mathrm{O}_{2}$ and $\mathrm{Sm}_{9.33}\left(\mathrm{SiO}_{4}\right)_{6} \mathrm{O}_{2}{ }^{18), 37)}$ On the other hand, the $\sigma_{\perp}$ values were almost independent of the lanthanoid species.

With respect to the conductivity of $\mathrm{Nd}_{9.33-x}\left(\mathrm{SiO}_{4}\right)_{6} \mathrm{O}_{2-1.5 x}$ $(0 \leq x \leq 0.7)$, the $\sigma_{\|}$and $\sigma_{\perp}$ tended to increase with increasing $x$ at temperatures above $673 \mathrm{~K}^{35)}$ The chemical compositions were determined by electron probe micro-analysis (EPMA). If the $\sigma_{\|}$and $\sigma_{\perp}$ are functions of oxygen deficiencies at the O4(2a) site (1.5x), a linear relationship should be observed in the plots of $\sigma_{\|}$and $\sigma_{\perp}$ vs. $1.5 x$ (Fig. 5). Although these plots showed nonlinear relationships, the oxygen-ion vacancies appeared to affect the $\sigma_{\|}$and $\sigma_{\perp}$ at temperatures greater than $673 \mathrm{~K}$. In addition, the determination of the chemical composition of apatite-type lanthanoid silicates by EPMA was difficult because of the large uncertainty of the concentration of the lanthanoid species compared with those of silicon and oxygen. ${ }^{38)}$

The next successful single crystal growth was reported in 2011 by An et al., who used the floating zone method to grow Al-doped $\mathrm{Nd}_{9.33+x / 3} \mathrm{Si}_{6-x} \mathrm{Al}_{x} \mathrm{O}_{26}(0 \leq x \leq 1) .{ }^{39)}$ Single crystals of approximately $5 \mathrm{~mm}$ in diameter and more than $20 \mathrm{~mm}$ in length were obtained. These crystals were grown along the $c$-axis, similar to the single crystals reported by Higuchi et al. ${ }^{18), 34)}$ With respect to the conductivity of the crystals, ${ }^{40)}$ An et al. reported four important results; however the explanations in the text and figures were inconsistent. The first important result was that the difference between the $\sigma_{\|}$and $\sigma_{\perp}$ values decreased with increasing $\mathrm{Al}$ concentration in the as-prepared single crystals (Fig. 4). The $\sigma_{\|}$values were higher than the $\sigma_{\perp}$ values. The second important result was that the $\sigma_{\|}$values decreased with increasing post-annealing time at $1223 \mathrm{~K}$ for crystals annealed for approximately 3 months. However, the annealing temperature was reported as $1123 \mathrm{~K}$ in the figure caption of this study. Although the grain boundary conductivity increased with annealing period in the case of the $\mathrm{Nd}_{9.33}\left(\mathrm{SiO}_{4}\right)_{6} \mathrm{O}_{2}$ single crystal, the grain boundary conductivity decreased with elongation of the annealing period at temperatures above $773 \mathrm{~K}$ in the case of the $\mathrm{Nd}_{9.5} \mathrm{Si}_{5.5} \mathrm{Al}_{0.5} \mathrm{O}_{26}$ single crystal. The third important result was that impedance spectra measured along the $c$-axis direction indicated the presence of grain boundaries even though the samples were high-quality single crystals. In the case of Alcontaining single crystals, the grain-boundary conductivity became higher than the bulk conductivity. The fourth important result was that activation energy of the $\sigma_{\|}$and $\sigma_{\perp}$ for all samples 
was almost independent of crystal direction. An et al. provided no consistent explanation of why grain-boundary impedance was observed from their single crystals.

A comparison of the $\sigma_{\perp}$ and $\sigma_{\|}$values of $\mathrm{Nd}_{9.33}\left(\mathrm{SiO}_{4}\right)_{6} \mathrm{O}_{2}$ reported by Nakayama et al. ${ }^{33), 35)-37), 41)}$ (Fig. 4) reveals two differences related to the $\sigma_{\perp}$ : (1) the $\sigma_{\perp}$ values measured for an as-grown single crystal by An et al. is slightly higher than that reported by Nakayama et al;3),35)-37),41) and (2) the activation energy of $\sigma_{\perp}$ measured for the as-grown single crystal is greater than that reported by Nakayama et al..$^{33), 35)-37), 41)}$ With respect to the $\sigma_{\perp}$, both groups' data show good agreement with each other. The $\sigma_{\|}$measured after 3 months of annealing is approximately the same as the $\sigma_{\perp}$ measured in the as-grown crystal (Fig. 4).

\section{Crystal structure model after the discovery of oxygen-ion conductivity}

With respect to the crystal-structure model of rare-earth silicate oxyapatite, the structure model has been revised step-by-step and continues to be revised even today. Hence, we briefly review the crystal-structure reports published since 1995. Prior to the discovery of oxygen-ion conductivity in rare-earth silicate oxyapatites, their space groups were reported to be a hexagonal system (space groups $P 6_{3} / \mathrm{m}$ and $\left.P 6_{3}\right)^{42), 43)}$ and a monoclinic system (space group is $P 2_{1}$ setting 2 ) ${ }^{44)}$ and point defects were reported as rare-earth (RE) vacancies at the RE1( $f f$ ) sites and oxygen vacancies at the $\mathrm{O} 4(2 a)$ sites, as noted in our previous review. ${ }^{5)}$ After the discovery of oxygen-ion conductivity, however, other space groups and point defects were reported. In particular, the existence and the atomic coordination of the interstitial oxygen ions were detected by several powder diffraction analyses, even though the possibility of interstitial oxygen ions and abnormalities existing in the powder diffraction data had been recognized between 1965 and 1993. The structural analyses published prior to 1993 is summarized in our previous review. ${ }^{5)}$ To explain the features of the crystal structure data presented below, the site names, their occupancy, and the atomic coordinates of the rare-earth silicate oxyapatites are presented for structure models with $P 6_{3} / \mathrm{m}^{45)}$ and $P 6_{3}{ }^{46)}$ space symmetry in Table 1(a) and 1(b), respectively. The corresponding structure figures, which were plotted using the VESTA program, ${ }^{47)}$ are presented in Figs. 6(a) and 6(b). These structure models include the interstitial oxygen ions.

In 2001, Sansom et al. ${ }^{48)}$ reported a new crystal-structure model of $\mathrm{La}_{9.33}\left(\mathrm{SiO}_{4}\right)_{6} \mathrm{O}_{2}$ and $\mathrm{La}_{8} \mathrm{Sr}_{2}\left(\mathrm{SiO}_{4}\right)_{6} \mathrm{O}_{2}$ determined by a combination of high-resolution powder neutron diffraction (HRPD) patterns and Rietveld analysis. They described that "three possible space groups were examined, $P 6_{3}$ (no. 174), $P 6_{3} / \mathrm{m}$ (no. 177), and $P \overline{3}$ (no. 147) in accordance with previous studies of apatite-type structures" without any citation (see Appendix B). According to a review study about the crystal chemistry of apatites, ${ }^{49)}$ belovite $\left[\mathrm{Ba}_{4} \mathrm{Nd}_{3} \mathrm{Na}_{3}\left(\mathrm{PO}_{4}\right)_{6} \mathrm{~F}_{2}, \mathrm{Na}_{0.981^{-}}\right.$ $\mathrm{La}_{0.999} \mathrm{Sr}_{2.754} \mathrm{Ba}_{0.12} \mathrm{Ca}_{0.06}\left(\mathrm{PO}_{4}\right)_{6} \mathrm{OH}$, etc.] crystallizes in space group $P \overline{3}$. However, no natural apatite with space group $P \overline{3}$ has been observed for lanthanoid-rich silicates. ${ }^{5), 49)}$ Sansom et al. determined the space group of $\mathrm{La}_{9.33}\left(\mathrm{SiO}_{4}\right)_{6} \mathrm{O}_{2}$ and $\mathrm{La}_{8} \mathrm{Sr}_{2^{-}}$ $\left(\mathrm{SiO}_{4}\right)_{6} \mathrm{O}_{2}$ as $P \overline{3}$ because they obtained best-fit results when they employed this space group and anisotropic thermal-displacement parameters for the six oxygen sites. The atomic coordinates and the crystal structure are presented in Table 2 and Fig. 7, respectively. The O6(2c) site is the interstitial oxygen-ion site. The main reason that they used a lower symmetry structure compared with the typical apatite structure $\left(P 6_{3} / \mathrm{m}\right)$ is that they appeared to have considered the necessity of interstitial oxygen
Table 1. Coordinates of the atoms in lanthanum silicate oxyapatite with different structure models: (a) $\mathrm{La}_{9.55}\left(\mathrm{SiO}_{4}\right)_{6} \mathrm{O}_{2.325}$ with space group $P 6_{3} / \mathrm{m}^{45)}$ and (b) $\mathrm{La}_{9.67}\left(\mathrm{SiO}_{4}\right)_{6} \mathrm{O}_{2.505}$ with space group $P 6_{3}{ }^{46)}$ Constrains of the anisotropic thermal-displacement parameters $\left(\beta_{i j}\right)$ for each space group $^{51)}$ are presented under the tables

(a)

\begin{tabular}{|c|c|c|c|c|}
\hline \multicolumn{5}{|c|}{$\begin{array}{l}\text { Symmetry: hexagonal } \\
\text { Space group: } P 6_{3} / \mathrm{m}(176) \\
a=b \neq c, \alpha=\beta=90^{\circ}, \gamma=120^{\circ}\end{array}$} \\
\hline Sites & Occupancy & $x$ & $y$ & $z$ \\
\hline $\operatorname{RE} 1(4 f)$ & 0.887 & $1 / 3$ & $2 / 3$ & -0.0015 \\
\hline RE2(6h) & 1 & 0.2282 & -0.0125 & $1 / 4$ \\
\hline $\operatorname{Si}(6 h)$ & 1 & 0.4014 & 0.3712 & $1 / 4$ \\
\hline O1(6h) & 1 & 0.3227 & 0.4839 & $1 / 4$ \\
\hline $\mathrm{O} 2(6 h)$ & 1 & 0.5949 & 0.4732 & $1 / 4$ \\
\hline $\mathrm{O} 3(12 i)$ & 1 & 0.3467 & 0.2566 & 0.0695 \\
\hline $\mathrm{O} 4(2 a)$ & 0.98 & 0 & 0 & $1 / 4$ \\
\hline $\mathrm{O} 5(12 i)$ & 0.019 & -0.001 & 0.224 & 0.58 \\
\hline
\end{tabular}

$\overline{\beta_{11}=\beta_{22}=2 \beta_{12} \text { and } \beta_{13}=\beta_{23}=0 \text { for RE1(4f) and } \mathrm{O} 4(2 a) \text { sites. }}$ $\beta_{13}=\beta_{23}=0$ for RE2(6h), Si $(6 h), \mathrm{O} 1(6 h)$, and O2(6h) sites.

(b)

\begin{tabular}{|c|c|c|c|c|}
\hline \multicolumn{5}{|c|}{$\begin{array}{l}\text { Symmetry: hexagonal } \\
\text { Space group: } P 6_{3}(173) \\
a=b \neq c, \alpha=\beta=90^{\circ}, \gamma=120^{\circ}\end{array}$} \\
\hline Sites & Occupancy & $x$ & $y$ & $z$ \\
\hline $\operatorname{RE} 1(2 b)$ & 0.89 & $1 / 3$ & $2 / 3$ & 0.0002 \\
\hline RE2 $(2 b)$ & 0.89 & $2 / 3$ & $1 / 3$ & 0.0016 \\
\hline $\operatorname{RE} 3(6 c)$ & 0.983 & 0.2271 & -0.0123 & 0.238 \\
\hline $\operatorname{Si}(6 c)$ & 1 & 0.4022 & 0.3734 & 0.2335 \\
\hline $\mathrm{O} 1(6 c)$ & 1 & 0.3242 & 0.4851 & 0.2410 \\
\hline $\mathrm{O} 2(6 c)$ & 1 & 0.5962 & 0.4739 & 0.2310 \\
\hline $\mathrm{O} 3(6 c)$ & 1 & 0.3499 & 0.2586 & 0.0555 \\
\hline $\mathrm{O} 4(6 c)$ & 1 & 0.6520 & 0.7448 & 0.9208 \\
\hline $\mathrm{O} 5(2 a)$ & 0.83 & 0 & 0 & 0.2500 \\
\hline $\mathrm{O} 6(6 c)$ & 0.1133 & 0.0368 & 0.2772 & 0.5840 \\
\hline
\end{tabular}

$\beta_{11}=\beta_{22}=2 \beta_{12}$ and $\beta_{13}=\beta_{23}=0$ for RE1(2b), RE2( $\left.2 b\right)$, and $\mathrm{O} 5(2 a)$ sites.

ions in $\mathrm{La}_{9.33}\left(\mathrm{SiO}_{4}\right)_{6} \mathrm{O}_{2}$ and $\mathrm{La}_{8} \mathrm{Sr}_{2}\left(\mathrm{SiO}_{4}\right)_{6} \mathrm{O}_{2}$, if both samples showed oxygen-ion conductivity. As the authors explained, "the oxygen atoms were displaced from the ideal $[\mathrm{O} 5(2 c)]$ site to a new interstitial site creating Frenkel-like defects" (Appendix C). This chemical defect was important to explain oxygen-ion conduction. If all oxygen ions were located at their normal sites in the typical apatite structure $\left(P 6_{3} / \mathrm{m}\right)$, no ionic conduction would be observed because many oxygen ions would simultaneously hop from their normal position to a neighboring normal position when more than two oxygen ions were simultaneously occupied at the same $\mathrm{O} 4(2 a)$ positions. Hence, oxygen defects are necessary for oxygen-ion conduction in crystals. ${ }^{4)}$ After this study was published, the determination of the position and occupation of interstitial oxygen ions became an important aim of the crystal structure analysis of rare-earth silicate oxyapatites.

In Fig. 8, we compare the diffraction patterns of $\mathrm{La}_{9.33^{-}}$ $\left(\mathrm{SiO}_{4}\right)_{6} \mathrm{O}_{2}$ using the Sansom model (space group: $\left.P \overline{3}\right)$ and a typical apatite structure reported by Okudera et al. ${ }^{42)}$ (space group: $P 6_{3} / \mathrm{m}$ ). In the XRD patterns simulated using the RIETAN-FP software, ${ }^{50)}$ a distinguishable peak (001 peak) is observed at $2 \theta \approx 12.3^{\circ}$. Although the intensity of this 001 peak in the pattern simulated on the basis of the $P \overline{3}$ model is weak, it is detectable by modern XRD instruments. Hence, the applicability of the $P \overline{3}$ model can be determined by checking the XRD pattern at $2 \theta \approx 12.3^{\circ}$. With respect to the constraints of anisotropic 

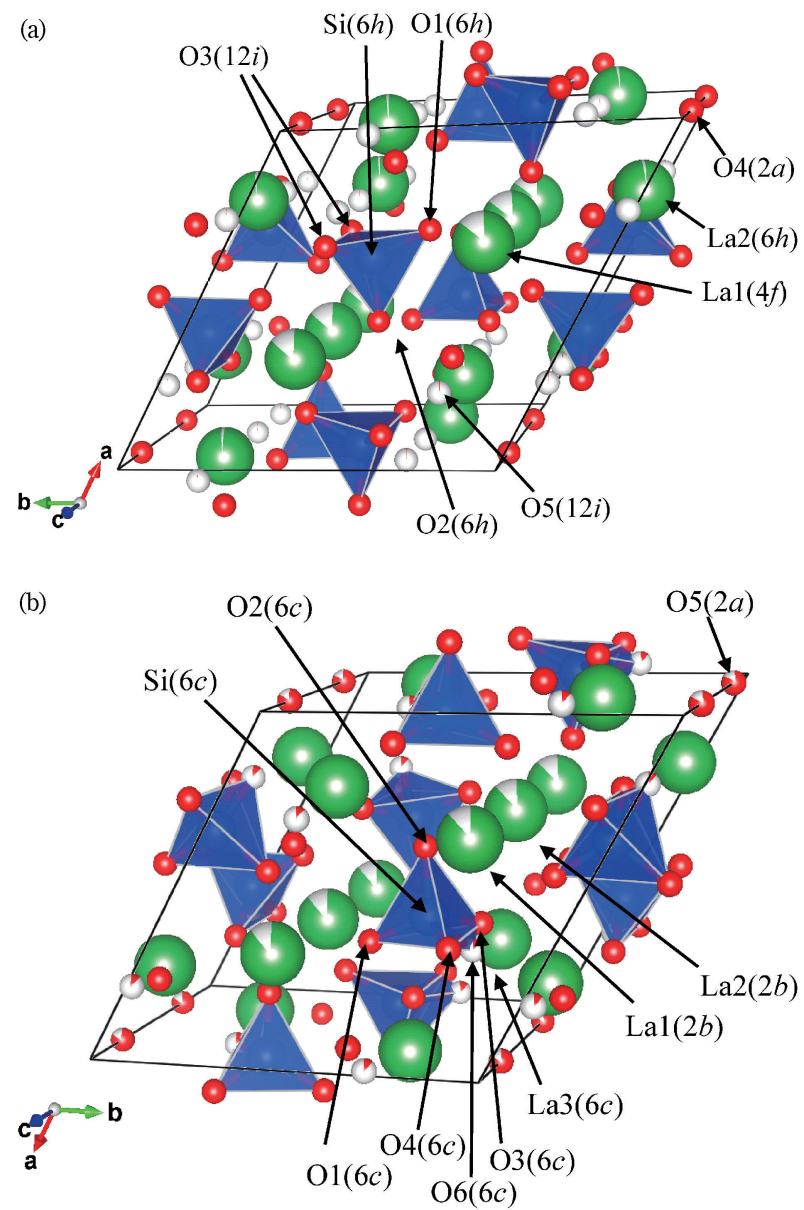

Fig. 6. Crystal structures of rare-earth silicate oxyapatites with $P 6_{3} / \mathrm{m}$ (a) based on the crystallographic data in reference ${ }^{45)}$ and $P 6_{3}$ (b) based on the data in the reference. ${ }^{71)}$ These figures were drawn using the VESTA program. ${ }^{47)}$ The $\mathrm{O} 5(12 i)$ of the $P 6_{3} / \mathrm{m}$ model and the O6(6c) of the $P 6_{3}$ model correspond to the interstitial oxygen sites. In the case of the $P 6_{3}$ model, the $\mathrm{O} 6(6 c)$ site is close to the $\mathrm{SiO}_{4}$ tetrahedron; as a result, a $\left[\mathrm{SiO}_{5}\right]^{6-}$ polyhedron appears to have formed.

Table 2. Coordinates of the atoms in $\mathrm{La}_{933}\left(\mathrm{SiO}_{4}\right)_{6} \mathrm{O}_{2}$ with the $P \overline{3}$ model in the literature. ${ }^{48)}$ Constraints of the anisotropic thermal-displacement parameters $\left(\beta_{i j}\right)^{51)}$ are presented under the table

\begin{tabular}{|c|c|c|c|c|}
\hline \multicolumn{5}{|c|}{$\begin{array}{l}\text { Symmetry: Trigonal } \\
\text { Space group: } P \overline{3}(147) \\
a=b \neq c, \alpha=\beta=90^{\circ}, \gamma=120^{\circ}\end{array}$} \\
\hline Sites & Occupancy & $x$ & $y$ & $z$ \\
\hline $\operatorname{RE1}(2 d)$ & 0.83 & $1 / 3$ & $2 / 3$ & -0.0086 \\
\hline $\operatorname{RE} 2(2 d)$ & 0.86 & $1 / 3$ & $2 / 3$ & 0.4948 \\
\hline RE3(6g) & 0.98 & 0.0138 & 0.2445 & 0.2527 \\
\hline $\operatorname{Si}(6 g)$ & 1 & 0.4005 & 0.3709 & 0.250 \\
\hline $\mathrm{O} 1(6 g)$ & 1 & 0.3223 & 0.4829 & 0.2572 \\
\hline $\mathrm{O} 2(6 g)$ & 1 & 0.5942 & 0.4722 & 0.2522 \\
\hline $\mathrm{O} 3(6 g)$ & 1 & 0.3377 & 0.2518 & 0.0731 \\
\hline $\mathrm{O} 4(6 g)$ & 1 & 0.3491 & 0.2569 & 0.4329 \\
\hline $\mathrm{O} 5(2 c)$ & 0.84 & 0 & 0 & 0.245 \\
\hline $\mathrm{O} 6(2 c)$ & 0.14 & 0 & 0 & 0.379 \\
\hline
\end{tabular}

$\beta_{11}=\beta_{22}=2 \beta_{12}$ and $\beta_{13}=\beta_{23}=0$ for RE1(2d), RE2(2d), O5(2c), and O6(2c) sites.

displacement parameters (see Table 2), the anisotropic displacement parameters of the $\mathrm{O} 5(2 c)$ and $\mathrm{O} 6(2 c)$ sites do not satisfy the necessary constraints imposed by the site symmetry. ${ }^{51)}$

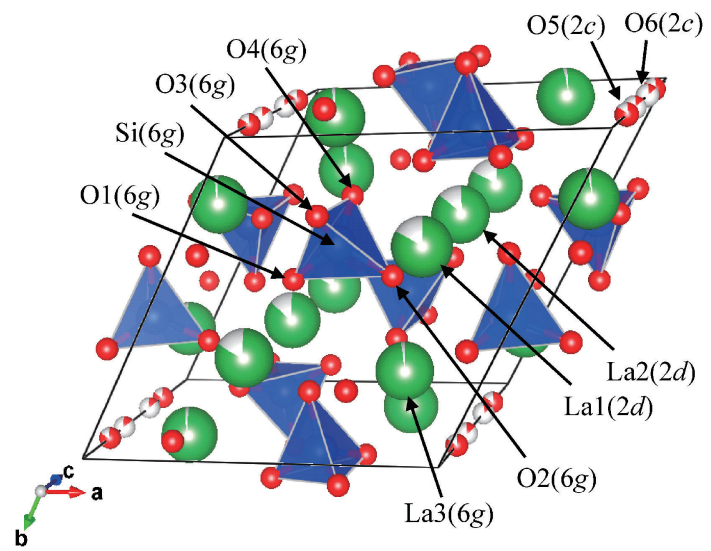

Fig. 7. Crystal structure of the $P \overline{3}$ model. ${ }^{48)}$ The O6(2c) located on the $c$-axis is the interstitial oxygen site.

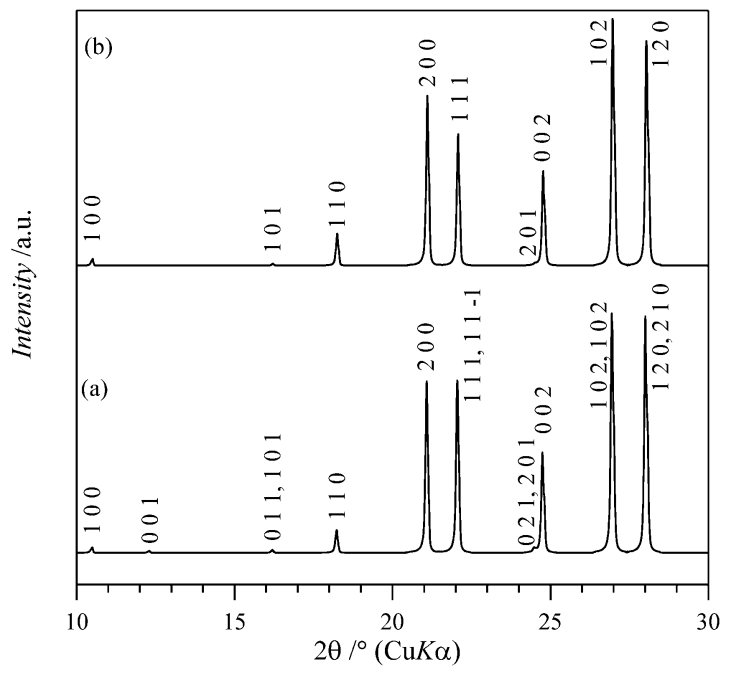

Fig. 8. Simulated XRD patterns based on the model by Sansom et al. $(P \overline{3})^{48)}$ and by Okudera et al. $\left(P 6_{3} / \mathrm{m}\right)^{42)}$ are presented in (a) and (b), respectively. Miller indices are labeled for each peak. The 001 peak in (b) was confirmed to be due to lower symmetry compared to the $P 6_{3} / \mathrm{m}$ model.

In 2003, Redhammer and Roth determined crystal structure models of $\mathrm{LiY}_{9}\left(\mathrm{SiO}_{4}\right)_{6} \mathrm{O}_{2}$ and $\mathrm{NaY}_{9}\left(\mathrm{SiO}_{4}\right)_{6} \mathrm{O}_{2}$ at $100 \mathrm{~K}$ and near room temperature using single crystals grown by the flux method. ${ }^{52)}$ The crystal structures of both materials at both temperatures were refined using space group $P 6_{3} / \mathrm{m}$. Na and $\mathrm{Li}$ were concluded to be located at the Y $14 f$ site, similar to the conclusions of Felsche. ${ }^{26), 53)}$ The presence of the interstitial oxygen was not proposed by Redhammer and Roth, although they gave anisotropic thermal-displacement parameters using correct constraints presented at Table 1(a).

In 2004, three groups reported crystal-structure data for rareearth silicate oxyapatites. Masubuchi et al. ${ }^{41), 54)}$ reported the crystal structure data for $\mathrm{Nd}_{9.33}\left(\mathrm{SiO}_{4}\right)_{6} \mathrm{O}_{2}$ and $\mathrm{Sr}_{2} \mathrm{Nd}_{8}\left(\mathrm{SiO}_{4}\right)_{6} \mathrm{O}_{2}$ at room temperature, as analyzed by combinations of Laue-back scattering patterns of sliced single crystals and high-resolution neutron powder diffraction (NPD). They reported that space group $P 6_{3} / \mathrm{m}$ was preferable to space group $P \overline{3}$ for $\mathrm{Nd}_{9.33^{-}}$ $\left(\mathrm{SiO}_{4}\right)_{6} \mathrm{O}_{2}$ and $\mathrm{Sr}_{2} \mathrm{Nd}_{8}\left(\mathrm{SiO}_{4}\right)_{6} \mathrm{O}_{2}$, even though they employed anisotropic thermal-displacement parameters for all constituent sites. Anisotropic thermal-displacement parameters in the study by Masubuchi et al. were determined using correct constraints. 
However, oxygen ions on the $c$-axis [O4(2a) site] were observed to have larger anisotropic displacement parameters along the $c$-axis direction compared with the parameters along the $a$ - and $b$-axis. Furthermore, an additional oxygen-ion site was not necessary for their crystal structure refinement. Masubuchi et al. appeared to have considered that the large anisotropic expansion on the existence probability along the $c$-axis could explain the high electrical conductivity along this axis. However, explaining the high oxygen-ion conductivity along the $c$-axis solely on the basis of the large anisotropic expansion is difficult, as previously discussed.

Okudera et al. reported their determination of the crystallographic space group ${ }^{55)}$ and temperature dependence of the structural parameters of a $\mathrm{Nd}_{9.33}\left(\mathrm{SiO}_{4}\right)_{6} \mathrm{O}_{2}$ single crystal at temperatures between 150 and $900 \mathrm{~K}^{56}$ ) On the basis of their determinations of the crystallographic space group and the atomic arrangements of $\left.\mathrm{Nd}_{9.33}\left(\mathrm{SiO}_{4}\right)_{6} \mathrm{O}_{2},{ }^{55}\right)$ the possibility of space group $P \overline{3}$ existing in $\mathrm{Nd}_{9.33}\left(\mathrm{SiO}_{4}\right)_{6} \mathrm{O}_{2}$ was completely ruled out; the authors concluded that space group $P 6_{3} / \mathrm{m}$ was most probably present in the compound. Refinement of the crystal-structure parameters was conducted under correct constraints of the anisotropic thermal-displacement parameters. The anisotropic thermal motion of oxygen at the O4(2a) site was highly expanded along the $c$-axis, and no potential minimum existed for the additional oxygen site within the unit cell, except on the $c$-axis. Moreover, the rigidity of the $\mathrm{SiO}_{4}$ tetrahedra was confirmed and distortion of the $\mathrm{SiO}_{4}$ tetrahedra was concluded to be low in $\mathrm{Nd}_{9.33}\left(\mathrm{SiO}_{4}\right)_{6} \mathrm{O}_{2}$. With respect to the temperature dependence of $\mathrm{Nd}_{9.33}\left(\mathrm{SiO}_{4}\right)_{6} \mathrm{O}_{2}$, the fundamental structure was observed to be approximately the same between 150 and $900 \mathrm{~K}$. The site occupancy factor for the $\operatorname{Nd} 1(4 f)$ site was almost constant in this temperature range, and the $\mathrm{Nd}$ vacancy was concluded to be formed only at the $\mathrm{Nd} 1(4 f)$ site. The authors concluded that the oxygen bonded to Si does not participate in oxygen-ion conductivity. These results were consistent with the results of Masubuchi et al. ${ }^{41), 54)}$ A new question arose as follows: "Nakayama et al. ${ }^{33)}$ reported an inflection point in thermal change in conductivity at around $600 \mathrm{~K}$, we could not find any apparent difference on structures below and above the temperature." For results obtained at room temperature, the results on anisotropic thermal displacement of oxygen at the $\mathrm{O} 4(2 a)$ site and the rigidity of $\mathrm{SiO}_{4}$ tetrahedra were consistent with the crystal structure analysis of $\mathrm{Cd}_{2} \mathrm{Nd}_{8}\left(\mathrm{SiO}_{4}\right)_{6} \mathrm{O}_{2}$ by Sidrov et al. ${ }^{57)}$

León-Reina et al. reported a crystal-structure model of $\mathrm{La}_{9.55^{-}}$ $\left(\mathrm{SiO}_{4}\right)_{6} \mathrm{O}_{2.32}$ based on XRD and NPD as a function of temperature; their model included an interstitial oxygen position. ${ }^{45)}$ In this study, the authors speculated that $\mathrm{OH}$ and $\mathrm{H}_{2} \mathrm{O}$ species might be contained in the structure to achieve charge neutrality with the different cation ratio. However, this speculation was not based on experimental data and was not reflected in the crystal-structure analysis. The space group was concluded to be $P 6_{3} / \mathrm{m}$. On the basis of pattern fitting by the Rietveld method using the GSAS suite program, ${ }^{58)}$ they determined the occupancy of O4(2a) and O5(12i) sites and the anisotropic thermal-displacement factor for all sites except for the O5(12i) position, which corresponds to the interstitial oxygen site. The authors discussed the certainty of the interstitial oxygen position by comparison with the position predicted by the atomistic simulation. ${ }^{59)}$ The refinement was conducted with correct constraints of the anisotropic thermaldisplacement parameters. Notably, the thermal displacement parameter of the $\mathrm{O} 5(12 i)$ site was fixed at $3 \times 10^{-4} \mathrm{~nm}^{2}$, independent of temperature; however, the physical basis for this value was not explained. From their analysis, $1-2 \%$ of oxygen at the

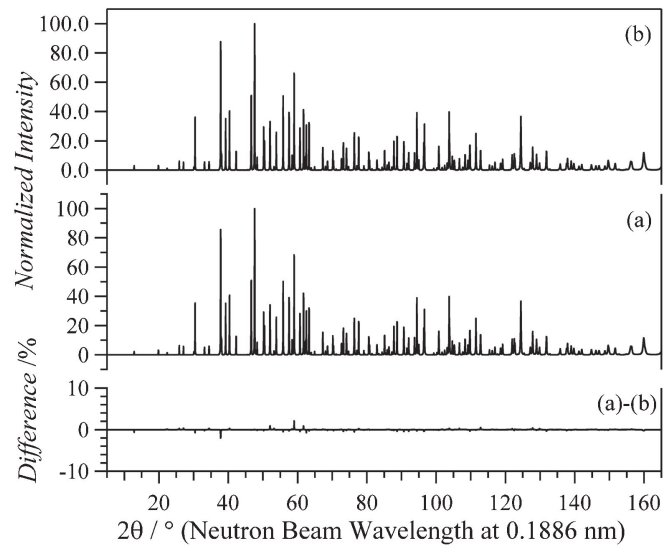

Fig. 9. Simulated neutron diffraction patterns of $\mathrm{La}_{9.55}\left(\mathrm{SiO}_{4}\right)_{6} \mathrm{O}_{2.32}$ using the crystal structure data reported by León-Reina et al. ${ }^{45)}$ The pattern simulated from the original data that includes interstitial oxygen and that simulated using a modified model that does not include the interstitial oxygen are presented in (a) and (b), respectively. The difference between (a) and (b) is given in the bottom curve. The wavelength of the neutron beam was $0.1886 \mathrm{~nm}$.

O4(2a) sites appeared to have shifted to the O5(12i) sites. Recalculating the number of oxygen atoms using site occupancy factors at the $\mathrm{O} 4(2 a)$ and $\mathrm{O} 5(12 i)$ sites, the authors determined that the total number of oxygen atoms was approximately 0.3 lower than the value calculated on the basis of the number of oxygen atoms necessary to maintain charge neutrality given the numbers of $\mathrm{La}$ and $\mathrm{Si}$ atoms in one unit cell.

Here, we verify the quantitative influence of the existence of interstitial oxygen on the NPD pattern calculated using the RIETAN-FP software. ${ }^{50)}$ The wavelength of the neutron beam used in the simulation was $0.1886 \mathrm{~nm}$ and was based on the wavelength reported by León-Reina et al. ${ }^{45)}$ Figure 9 shows the neutron diffraction patterns simulated using the crystal structural data of León-Reina et al.; the original model contained interstitial oxygen [Fig. 9(a)], whereas the modified model [Fig. 9(b)] did not contain interstitial oxygen. We calculated the $R$-weighted pattern index factor $\left(R_{\mathrm{wp}}\right)$ under the assumption that the NPD pattern data simulated using the original model and the one simulated using the modified model are ideal data and virtually collected data, respectively; in addition, each data point was equally weighted. In this case, the $R_{\mathrm{wp}}$ value became $0.23 \%$. The results of this evaluation indicate that a good fit, within $1 \%$, is necessary to evaluate the interstitial oxygen site if the site occupancy of interstitial oxygen at the O5(12i) site is approximately $2 \%$. Thus, an $R_{\mathrm{wp}}$ of $3.18 \%$ in the case of the NPD analysis at room temperature might not be sufficient to evaluate the interstitial oxygen position.

The crystal structure and anisotropic thermal expansion of $\mathrm{Dy}_{4.67}\left(\mathrm{SiO}_{4}\right)_{3} \mathrm{O}$ were reported by Misture et al. ${ }^{60)}$ They analyzed the crystal structure using a combination of powder XRD performed on a laboratory instrument and single-crystal diffraction using a synchrotron X-ray instrument. The single crystal was obtained from a sample of ceramic powder synthesized at $1873 \mathrm{~K}$ for $24 \mathrm{~h}$. Our evaluation of the anisotropic displacement parameters revealed incorrect constraints at the $\mathrm{O} 4(2 a)$ site. Dysprosium vacancies were concluded to be located at the Dy1(4f) sites. Although anisotropic thermal displacement of oxygen at the O4(2a) sites was observed from the anisotropic thermal displacement parameters, the magnitude of the expansion along the $c$-axis was lower compared with the corresponding expansion of 
$\mathrm{Nd}_{9.33}\left(\mathrm{SiO}_{4}\right)_{6} \mathrm{O}_{2} .{ }^{55), 56)}$ With respect to the oxygen bonded to $\mathrm{Si}$, a large isotropic displacement was indicated by the plotting of an ellipsoid. According to their results, isolated $\mathrm{SiO}_{4}$ tetrahedra appeared to exhibit highly rotational vibrations.

In 2005, five groups reported crystal structures of rare-earth silicate oxyapatite phases. Hartenbach and Schleid reported the crystal structure of $\mathrm{RE}_{4.667}\left(\mathrm{SiO}_{4}\right)_{3} \mathrm{Ch}(\mathrm{RE}=\mathrm{Nd}$ or $\mathrm{Sm} ; \mathrm{Ch}=\mathrm{O}$ or S) using single crystals grown by the flux method. ${ }^{61)}$ The flux was cesium chloride. The space group of these compounds was determined as $P 6_{3} / \mathrm{m}$. With respect to the lattice parameters of $\mathrm{RE}_{4.667}\left(\mathrm{SiO}_{4}\right)_{3} \mathrm{O}$ and $\mathrm{RE}_{4.667}\left(\mathrm{SiO}_{4}\right)_{3} \mathrm{~S}$, simple Vegard's law was not observed because the lattice constant of the $c$-axis for $\mathrm{RE}_{4.667^{-}}$ $\left(\mathrm{SiO}_{4}\right)_{3} \mathrm{~S}$ was smaller than that for $\mathrm{RE}_{4.667}\left(\mathrm{SiO}_{4}\right)_{3} \mathrm{O}$ even though the ionic radius of the $\mathrm{S}^{2-}$ ion is larger than that of the $\mathrm{O}^{2-}$ ion. However, with respect to the lattice constants of the $a$-axis, the usual Vegard's law behavior was observed. Anisotropic displacement parameters were not discussed in this study.

Werner and Kubel reported the crystal structure of a $\mathrm{Pr}_{9} \mathrm{~K}$ $\left(\mathrm{SiO}_{4}\right)_{6} \mathrm{O}_{2}$ single crystal grown by the flux method. Potassium fluoride was used as the flux. ${ }^{62)}$ The space group was determined to be $P 6_{3} / \mathrm{m}$ on the basis of single-crystal XRD. Refinement of the crystal structure data was conducted under correct constraints of the anisotropic displacement parameters. The authors explained that the accuracy of analyses by electron probe EPMA and energy-dispersive X-ray spectroscopy (EDX) was approximately $0.5 \%$. Potassium was located only at the $\operatorname{Pr} 1(4 f)$ site, similar to the cases of sodium and lithium in rare-earth silicate oxyapatites. ${ }^{26), 53), 63)}$ Large anisotropic displacement of oxygen at the $\mathrm{O} 4(2 a)$ site along the $c$-axis direction was also confirmed in $\mathrm{Pr}_{9} \mathrm{~K}\left(\mathrm{SiO}_{4}\right)_{6} \mathrm{O}_{2}$. However, the isotropic displacement parameter of $\mathrm{O} 4(2 a)$ site was abnormally large. Small impurity peaks were observed at $2 \theta \approx 30^{\circ}$ and $34^{\circ}$ in the powder XRD pattern presented in this study.

León-Reina et al. reported the crystal structure of $\mathrm{La}_{9.33^{-}}$ $\left(\mathrm{SiO}_{4}\right)_{6} \mathrm{O}_{2}$ and $\mathrm{La}_{8} \mathrm{Sr}_{2}\left(\mathrm{SiO}_{4}\right)_{6} \mathrm{O}_{2}$ powders. ${ }^{64)}$ They analyzed the crystal-structure parameters using a combination of laboratory powder XRD, time-of-flight (TOF) and constant-wavelength NPDs. They concluded that the space group of $\mathrm{La}_{9.33}\left(\mathrm{SiO}_{4}\right)_{6} \mathrm{O}_{2}$ and $\mathrm{La}_{8} \mathrm{Sr}_{2}\left(\mathrm{SiO}_{4}\right)_{6} \mathrm{O}_{2}$ was $P 6_{3} / \mathrm{m}$. With respect to the anisotropic displacement parameters, we observed a small deviation from the correct constraints of the anisotropic displacement parameters at the RE1(4f) and O4(2a) sites. The authors insisted that the interstitial oxygen site could be determined by their Rietveld analysis because of the consistency of their results with atomistic simulations. ${ }^{59), 65)}$ By reverse calculation of their NPD patterns using the original model that includes interstitial oxygen and a modified model without interstitial oxygen, we confirmed their results to be similar to the case of $\mathrm{La}_{9.55}\left(\mathrm{SiO}_{4}\right)_{6} \mathrm{O}_{2.32}$, as explained previously. Furthermore, the activation energy of the anti-Frenkel defect formation for $\mathrm{La}_{9.33}\left(\mathrm{SiO}_{4}\right)_{6} \mathrm{O}_{2}$ was calculated to be $0.047 \pm$ $0.004 \mathrm{eV}$ on the basis of the temperature dependence of the site occupancy of the O4(2a) and O5(12i) sites. This value may be too small for the anti-Frenkel defect formation. Another feature of their results was that oxygen bonded to Si appeared to have been affected by the presence of interstitial oxygen because the anisotropic thermal displacements of the O1(6h) and O3(12i) sites were larger than that of the $\mathrm{O} 2(6 h)$ site. Moreover, the anisotropic thermal displacement parameters of the O1(6h) and O3(12i) sites were similar to that of the interstitial oxygen site, O5 (12i)

Okudera et al. ${ }^{42)}$ reported full crystal-structure data for $\mathrm{La}_{9.33^{-}}$ $\left(\mathrm{SiO}_{4}\right)_{6} \mathrm{O}_{2}$ using single-crystal XRD analysis. They selected a spherical single grain from the sintered ceramics fabricated by heating under an infrared light using a floating-zone instrument. One important fact reported in the experimental section was that "there was no $\mathrm{OH}$ group in the structure," as determined by Fourier-transform infrared (FT-IR) spectroscopy. Furthermore, they successfully determined all crystallographic parameters, including the anisotropic thermal-displacement parameters, for all sites using correct constraints. The space group of $\mathrm{La}_{9.33^{-}}$ $\left(\mathrm{SiO}_{4}\right)_{6} \mathrm{O}_{2}$ was determined as $P 6_{3} / \mathrm{m}$, and the possibilities of $P 6_{3}$ and $P \overline{3}$ were ruled out. According to the residual electron density map (difference Fourier map), the La vacancies were preferentially located at the La1 $(4 f)$ site. In addition, the possibility of interstitial oxygen at the O5(12i) site was ruled out by their single-crystal XRD refinement. With respect to the anisotropic thermal displacement of $\mathrm{La}$ and $\mathrm{SiO}_{4}$ tetrahedra, structural frustration induced by the $\mathrm{La}$ vacancies was relaxed by $\mathrm{SiO}_{4}$ rotation around the central $\mathrm{Si}$ atom. This rotation means that the origin of the anisotropic thermal displacement of oxygen bonded to $\mathrm{Si}[\mathrm{O} 1(6 h), \mathrm{O} 2(6 h)$, and $\mathrm{O} 3(12 i)$ sites] is not the existence of interstitial oxygen close to the $\mathrm{SiO}_{4}$ tetrahedra. In addition, anisotropic thermal displacements along the $c$-axis were proposed not only for the O4(2a) site but also for the La1 $(4 f)$ site. In particular, in the case of anisotropy of the O4(2a) site, the displacement along the $c$-axis was approximately five times larger than that in the case of $\mathrm{Nd}_{9.33}\left(\mathrm{SiO}_{4}\right)_{6} \mathrm{O}_{2}$.

In another study, Fleet and $\mathrm{Liu}^{66)}$ reported the crystal structure of holmium silicate hydroxyapatite, $\mathrm{Ho}_{8.67}\left(\mathrm{SiO}_{4}\right)_{6}(\mathrm{OH})_{2}$, formed as a byproduct of a disilicate crystal under high pressure ( $2 \mathrm{GPa}$ ). In the case of this compound, the space group was refined as $P 6_{3} /$ $\mathrm{m}$. The Ho vacancies were preferentially located on the Ho1 $(4 f)$ site rather than the Ho2(6h) site, consistent with results reported for other oxyapatites.

In 2006, Masubuchi et al. reported the crystal structures of $\mathrm{RE}_{9.33}\left(\mathrm{SiO}_{4}\right)_{6} \mathrm{O}_{2}$ and $\mathrm{Sr}_{2} \mathrm{RE}_{8}\left(\mathrm{SiO}_{4}\right)_{6} \mathrm{O}_{2}(\mathrm{RE}=\mathrm{La}$ and $\mathrm{Nd})$, as analyzed by NPD. ${ }^{67)}$ Using a combination of Rietveld analyses and the maximum entropy method (MEM) implemented in the RIETAN-2000 and PRIMA software, ${ }^{68), 69)}$ they refined the crystal-structure parameters and constructed a nuclear scattering density map. The structure was refined using space group $P 6_{3} / \mathrm{m}$. In this study, accurate constraints were given for the anisotropic displacement parameters. The occupation preference of RE vacancies and strontium was observed at the RE1(4f) site in all their compounds. Similar to Okudera's results, ${ }^{55), 56)}$ the vacancy at the $\mathrm{RE} 1(4 f)$ site appeared to be relaxed by the rotation of $\mathrm{SiO}_{4}$ tetrahedra because anisotropic thermal displacements for the O1 $(6 h)$, $\mathrm{O} 2(6 h)$, and $\mathrm{O} 3(12 i)$ sites of $\mathrm{RE}_{9.33}\left(\mathrm{SiO}_{4}\right)_{6} \mathrm{O}_{2}$ were larger than the displacements of $\mathrm{Sr}_{2} \mathrm{RE}_{8}\left(\mathrm{SiO}_{4}\right)_{6} \mathrm{O}_{2}$. Moreover, anisotropic thermal displacements of the RE1 $(4 f)$ site of $\mathrm{RE}_{9.33}\left(\mathrm{SiO}_{4}\right)_{6} \mathrm{O}_{2}$ were slightly expanded along the $c$-axis. Although Masubuchi et al. explained these anisotropic thermal displacements by the electrostatic repulsion of the cation vacancy, which has a negative formal charge, this explanation is inaccurate because the RE vacancy in $\mathrm{RE}_{9.33}\left(\mathrm{SiO}_{4}\right)_{6} \mathrm{O}_{2}$ is electrically neutral, as explained in our previous review. ${ }^{5)}$ With respect to the $\mathrm{O} 4(2 a)$ site, the thermal displacement along the $c$-axis of $\mathrm{RE}_{9.33}\left(\mathrm{SiO}_{4}\right)_{6} \mathrm{O}_{2}$ is larger than the displacement of $\mathrm{Sr}_{2} \mathrm{RE}_{8}\left(\mathrm{SiO}_{4}\right)_{6} \mathrm{O}_{2}$. Results of MEM analyses were consistent with the results of Rietveld analysis. Another important result was that no evidence of interstitial oxygen exsisting within the unit cell was obtained from either the Rietveld or MEM analyses.

Different results related to the interstitial oxygen site were reported by León-Reina et al. ${ }^{70)}$ in the same year the report by Masubuchi et al. was published. León-Reina et al. synthesized strontium-doped lanthanum silicates, $\mathrm{La}_{8.65} \mathrm{Sr}_{1.35}\left(\mathrm{SiO}_{4}\right)_{6} \mathrm{O}_{2.32}$ and 
$\mathrm{La}_{9} \mathrm{Sr}\left(\mathrm{Si}_{5.5} \mathrm{Al}_{0.5} \mathrm{O}_{4}\right)_{6} \mathrm{O}_{2.35}$, by a conventional solid-state reaction method. The crystal structures were analyzed by a combination of laboratory XRD, room-temperature and high-temperature NPD, and room-temperature powder synchrotron XRD methods. They analyzed the crystal-structure parameters by employing space group $P 6_{3} / \mathrm{m}$. Similar to a 2004 report, ${ }^{45}$ ) the thermal displacement parameter of the interstitial oxygen site [O5(12i)] was assumed to be independent of temperature $\left(3 \times 10^{-4} \mathrm{~nm}^{2}\right)$. A comparison of the results by Okudera et al. ${ }^{42)}$ and Masubuchi et al. ${ }^{67)}$ reveals that the main differences are the anisotropic thermal displacements of the Lal $(4 f)$ site, and whether the interstitial oxygen site is within the unit cell. For anisotropic thermal displacement of the La1 $(4 f)$ site, an almost isotropic displacement was proposed by León-Reina et al. However, anisotropic thermal displacement along the $c$-axis was proposed by Okudera et al. ${ }^{42)}$ and Masubuchi et al. ${ }^{67)}$ Examination of the anisotropic thermal-displacement parameters reveals slightly loose constraints at the La1 $(4 f)$ and $\mathrm{O} 4(2 a)$ sites.

Lambert et al. reported the crystal structures of $\mathrm{La}_{9.33^{-}}$ $\left(\mathrm{SiO}_{4}\right)_{6} \mathrm{O}_{2}, \quad \mathrm{La}_{9} \mathrm{Ba}\left(\mathrm{SiO}_{4}\right)_{6} \mathrm{O}_{2.5}, \quad \mathrm{La}_{9} \mathrm{Sr}\left(\mathrm{SiO}_{4}\right)_{6} \mathrm{O}_{2.5}$, and $\mathrm{La}_{9} \mathrm{Ca}-$ $\left(\mathrm{SiO}_{4}\right)_{6} \mathrm{O}_{2.5}$ synthesized by the conventional solid-state reaction method. ${ }^{71)}$ They collected powder XRD and NPD patterns and refined the crystal-structure parameters using the Rietveld method. Peak broadening of the powder XRD patterns was confirmed for all diffraction peaks. The possibility of the particlesize effect was ruled out because the particle size of their powders was of the order of a few microns. Because of peak broadening, the authors appeared to consider that their samples exhibited lower crystal symmetry compared with that of a typical apatite structure $\left(P 6_{3} / \mathrm{m}\right)$; they consequently used space group $P 6_{3}$ for the refinement. Although they reported the isotropic thermal displacement parameters of all sites, the isotropic thermaldisplacement parameters of the O3(6c) site in all their samples were inadequate because the ellipsoidal anisotropic thermal displacements could not be plotted using the parameters. With respect to the $\mathrm{O} 5(2 a)$ site, the authors reported anisotropic thermal displacement along the $c$-axis. Moreover, they did not determine the interstitial oxygen site because of low site occupancy, even though they analyzed the Fourier map of the nuclear density. With respect to the constraints of the anisotropic thermaldisplacement parameters, excess constraints were observed for the $\mathrm{La} 3(6 c), \mathrm{Si}(6 c), \mathrm{O} 1(6 c), \mathrm{O} 2(6 c), \mathrm{O} 3(6 c)$, and $\mathrm{O} 4(6 c)$ sites.

Yoshioka refined the crystal structure data of $\mathrm{La}_{x}\left(\mathrm{SiO}_{4}\right)_{6}{ }^{-}$ $\mathrm{O}_{1.5 x-12}(x=9.29,9.60$, and 9.92) synthesized by the sol-gel method. ${ }^{72)}$ The powder diffraction data were collected using a laboratory XRD instrument. He determined that the samples with $x=9.29$ and 9.60 were oxyapatite single phases, but the sample with $x=9.92$ was a two-phase mixture of oxyapatite and $\mathrm{La}_{2} \mathrm{SiO}_{5}$ phases. The lattice constants appeared to be almost independent of $x$. Furthermore, one XRD peak that could not be indexed was observed in the XRD pattern of the sample with $x=10.25$.

With respect to silicate oxy-hydroxy and hydroxyapatite, two studies have been published. Ferdov et al. reported the crystal structure and photoluminescence properties of $\mathrm{Eu}_{8.18} \mathrm{Na}_{1.08^{-}}$ $\left(\mathrm{SiO}_{4}\right)_{6}(\mathrm{OH})_{1.62-2 y} \mathrm{O}_{y}$ and $\mathrm{Eu}_{3.96} \mathrm{Gd}_{3.96} \mathrm{Na}_{1.2}\left(\mathrm{SiO}_{4}\right)_{6}(\mathrm{OH})_{1.86-2 y} \mathrm{O}_{y}$ powders synthesized under mild hydrothermal conditions. ${ }^{73)}$ The crystal-structure parameters were refined by the Rietveld method using diffraction patterns collected by a laboratory powder XRD instrument. The crystal structures were refined using space group $\mathrm{P6}_{3} / \mathrm{m}$. In their results, the atomic position of $\mathrm{O}$ and $\mathrm{OH}$ on the $c$-axis $(0,0,0.17-0.18)$ was slightly shifted from the ideal position in the apatite structure $(0,0,1 / 4)$. The presence of $\mathrm{OH}$ was suggested by a broad transmittance peak near $3500 \mathrm{~cm}^{-1}$ in the infrared spectrum, and the number of oxygen atoms on the $c$-axis calculated via Rietveld refinement on the basis of the site occupancy was larger than the number of oxygen atoms calculated without considering the presence of $\mathrm{OH}$ on the basis of charge neutrality. An additional feature was that $\mathrm{Na}$ was substituted only on the RE1 $(4 f)$ site (RE = Eu and Gd). Peculiar photoluminescent properties associated with the $D_{0} \rightarrow{ }^{7} F_{1,2}$ transition were observed for $\mathrm{Eu}_{3.96} \mathrm{Gd}_{3.96} \mathrm{Na}_{1.2}\left(\mathrm{SiO}_{4}\right)_{6}(\mathrm{OH})_{1.86-2 y} \mathrm{O}_{y}$. The authors speculated that these properties resulted from incommensurate ordering of oxygen ions on the $c$-axis and/or distortion of the local coordination with $\left[\mathrm{RE} 1(4 f) \mathrm{O}_{9}\right]$ and $\left[\mathrm{RE} 2(6 h) \mathrm{O}_{7}\right]$.

Wang et al. reported the crystal structure of $\mathrm{Gd}_{4.33} \mathrm{Ho}_{4.33^{-}}$ $\left(\mathrm{SiO}_{4}\right)_{6}(\mathrm{OH})_{2}$ synthesized under high pressure $(2.0 \mathrm{GPa})$ at $1723 \mathrm{~K}^{74)}$ The crystal structure was determined by a combination of single-crystal XRD and powder XRD methods. Although the space group was the same as that of the typical apatite structure $\left(P 6_{3} / \mathrm{m}\right)$, the atomic coordinate of the hydroxyl $\left(\mathrm{OH}^{-}\right)$ion also slightly shifted from the $(0,0,1 / 4)$ position. In addition, the $\mathrm{H}^{+}$ in $\mathrm{OH}^{-}$ions was also located on the $c$-axis.

Redrígues-Reyna et al. reported partial results of their Rietveld refinement of $\mathrm{La}_{x}\left(\mathrm{SiO}_{4}\right)_{6} \mathrm{O}_{1.5 x-12}(x=9.25,9.42$, and 9.5) synthesized by a mechanical milling method. ${ }^{75)}$ They only reported the lattice constants and pattern index factors $\left(R_{\mathrm{wp}}, R_{\mathrm{B}}, R_{\mathrm{exp}}\right.$, etc.). Refinement of the crystal-structure parameters other than the lattice constants from the XRD pattern reported in this study would be impossible because of low peak intensity and large signal-to-noise $(\mathrm{S} / \mathrm{N})$ ratio. However, the authors' detailed discussion of the Raman scattering and infrared reflection spectra are valuable to researchers.

In 2007, the crystal structure parameters of $\mathrm{La}_{9.33}\left(\mathrm{SiO}_{4}\right)_{6} \mathrm{O}_{2}$ and $\mathrm{La}_{8.65} \mathrm{Sr}_{1.35}\left(\mathrm{SiO}_{4}\right)_{6} \mathrm{O}_{2.32}$ at 15 and $4 \mathrm{~K}$ were refined by Rietveld analysis of powder NPD patterns. ${ }^{76)}$ The space group was $P 6_{3} / \mathrm{m}$. In this study also, the authors analyzed the interstitial oxygen position by assuming that the thermal displacement parameters $\left(1 \times 10^{-4} \mathrm{~nm}^{2}\right)$ were fixed at low temperatures. With respect to the anisotropic thermal-displacement parameters, inaccurate constraints of the parameters are observed for the La1 $(4 f)$ and $\mathrm{O} 4(2 a)$ sites. In addition, the parameter values of the O3(12i) site for $\mathrm{La}_{9.33}\left(\mathrm{SiO}_{4}\right)_{6} \mathrm{O}_{2}$ at $15 \mathrm{~K}$ and the values of $\mathrm{La} 1(6 h), \mathrm{Si}(6 h)$, and $\mathrm{O} 1(6 h)$ sites for $\mathrm{La}_{8.65} \mathrm{Sr}_{1.35}\left(\mathrm{SiO}_{4}\right)_{6} \mathrm{O}_{2.32}$ at $4 \mathrm{~K}$ appear to be inadequate because thermal displacement ellipsoids could not be plotted using these values. Other important results were that anisotropic thermal displacement of the O4(2a) site was expanded along the $c$-axis at 15 and $4 \mathrm{~K}$. The degree of the displacement along the $c$-axis of $\mathrm{La}_{8.65} \mathrm{Sr}_{1.35}\left(\mathrm{SiO}_{4}\right)_{6} \mathrm{O}_{2.32}$ was much larger than the displacement of $\mathrm{La}_{9.33}\left(\mathrm{SiO}_{4}\right)_{6} \mathrm{O}_{2}$. The anisotropic displacement of the $\mathrm{La} 2(6 h)$ site in $\mathrm{La}_{9.33}\left(\mathrm{SiO}_{4}\right)_{6} \mathrm{O}_{2}$ was expanded along the $c$-axis. The authors insisted that the interstitial oxygen site could be determined from the difference Fourier map.

Iwata et al. refined the crystal structure parameters of $\mathrm{La}_{9.33^{-}}$ $\left(\mathrm{SiO}_{4}\right)_{6} \mathrm{O}_{2}$ by a combination of Rietveld analysis, the MEM method, and MEM-based pattern fitting using powder XRD patterns collected at temperatures from room temperature to $1073 \mathrm{~K}^{77)}$ By conventional Rietveld analysis, they used a structure model with space group $P 6_{3} / \mathrm{m}$, referencing Okudera's study. ${ }^{42)}$ They determined that their sample was not a single phase but a two-phase mixture of $\mathrm{La}_{9.33}\left(\mathrm{SiO}_{4}\right)_{6} \mathrm{O}_{2}$ as the major phase and $\mathrm{La}_{2} \mathrm{SiO}_{5}(3.4$ mass \%) as minor impurity phase. With respect to the isotropic thermal-displacement parameters, correct constraints for the parameters were employed for the analysis. With respect to the anisotropic thermal displacement of the La1 $(4 f)$ site, anisotropic displacement along the $c$-axis direction 
was observed at room temperature. Conversely, the displacement of the La1 $(4 f)$ site at $1073 \mathrm{~K}$ became isotropic compared with that at room temperature. With respect to the O4(2a) site, anisotropic thermal displacement along the $c$-axis was observed not only at room temperature but also at $1073 \mathrm{~K}$.

Yoshioka reported crystal-structure data for nondoped and Sr-, $\mathrm{Mg}$-, Al-, and Nd-doped lanthanum silicate oxyapatites. ${ }^{78)} \mathrm{He}$ refined the atomic coordinates and isotropic thermal displacement parameters by the Rietveld method using powder XRD patterns and employing a structure model with space group $P 6_{3} / \mathrm{m}$.

Zhang et al. reported structure data for $\mathrm{La}_{9.33}\left(\mathrm{SiO}_{4}\right)_{6} \mathrm{O}_{2}$ acquired using a combination of powder XRD and single-crystal XRD. ${ }^{79)}$ They collected the single-crystal grain from a sintered ceramic powder. They determined the space group to be $P 6_{3} / \mathrm{m}$. Large anisotropy was observed at the O3(12i) site on the basis of the isotropic thermal displacement parameters, whereas almost no anisotropic displacement was observed at the O4(2a) site.

In 2008, Ali et al. reported the crystal structure of $\mathrm{La}_{9.69^{-}}$ $\left(\mathrm{Si}_{5.70} \mathrm{Mg}_{0.30}\right) \mathrm{O}_{26.24}$ at room temperature and $1796 \mathrm{~K}$ by combinations of Rietveld analysis and the MEM method using NPD patterns. ${ }^{80)}$ They refined the structure parameters using a structure model with $P 6_{3} / \mathrm{m}$. A feature of their results was that anisotropic thermal displacements of the La1 $(4 f)$ and La2 $(6 h)$ sites were expanded along the $c$-axis and the $a-b$ plane, respectively, at room temperature. However, the anisotropic displacement of $\mathrm{La}$ ions became an isotropic displacement at $1796 \mathrm{~K}$. With respect to the $\mathrm{O} 4(2 a)$ site, large anisotropy along the $c$-axis was observed at both temperatures. By analyzing the nuclear scattering density, they visualized the oxygen diffusion paths.

Iwata et al. refined the crystal structure parameters of $\mathrm{La}_{9.16^{-}}$ $\left(\mathrm{SiO}_{4}\right)_{6} \mathrm{O}_{1.75}, \mathrm{La}_{9.21}\left(\mathrm{SiO}_{4}\right)_{6} \mathrm{O}_{1.81}$, and $\mathrm{La}_{9.33}\left(\mathrm{SiO}_{4}\right)_{6} \mathrm{O}_{2}$ using powder XRD patterns. ${ }^{81)}$ The compositions of these samples corresponded to $43.29 \mathrm{~mol} \% \mathrm{La}_{2} \mathrm{O}_{3}-56.71 \mathrm{~mol} \% \mathrm{SiO}_{2}, 43.42$ $\mathrm{mol} \% \mathrm{La}_{2} \mathrm{O}_{3}-56.58 \mathrm{~mol} \% \mathrm{SiO}_{2}$, and $43.74 \mathrm{~mol} \% \mathrm{La}_{2} \mathrm{O}_{3}-56.26$ $\mathrm{mol} \% \mathrm{SiO}_{2}$. They reported that phases with compositions of $\mathrm{La}_{9.16}\left(\mathrm{SiO}_{4}\right)_{6} \mathrm{O}_{1.75}$ and $\mathrm{La}_{9.21}\left(\mathrm{SiO}_{4}\right)_{6} \mathrm{O}_{1.81}$, formed after reaction at $1773 \mathrm{~K}$ for $4 \mathrm{~h}$ in air, were mixtures of oxyapatite and $\mathrm{La}_{2} \mathrm{Si}_{2} \mathrm{O}_{7}$. However, they also reported that the formed phase $\mathrm{La}_{9.33^{-}}$ $\left(\mathrm{SiO}_{4}\right)_{6} \mathrm{O}_{2}$ was a mixture of oxyapatite and $\mathrm{La}_{2} \mathrm{SiO}_{5}$. Assuming that their samples achieved an equilibrium state, the oxyapatite single phase must contain between $56.58 \mathrm{~mol} \% \mathrm{SiO}_{2}$ and 56.26 mol $\% \mathrm{SiO}_{2}$ according to the Gibbs' phase rule. ${ }^{82)}$ They refined the crystal structure parameters using the nominal chemical compositions of the samples. Although the dependences of the lattice parameters and lattice volume on the nominal chemical compositions show a linear relationship, these dependences are inconsistent with the Gibbs' phase rule. Features of their results included preferential La vacancy formation at the La1 $(4 f)$ site and formation of an oxygen vacancy at the $\mathrm{O} 4(2 a)$ site. Other structural defects were not proposed. Anisotropic thermal displacement of the La1 $(4 f)$ site was observed in all samples. However, almost isotropic thermal displacement of the $\mathrm{O} 4(2 a)$ site was reported in the case of $\mathrm{La}_{9.16}\left(\mathrm{SiO}_{4}\right)_{6} \mathrm{O}_{1.75}$.

Tolchard and Slater reported the crystal structure parameters of $\mathrm{La}_{9.67}\left(\mathrm{SiO}_{4}\right)_{6} \mathrm{O}_{2.5}$ refined by the Rietveld method using NPD patterns obtained between room temperature and $1173 \mathrm{~K}^{46)}$ They employed the structure model with space group $P_{6}$ because lowest $R_{\mathrm{wp}}$ values were obtained with this model. The anisotropic thermal displacement parameters were refined only for the $\mathrm{O} 1(6 c), \mathrm{O} 2(6 c), \mathrm{O} 3(6 c), \mathrm{O} 4(6 c)$, and $\mathrm{O} 5(2 a)$ sites. With respect to the anisotropic thermal displacement parameters of $\mathrm{O} 3(6 c)$, the displacement ellipsoid decreased at $1173 \mathrm{~K}$ compared with that at lower temperatures. With respect to the site occupancy factors of the $\mathrm{O5}(2 a)$ and $\mathrm{O} 6(6 c)$ sites, the occupancy factor values were independent of temperature, which indicates that the number of interstitial oxygen at the O6(6c) site was determined by the cation concentration.

Kobayashi et al. refined the crystal structure parameters of $\mathrm{La}_{9.50}\left(\mathrm{SiO}_{4}\right)_{6} \mathrm{O}_{2.25}$ by the Rietveld method using a laboratory XRD pattern collected at room temperature and a high resolution powder diffraction (HRPD) pattern collected at $3 \mathrm{~K} .{ }^{83)}$ They refined the crystal structure using the $P 6_{3} / \mathrm{m}$ model. La vacancies were only located on the Lal $(4 f)$ site in both refinements. The authors could not determine the interstitial oxygen-ion site because of the weak reflection from the interstitial oxygen. Only the isotropic thermal displacement parameters were refined.

Yoshioka and Tanase refined the crystal-structure parameters of $\mathrm{La}_{9.8} \mathrm{Si}_{5.7} \mathrm{Mg}_{0.3} \mathrm{O}_{26.4}$ by the Rietveld method using laboratory XRD patterns collected at room temperature. ${ }^{84)}$ In this analysis, the authors adopted $\mathrm{O} 5(12 i)$ as the interstitial oxygen site by referring to other studies. ${ }^{45), 48), 59), 65), 70), 80)}$ Considering that the site occupancy of O5(12i) was only $3.3 \%$, determination of the coordinates of this site by the Rietveld method might be difficult.

Ali et al. refined the crystal structure parameters and electron density of $\mathrm{La}_{9.71}\left(\mathrm{Si}_{5.8} \mathrm{Mg}_{0.2}\right) \mathrm{O}_{26.37}$ using a combination of Rietveld and MEM analyses of synchrotron powder XRD patterns collected at 302,674 , and $1010 \mathrm{~K} .{ }^{85)}$ Moreover, they used second-harmonic-generation (SHG) measurements to experimentally clarify that the crystal structure of their sample [ $\mathrm{La}_{9.71^{-}}$ $\left.\left(\mathrm{Si}_{5.8} \mathrm{Mg}_{0.2}\right) \mathrm{O}_{26.37}\right]$ must belong to a space group containing a center of symmetry. On the basis of their results, the authors ruled out the crystal structure model with space group $P 6_{3}$ and concluded that the structure model with space group $P 6_{3} / \mathrm{m}$ was adequate for refinement of their data. They only refined the anisotropic thermal-displacement parameters of the O3(12i) and O4(2a) sites. The anisotropic thermal-displacement parameters of the $\mathrm{O} 3(12 i)$ site at $302 \mathrm{~K}$ might be inadequate because an ellipsoid could not be plotted using the parameters. With respect to the $\mathrm{O} 4(2 a)$ site, anisotropic thermal-displacement was expanded along the $c$-axis. La vacancies were located only at the La1 $(4 f)$ site, and $\mathrm{Mg}$ ions were concluded to be located at the $\mathrm{Si}(6 h)$ site.

Matsushita et al. reported the structure of $\mathrm{La}_{9.50}\left(\mathrm{SiO}_{4}\right)_{6} \mathrm{O}_{2.25}$ using a combination of Rietveld and MEM analysis of HRPD patterns obtained at $10 \mathrm{~K}^{86}$ ) In this study also, the adequacy of the space group was confirmed by SHG measurements and space group $P 6_{3} / \mathrm{m}$ was concluded to be adequate. Even in the case of the low-temperature measurements and MEM analysis, the authors concluded that the interstitial oxygen position could not be determined because of low concentration of interstitial oxygen compared with the equivalent number of interstitial oxygen sites.

Guillot et al. investigated the crystal structure of $\mathrm{La}_{9.67-}$ $\left(\mathrm{SiO}_{4}\right)_{6} \mathrm{O}_{2.5}$ using primarily Rietveld analysis of NPD patterns collected at 3,100 , and $300 \mathrm{~K}^{87}$ ) They refined the structure parameters on the basis of the model with space group $P 6_{3} / \mathrm{m}$. They compared $R_{\mathrm{wp}}$ values for the models with and without the O5(12i) site, and the structure model with the O5(12i) site was concluded to be promising. Initially, the coordinates of the O5(12i) site was estimated from the Fourier difference map of the nuclear scattering density fabricated from the structure model without the O5(12i) site. They subsequently refined the O5(12i) coordinates using the Rietveld method. Their results indicated that the O5(12i) site was located close to $z=0.06$ and 0.44 around the $c$-axis. Furthermore, they concluded that the site occupancy of the $\mathrm{O} 4(2 a)$ site was fixed at approximately 0.4 when the O5(12i) site was taken into account. This result might be explainable only by invoking an ordered apatite structure. 
With respect to the anisotropic thermal displacement parameters, the parameters of all sites, except for the O4(2a) and O5(12i) sites, were refined, although the parameters of the O1(6h) site at $100 \mathrm{~K}$ might be inadequate because an ellipsoid could not be plotted using the reported parameters. A slight anisotropic thermal displacement of the La1 $(4 f)$ site was observed along the $c$-axis at three temperatures.

In 2010, Kinoshita et al. reported the crystal structure of $\mathrm{La}_{9.93}\left(\mathrm{Si}_{5.11} \mathrm{Mg}_{0.89}\right) \mathrm{O}_{26}$ and $\mathrm{La}_{8.48} \mathrm{Mg}_{1.28} \mathrm{Si}_{6} \mathrm{O}_{26}$ by single-crystal XRD. ${ }^{88)}$ The single crystals were obtained from ceramic powders sintered at $1873 \mathrm{~K}$. In the case of $\mathrm{La}_{9.93}\left(\mathrm{Si}_{5.11} \mathrm{Mg}_{0.89}\right) \mathrm{O}_{26}$, the space group was determined to be $P 6_{3} / \mathrm{m}$. La vacancies formed only at the La1( $4 f)$ site. The magnesium was substituted at the $\mathrm{Si}(6 h)$ site. However, the space group of $\mathrm{La}_{8.48} \mathrm{Mg}_{1.28} \mathrm{Si}_{6} \mathrm{O}_{26}$ was determined to be $P 6_{3}$. La vacancies formed at the La1(2b) and $\mathrm{La} 2(2 b)$ sites, where $\mathrm{Mg}$ was also located. No defects were present in other sites. With respect to the anisotropic thermal displacements, almost isotropic displacements were observed at the $\mathrm{La} 1(4 f)$ and $\mathrm{La} 2(6 h)$ sites for $\mathrm{La}_{9.93}\left(\mathrm{Si}_{5.11} \mathrm{Mg}_{0.89}\right) \mathrm{O}_{26}$ with space group $P 6_{3} / \mathrm{m}$. However, a slight anisotropic expansions along the $c$-axis were observed at the $\mathrm{La} 1(2 b)$ and $\mathrm{La} 2(2 b)$ sites in the case of $\mathrm{La}_{8.48} \mathrm{Mg}_{1.28} \mathrm{Si}_{6} \mathrm{O}_{26}$ with $P 6_{3}$. With respect to the $\mathrm{O} 4(2 a)$ site in $P 6_{3} / \mathrm{m}$ and the O5(2a) site in $P 6_{3}$, anisotropic thermal displacements along the $c$-axis were observed in both samples.

Nojiri et al. reported the crystal structures of $\mathrm{La}_{10}\left(\mathrm{SiO}_{4}\right)_{6} \mathrm{O}_{3}$ and $\mathrm{La}_{9.4} \mathrm{Ba}_{0.6}\left(\mathrm{SiO}_{4}\right)_{6} \mathrm{O}_{2.7}$ determined by the Rietveld analysis of synchrotron XRD patterns. ${ }^{89)}$ The structure parameters were refined using the model with space group $P 6_{3} / \mathrm{m}$. Ba was located at the La1 $(4 f)$ site. The atomic coordinates of the interstitial oxygen O5(12i) site were fixed at the center between the O3(12i) and $\mathrm{O} 4(2 a)$ sites. This coordinate was not refined during the Rietveld analysis, and the adequacy of the O5(12i) site was not discussed.

Sakakura et al. reported the crystal structure of a $\mathrm{SrPr}_{4}-$ $\left(\mathrm{SiO}_{4}\right)_{3} \mathrm{O}$ single crystal grown by the flux method. ${ }^{90}$ They used $\mathrm{SrCl}_{2}$ as a flux. The space group was determined to be $P 6_{3} / \mathrm{m}$. Although Sr was located on both $\operatorname{Pr} 1(4 f)$ and $\operatorname{Pr} 2(6 h)$ sites, the $\operatorname{Pr} 1(4 f)$ site was preferable for Sr substitution. With respect to the isotropic thermal displacements of the $\operatorname{Pr} 1(4 f)$ and $\operatorname{Pr} 2(6 h)$ sites, the displacement observed was close to the isotropic displacement. With respect to the displacement of the O4(2a) site, weak anisotropic thermal displacement was confirmed along the $c$-axis.

Shen et al. reported the crystal structure of $\mathrm{Sr}_{2} \mathrm{Y}_{8}\left(\mathrm{SiO}_{4}\right)_{6} \mathrm{O}_{2}$ and $\mathrm{Sr}_{2} \mathrm{Y}_{6} \mathrm{Eu}_{2}\left(\mathrm{SiO}_{4}\right)_{6} \mathrm{O}_{2}$ using laboratory XRD patterns and HRTEM images. ${ }^{91), 92)}$ According to their Rietveld results, Sr was located only on the Y1(4f) site. Although Eu appeared to exhibit an occupation preference, the actual site occupancy values of Eu could not be determined.

Uvarov et al. reported apatite-structured bismuth calcium oxysilicate. ${ }^{93)}$ The molecular formula was $\mathrm{Ca}_{4} \mathrm{Bi}_{4.3}\left(\mathrm{SiO}_{4}\right)\left(\mathrm{HSiO}_{4}\right)_{5}$ $\mathrm{O}_{0.95}$. The crystal-structural parameters were refined by Rietveld analysis of a laboratory XRD pattern. The crystal-structure model with space group $P 6_{3} / \mathrm{m}$ was employed. The $\mathrm{Ca}$ ion was preferentially located at the $\mathrm{Ca}(4 f)$ site and was also located at the $\mathrm{Bi}(6 h)$ site. Approximately $42 \%$ of oxygen ions at the O3(12i) site were hydroxyl ions $\left(\mathrm{OH}^{-}\right)$. The site occupancy of the $\mathrm{O} 4(2 a)$ site was approximately 0.48 .

In addition, Baikie et al. proposed a stacking-fault model instead of point-defect model for $\mathrm{La}_{9.33}\left(\mathrm{SiO}_{4}\right)_{6} \mathrm{O}_{2}$ and $\mathrm{La}_{9.67^{-}}$ $\left(\mathrm{SiO}_{4}\right)_{6} \mathrm{O}_{2.5}{ }^{94)}$ This structure model appeared to be close to an incommensurate one, if no diffraction peaks associated with an ordering structure were observed. Baikie et al. speculated that the stacking-fault model was necessary because the presence of $\mathrm{Si}_{2} \mathrm{O}_{7}$ units was confirmed by ${ }^{29} \mathrm{Si}$ nuclear magnetic resonance $\left({ }^{29} \mathrm{Si} \mathrm{NMR}\right)$ of $\mathrm{La}_{9.33}\left(\mathrm{SiO}_{4}\right)_{6} \mathrm{O}_{2}$ and $\mathrm{La}_{9.33-x} \mathrm{AE}_{\mathrm{y}}\left(\mathrm{SiO}_{4}\right)_{6-}$ $\mathrm{O}_{2-3 x / 2-y}, \quad(0<x \leq 1.33,1<y \leq 2, \mathrm{AE}=\mathrm{Ca}, \mathrm{Sr}, \mathrm{Ba}) .{ }^{95), 96)}$ However, Takeda et al. pointed out that the $\mathrm{Si}_{2} \mathrm{O}_{7}$ detected by ${ }^{29} \mathrm{Si}$ NMR was because of a $\mathrm{La}_{2} \mathrm{Si}_{2} \mathrm{O}_{7}$ impurity phase. ${ }^{97)}$ Hence, the stacking fault model should be carefully considered before being applied.

Guillot et al. analyzed the crystal structure of $\mathrm{La}_{9} \mathrm{Ba}\left(\mathrm{SiO}_{4}\right)_{6} \mathrm{O}_{2.5}$ by the Rietveld method using NPD patterns obtained at 293, 973,1073 , and $1173 \mathrm{~K}^{98)}$ With respect to the data at $293 \mathrm{~K}$, the structure parameters of $\mathrm{La}_{9.83} \mathrm{Si}_{5.5} \mathrm{Al}_{0.5} \mathrm{O}_{26.5}$ and $\mathrm{La}_{10} \mathrm{Si}_{5.5} \mathrm{Mg}_{0.5^{-}}$ $\mathrm{O}_{26.5}$ were also presented. All compounds were refined using the structure model with space group $P 6_{3} / \mathrm{m}$. Moreover, the interstitial oxygen ions were located at the O5(12i) site, which was close to $z=0.06$ and 0.44 around the $c$-axis, similar to their previous results. ${ }^{87)}$ The site occupancy of the O4(2a) site was reported to be independent of temperature. Confirming the anisotropic thermal displacements of $\mathrm{La}_{9} \mathrm{Ba}\left(\mathrm{SiO}_{4}\right)_{6} \mathrm{O}_{2.5}$, the $\mathrm{Si}(6 h)$ site exhibited an anisotropic displacement on the $a-b$ plane at $293 \mathrm{~K}$. The displacement along the $a-b$ plane was narrow. However, the anisotropic displacement of the $\mathrm{Si}(6 h)$ site became an isotropic displacement with an increase in temperature. In the case of $\mathrm{La}_{9.83} \mathrm{Si}_{5.5} \mathrm{Al}_{0.5} \mathrm{O}_{26.5}$, all sites exhibited anisotropic displacements, depending on the site. The anisotropic displacement parameter of the $\mathrm{Si}(6 h)$ site in $\mathrm{La}_{10} \mathrm{Si}_{5.5} \mathrm{Mg}_{0.5} \mathrm{O}_{26.5}$ were invalid because an ellipsoid could not be plotted from the parameters.

Leu et al. analyzed the crystal structures of $\mathrm{Sr}_{2} \mathrm{RE}_{8}\left(\mathrm{SiO}_{4}\right)_{6} \mathrm{O}_{2}$ $(\mathrm{RE}=\mathrm{La}, \mathrm{Pr}, \mathrm{Tb}, \mathrm{Tm}$, and $\mathrm{Y})$ using a combination of the Rietveld method, TEM observations, and electron diffraction methods. ${ }^{99)}$ They determined that the crystal structure could be refined using the $P 6_{3} / \mathrm{m}$ model in the cases of $\mathrm{La}, \mathrm{Pt}, \mathrm{Tb}$, and $\mathrm{Y}$. However, unrealistic low-metaprism-twist angles were observed in $\mathrm{Sr}_{2} \mathrm{Tm}_{8}\left(\mathrm{SiO}_{4}\right)_{6} \mathrm{O}_{2}$ by TEM. On the basis of this fact, a new structure model based on space group $P 2_{1} / \mathrm{m}$ was proposed for $\mathrm{Sr}_{2} \mathrm{Tm}_{8}\left(\mathrm{SiO}_{4}\right)_{6} \mathrm{O}_{2}$. In all investigated compounds, $\mathrm{Sr}$ preferentially occupied the $\operatorname{RE} 1(4 f)$ and $\operatorname{RE} 2(4 f)$ sites. Symmetry lowering in the case of $\mathrm{Sr}_{2} \mathrm{Tm}_{8}\left(\mathrm{SiO}_{4}\right)_{6} \mathrm{O}_{2}$ occurred owing to the small ionic radius of the $\mathrm{Tm}$ ion.

New structural defects were proposed after 2012 by two groups. Fukuda et al. reported the successful fabrication of $c$-axis-oriented polycrystalline $\mathrm{La}_{9.33}\left(\mathrm{Si}_{0.87} \mathrm{Ge}_{0.13} \mathrm{O}_{4}\right)_{6} \mathrm{O}_{2}$, which they obtained from sandwich-type $\mathrm{La}_{2} \mathrm{Si}_{2} \mathrm{O}_{7}\left|\mathrm{La}_{2}\left(\mathrm{Si}_{0.833} \mathrm{Ge}_{0.167}\right) \mathrm{O}_{5}\right| \mathrm{La}_{2} \mathrm{Si}_{2} \mathrm{O}_{7}$ compacted powder pellets by heating the pellets at $1873 \mathrm{~K}$ for 50 h. ${ }^{100)}$ Although the fabrication of $c$-axis-oriented $\mathrm{La}_{9.33+x^{-}}$ $\left(\mathrm{SiO}_{4}\right)_{6} \mathrm{O}_{2+1.5 x}(0 \leq x \leq 0.17)$ had been previously reported in $2011,{ }^{101)}$ the crystal structures were reported after 2012. The crystal structure was analyzed by single-crystal XRD and powder XRD methods. Although the space group was the same $\left(P 6_{3} / \mathrm{m}\right)$, the O3(12i) site was considered to be split into two sites$\mathrm{O} 3 \mathrm{~A}(12 i)$ and $\mathrm{O} 3 \mathrm{~B}(12 i)$-with occupancies of 0.228 and 0.772 , respectively. The authors employed a split-atom model because the isotropic thermal-displacement parameter for the O3(12i) site was too large when the split-atom model was not employed. Moreover, they employed a modified site-split model with anharmonic thermal displacements for the La1 $(4 f)$ and $\mathrm{La} 2(6 h)$ sites because they confirmed the presence of residual electron density peaks in the differential Fourier map near the La1 $(4 f)$ and La2(6h) sites. Finally, they concluded that only the anharmonic thermal displacements were necessary for the La1 $(4 f)$ and La2(6h) sites.

In the same year, Fukuda et al. analyzed the crystal structure of $\mathrm{La}_{9.50}\left(\mathrm{SiO}_{4}\right)_{6} \mathrm{O}_{2.25}$ and $\mathrm{La}_{9.33}\left(\mathrm{SiO}_{4}\right)_{6} \mathrm{O}_{2}$ using a combination of 
single-crystal XRD and powder XRD methods. ${ }^{102)}$ These two compounds were fabricated from compacted powder pellets sandwich of $\mathrm{La}_{2} \mathrm{Si}_{2} \mathrm{O}_{7}\left|\mathrm{La}_{2} \mathrm{SiO}_{5}\right| \mathrm{La}_{2} \mathrm{Si}_{2} \mathrm{O}_{7}$. With respect to the case of $\mathrm{La}_{9.50}\left(\mathrm{SiO}_{4}\right)_{6} \mathrm{O}_{2.25}$, two split-atom sites were introduced: one was the splitting of the $\mathrm{O} 3(12 i)$ site into the $\mathrm{O} 3 \mathrm{~A}(12 i)$ and $\mathrm{O} 3 \mathrm{~B}(12 i)$ sites with occupancies of 0.204 and 0.8 , respectively, and the second was the splitting of the $\mathrm{O} 4(2 a)$ site into the $\mathrm{O} 4 \mathrm{~A}(2 a)$ and $\mathrm{O} 4 \mathrm{~B}(4 e)$ sites with occupancies of 0.75 and 0.125 , respectively. The atomic coordinates of the $\mathrm{O} 4 \mathrm{~B}(4 \mathrm{e})$ site was $(0$, $0,0.121)$. Furthermore, additional oxygen sites were introduced at the $\mathrm{O} 5(6 h)$ site at coordinates $(0.27,0.08,1 / 4)$, with 0.043 occupancy. Although the La vacancies were formed only at the La1 $(4 f)$ site, fourth order anharmonic thermal displacement parameters were necessary to be considered. In the case of $\mathrm{La}_{9.33}\left(\mathrm{SiO}_{4}\right)_{6} \mathrm{O}_{2}$, the split-atom model was introduced only at the $\mathrm{O} 3(12 i)$ site, which was divided into $\mathrm{O} 3 \mathrm{~A}(12 i)$ and $\mathrm{O} 3 \mathrm{~B}(12 i)$ sites. The occupancies were 0.26 and 0.24 , respectively. Although the La vacancies were preferentially formed at the La1 $(4 f)$ site, they also formed at the La2 $(6 h)$ site. This model differs from those reported by other researchers. Significant residual electron density peaks in the difference Fourier map were observed for both of the abovementioned compounds; therefore, the authors introduced the split-atom model for both cases. In the 2011 study, a compositional gradient may have existed in the oxyapatite thin layer grown using the aforementioned sandwich method. ${ }^{101)}$ This possibility was apparently not considered during the crystal-structure analysis.

Preferential occupation of cations was reported by two groups. Kobayashi et al. analyzed the crystal structure of $\mathrm{Nd}_{9.33}\left(\mathrm{SiO}_{4}\right)_{6} \mathrm{O}_{2}$ and $\left(\mathrm{La}_{0.44} \mathrm{Nd}_{0.56}\right)_{9.33}\left(\mathrm{SiO}_{4}\right)_{6} \mathrm{O}_{2}$ by the Rietveld method using synchrotron XRD patterns. ${ }^{103)}$ The crystal structure model was $P 6_{3} / \mathrm{m}$. They did not succeed in determining the anisotropic thermal-displacement parameters at the O1(6h), O2(6h), and $\mathrm{O} 3(12 i)$ sites. The $\mathrm{RE}(\mathrm{RE}=\mathrm{La}$ and $\mathrm{Nd})$ vacancies formed only at the RE1 $(4 f)$ site. Moreover, no occupation preference of La or $\mathrm{Nd}$ ions was reported at either the RE1 $(4 f)$ or RE2 $(6 h)$ site.

$\mathrm{Hsu}$ et al. analyzed the crystal structure of $\mathrm{Mg}_{2}\left(\mathrm{Y}_{7.6} \mathrm{Ce}_{0.4}\right)$ $\left(\mathrm{SiO}_{4}\right)_{6} \mathrm{O}_{2}$ by the Rietveld method using a synchrotron XRD pattern. ${ }^{104)}$ The structure parameters were refined using the $P 6_{3} / \mathrm{m}$ space group. Although the $\mathrm{Mg}^{2+}$ and $\mathrm{Ce}^{3+}$ ions preferentially occupied the Y1(4f) site, both ions occupied the Y2 $(6 h)$ site.

In 2013, a new defect was reported on the basis of crystalstructure analysis. Fukuda et al. analyzed the crystal-structure parameters of $\mathrm{La}_{9.50}\left(\mathrm{Si}_{5.87}\right) \mathrm{O}_{26}$ using a combination of singlecrystal XRD and powder XRD measurements. The sample was fabricated from a sandwich-type $\mathrm{La}_{2} \mathrm{Si}_{2} \mathrm{O}_{7}\left|\mathrm{La}_{2} \mathrm{SiO}_{5}\right| \mathrm{La}_{2} \mathrm{Si}_{2} \mathrm{O}_{7}$ compacted powder. They concluded that the space group was $P 6_{3} / \mathrm{m}$. After they confirmed a significant residual electron density peak near the O3(12i) site in the difference Fourier map, they introduced a split-atom model similar to that used in their previous study. $\left.{ }^{105}\right)$ The O3(12i) site was divided into two sites: $\mathrm{O} 3 \mathrm{~A}(12 i)$ (occupancy $=0.20)$ and $\mathrm{O} 3 \mathrm{~B}(12 i)$ (occupancy $=$ $0.80)$. According to the anisotropic thermal-displacement parameters of $\mathrm{La} 1(4 f)$ and $\mathrm{La} 2(6 h)$ sites, both first and third order anharmonic anisotropic displacement parameters were considered. The authors did not confirm the presence of interstitial oxygen. However, the occupancy of $\operatorname{Si}(6 h)$ was 0.9788 , indicating the formation of $\mathrm{Si}$ vacancies. Although a very small deviation from charge neutrality was indicated by the occupancyfactor values, this deviation was within the error for the crystalstructure analysis method.

The split-atom model was also applied in the analysis of $\mathrm{Nd}_{9.46} \mathrm{Si}_{6} \mathrm{O}_{26.20}$ using single-crystal XRD and powder XRD data. ${ }^{40)}$ The authors noted that the chemical compositions refined by the Rietveld method $\left(\mathrm{Nd}_{9.46} \mathrm{Si}_{6} \mathrm{O}_{26.20}\right.$ and $\mathrm{Nd}_{9.77} \mathrm{Si}_{5.5} \mathrm{Al}_{0.5^{-}}$ $\left.\mathrm{O}_{26.41}\right)$ differed from the nominal compositions $\left(\mathrm{Nd}_{9.33} \mathrm{Si}_{6} \mathrm{O}_{26}\right.$ and $\mathrm{Nd}_{9.5} \mathrm{Si}_{5.5} \mathrm{Al}_{0.5} \mathrm{O}_{26}$ ). However, the compositions refined by the Rietveld method in the previously discussed case of single crystals annealed at $1223 \mathrm{~K}$ for 3 months changed and became closer to the nominal compositions $\left(\mathrm{Nd}_{9.35} \mathrm{Si}_{6} \mathrm{O}_{26.002}\right.$ and $\mathrm{Nd}_{9.51^{-}}$ $\left.\mathrm{Si}_{5.5} \mathrm{Al}_{0.5} \mathrm{O}_{26.012}\right)$. With respect to the crystal-structure model, the split-atom model was necessary only in the case of the O3(12i) site of as-grown $\mathrm{Nd}_{9.46} \mathrm{Si}_{6} \mathrm{O}_{26.20}$. After the crystals were annealed, thermal displacement parameters for both of the abovementioned compounds could be refined without invoking the split-atom model. One possibility is that the split-site model for the O3(12i) site was necessary when the chemical composition of the sample was inhomogeneous. Hence, further investigations of the crystal structure models of the oxyapatites are necessary.

Interesting studies from the different research fields were published in the same year. The phase transition of oxyapatite under high pressure was confirmed for $\mathrm{RE}_{9.33}\left(\mathrm{SiO}_{4}\right)_{6} \mathrm{O}_{2}(\mathrm{RE}=\mathrm{Ce}$, $\mathrm{Nd}, \mathrm{Eu}$, and $\mathrm{Gd})^{106)}$ and $\mathrm{La}_{10}\left(\mathrm{SiO}_{4}\right)_{6} \mathrm{O}_{3}{ }^{107)}$ by powder $\mathrm{XRD}$ and photoluminescence spectroscopy. The phase transition from $P 6_{3} / \mathrm{m}$ to $P 6_{3}$ was observed at approximately $15 \mathrm{GPa}$ at room temperature for $\mathrm{RE}_{9.33}\left(\mathrm{SiO}_{4}\right)_{6} \mathrm{O}_{2}(\mathrm{RE}=\mathrm{Ce}, \mathrm{Nd}, \mathrm{Eu}$, and $\mathrm{Gd})$ and $\mathrm{La}_{10}\left(\mathrm{SiO}_{4}\right)_{6} \mathrm{O}_{3}$.

Although results related to the Rietveld refinements of $\mathrm{ARE}_{9}\left(\mathrm{SiO}_{4}\right)_{6} \mathrm{O}_{2}(\mathrm{~A}=\mathrm{Li}$ and $\mathrm{Na}, \mathrm{RE}=\mathrm{La}, \mathrm{Pr}, \mathrm{Nd}, \mathrm{Sm}, \mathrm{Eu}$, $\mathrm{Gd}$, and Er) were published in the same year, the quality of the XRD patterns did not appear to be adequate for Rietveld refinements. ${ }^{108), 109)}$

Even when limited to the $P 6_{3} / \mathrm{m}$ model, the defect species proposed on the basis of the crystal-structure analyses were La vacancies, Si vacancies, and oxygen vacancies at the $\mathrm{O} 4(2 a)$ sites, and interstitial oxygen ions at the $\mathrm{O} 5(12 i)$ sites. In the case of a solid electrolyte, free electrons and holes must exist as minority charged species. Thus, too many species exist in one crystalline phase to allow a straightforward analysis of the defect equilibria.

\section{Oxygen-ion conductivity of nondoped lanthanum silicate oxyapatite ceramics}

Electrical conductivity of ceramics is well known to be sensitive to relative density and porosity. ${ }^{110)}$ Moreover, a comparison of the total conductivity of single-phase ceramics with that of impurity-contaminated ceramics is difficult because the actual chemical composition of the conductive part cannot be determined from the nominal composition. Meanwhile, data related to the total conductivity of lanthanoid silicate oxyapatites have been reported using porous ceramics and a significant amount of impurity-contaminated ceramics, because of the low sinterability and difficult synthesis of single phases in this system. Here, we summarize the literature conductivity data of samples with a relative density greater than $90 \%$ and no impurity segregation, as confirmed by XRD analysis. On the basis of this screening, 39 studies related to the total conductivity of $\mathrm{La}_{9.33+x}\left(\mathrm{SiO}_{4}\right)_{6} \mathrm{O}_{2+3 x / 2}$ were identified. ${ }^{72), 79), 89), 98), 101), 105), 111)-145) ~ T h e ~} \sigma_{\mathrm{t}} \mathrm{s}$ values are summarized in Fig. 10 as an Arrhenius plot. To confirm the influence of the sintering temperature on the conductivity, the relationship between the $\sigma_{\mathrm{t}}$ of $\mathrm{La}_{9.33}\left(\mathrm{SiO}_{4}\right)_{6} \mathrm{O}_{2}$ at $973 \mathrm{~K}$ and sintering temperature is presented in Fig. 11. Although the data are scattered, the $\sigma_{\mathrm{t}}$ appears to be almost independent of the sintering temperature at temperatures greater than $1773 \mathrm{~K}$, which might indicate that very high sintering temperatures of $1923 \mathrm{~K}$ or greater might not be necessary, in contrast to the initial report by Nakayama et al. ${ }^{3)}$ 


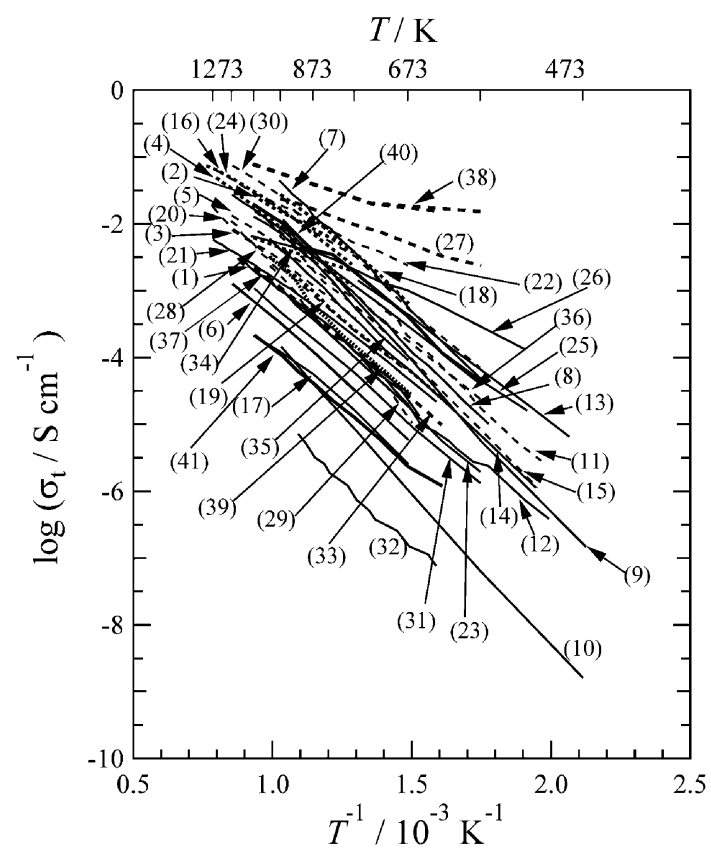

Fig. 10. Relationship between the total conductivity of $\mathrm{La}_{9.33+x^{-}}$ $\left(\mathrm{SiO}_{4}\right)_{6} \mathrm{O}_{2+3 x / 2}$ ceramics and reciprocal temperature. Total conductivities of $\mathrm{La}_{9.33}\left(\mathrm{SiO}_{4}\right)_{6} \mathrm{O}_{2}, \mathrm{La}_{9.33+x}\left(\mathrm{SiO}_{4}\right)_{6} \mathrm{O}_{2+3 x / 2}(0<x<0.67)$, and $\mathrm{La}_{10^{-}}$ $\left(\mathrm{SiO}_{4}\right)_{6} \mathrm{O}_{10}$ ceramics are drawn as a thin solid line, a thin broken line, and a thick dotted line, respectively. The conductivity measured by the crystal-oriented ceramics is represented by a thick broken line. The numbered labels are as follows: (1) $\mathrm{La}_{9.33}\left(\mathrm{SiO}_{4}\right)_{6} \mathrm{O}_{2}$ sintered at $\left.1873 \mathrm{~K},{ }^{112}\right)$ (2) $\mathrm{La}_{10}\left(\mathrm{SiO}_{4}\right)_{6} \mathrm{O}_{3}$ sintered at $\left.2023 \mathrm{~K},{ }^{115}\right)(3) \mathrm{La}_{9.6}\left(\mathrm{SiO}_{4}\right)_{6} \mathrm{O}_{2.4}$ sintered at $2023 \mathrm{~K},{ }^{116)}(4) \mathrm{La}_{10}\left(\mathrm{SiO}_{4}\right)_{6} \mathrm{O}_{3}$ sintered at $1973 \mathrm{~K},{ }^{118)}(5) \mathrm{La}_{9.6}\left(\mathrm{SiO}_{4}\right)_{6} \mathrm{O}_{2.4}$ sintered at $2023 \mathrm{~K},{ }^{72)}(6) \mathrm{La}_{9.33}\left(\mathrm{SiO}_{4}\right)_{6} \mathrm{O}_{2}$ sintered at $1898 \mathrm{~K},{ }^{119), 121)}(7)$ $\mathrm{La}_{9.33}\left(\mathrm{SiO}_{4}\right)_{6} \mathrm{O}_{2}$ sintered by spark plasma sintering (SPS) method at $1773 \mathrm{~K},{ }^{120)}(8) \mathrm{La}_{9.33}\left(\mathrm{SiO}_{4}\right)_{6} \mathrm{O}_{2}$ sintered at $1773 \mathrm{~K},{ }^{120)}(9) \mathrm{La}_{9.33}\left(\mathrm{SiO}_{4}\right)_{6} \mathrm{O}_{2}$ sintered at $1973 \mathrm{~K}$ under $\mathrm{N}_{2}$ atmosphere, ${ }^{79)}(10) \mathrm{La}_{9.33}\left(\mathrm{SiO}_{4}\right)_{6} \mathrm{O}_{2}$ sintered at $1973 \mathrm{~K}$ under air atmosphere, ${ }^{79)}(11) \mathrm{La}_{9.56}\left(\mathrm{SiO}_{4}\right)_{6} \mathrm{O}_{2.34}$ sintered at $1873 \mathrm{~K}^{122)}$ (12) $\mathrm{La}_{9.33}\left(\mathrm{SiO}_{4}\right)_{6} \mathrm{O}_{2}$ sintered at $\left.1873 \mathrm{~K},{ }^{122}\right)$ (13) $\mathrm{La}_{9.33-}$ $\left(\mathrm{SiO}_{4}\right)_{6} \mathrm{O}_{2}$ sintered at $1873 \mathrm{~K},{ }^{123)}(14) \mathrm{La}_{9.33}\left(\mathrm{SiO}_{4}\right)_{6} \mathrm{O}_{2}$ sintered by SPS method at $1773 \mathrm{~K}$, ${ }^{124)}(15) \mathrm{La}_{9.6}\left(\mathrm{SiO}_{4}\right)_{6} \mathrm{O}_{2.4}$ sintered by SPS method at $1773 \mathrm{~K},{ }^{124)}(16) \mathrm{La}_{9.67}\left(\mathrm{SiO}_{4}\right)_{6} \mathrm{O}_{2.505}$ sintered at $1973 \mathrm{~K},{ }^{125)}$ (17) $\mathrm{La}_{9.33^{-}}$ $\left(\mathrm{SiO}_{4}\right)_{6} \mathrm{O}_{2}$ sintered at $1673 \mathrm{~K},{ }^{126)}$ (18) $\mathrm{La}_{10}\left(\mathrm{SiO}_{4}\right)_{6} \mathrm{O}_{3}$ sintered at $1773 \mathrm{~K},{ }^{127}$ (19) $\mathrm{La}_{10}\left(\mathrm{SiO}_{4}\right)_{6} \mathrm{O}_{3}$ sintered at $1673 \mathrm{~K},{ }^{127)}$ (20) $\mathrm{La}_{9.50^{-}}$ $\left(\mathrm{SiO}_{4}\right)_{6} \mathrm{O}_{2.25}$ sintered at $\left.1773 \mathrm{~K},{ }^{128}\right)(21) \mathrm{La}_{9.33}\left(\mathrm{SiO}_{4}\right)_{6} \mathrm{O}_{2}$ sintered by reactive sintering method at $1923 \mathrm{~K},{ }^{129)}(22) \mathrm{La}_{9.67}\left(\mathrm{SiO}_{4}\right)_{6} \mathrm{O}_{2.505}$ sintered at $1973 \mathrm{~K},{ }^{98)}(23) \mathrm{La}_{9.33}\left(\mathrm{SiO}_{4}\right)_{6} \mathrm{O}_{2}$ sintered at $1823 \mathrm{~K},{ }^{130)}$ (24) $\mathrm{La}_{10^{-}}$ $\left(\mathrm{SiO}_{4}\right)_{6} \mathrm{O}_{3}$ sintered at $\left.1953 \mathrm{~K},{ }^{89}\right)(25) \mathrm{La}_{9.33}\left(\mathrm{SiO}_{4}\right)_{6} \mathrm{O}_{2}$ sintered at $1823 \mathrm{~K},{ }^{132)}$ (26) $\mathrm{La}_{9.33}\left(\mathrm{SiO}_{4}\right)_{6} \mathrm{O}_{2}$ sintered at $1673 \mathrm{~K},{ }^{134)}$ (27) $\mathrm{La}_{9.33-}$ $\left(\mathrm{SiO}_{4}\right)_{6} \mathrm{O}_{2}$ crystal oriented ceramic film parallel to the $c$-axis, ${ }^{101), 105)}(28)$ $\mathrm{La}_{8.58}\left(\mathrm{SiO}_{4}\right)_{6} \mathrm{O}_{0.87}$ thin film deposited by sputtering method and then annealed at $\left.1173 \mathrm{~K},{ }^{135}\right)(29) \mathrm{La}_{10}\left(\mathrm{SiO}_{4}\right)_{6} \mathrm{O}_{3}$ deposited by atmosphericplasma spray method and then annealed at $1273 \mathrm{~K},{ }^{136}$ ) (30) $\mathrm{La}_{9.67^{-}}$ $\left(\mathrm{SiO}_{4}\right)_{6} \mathrm{O}_{2.505}$ sintered at $1898 \mathrm{~K},{ }^{98)}(31) \mathrm{La}_{9.33}\left(\mathrm{SiO}_{4}\right)_{6} \mathrm{O}_{2}$ sintered at $1773 \mathrm{~K},{ }^{137)}$ (32) $\mathrm{La}_{9.33}\left(\mathrm{SiO}_{4}\right)_{6} \mathrm{O}_{2}$ sintered at $1713 \mathrm{~K},{ }^{138)}$ (33) $\mathrm{La}_{9.33^{-}}$ $\left(\mathrm{SiO}_{4}\right)_{6} \mathrm{O}_{2}$ crystal oriented ceramic film vertical to the $c$-axis, ${ }^{139)}$ (34) $\mathrm{La}_{10}\left(\mathrm{SiO}_{4}\right)_{6} \mathrm{O}_{3}$ sintered at $\left.1873 \mathrm{~K},{ }^{140}\right)(35) \mathrm{La}_{9.33}\left(\mathrm{SiO}_{4}\right)_{6} \mathrm{O}_{2}$ sintered at $1823 \mathrm{~K},{ }^{141)}(36) \mathrm{La}_{9.50}\left(\mathrm{SiO}_{4}\right)_{6} \mathrm{O}_{2.25}$ sintered at $1873 \mathrm{~K},{ }^{143)}$ (37) $\mathrm{La}_{9.33^{-}}$ $\left(\mathrm{SiO}_{4}\right)_{6} \mathrm{O}_{2}$ sintered at $\left.1823 \mathrm{~K},{ }^{145}\right)$ (38) $\mathrm{La}_{9.50}\left(\mathrm{SiO}_{4}\right)_{6} \mathrm{O}_{2.25}$ and $\mathrm{La}_{9.50^{-}}$ $\left(\mathrm{Si}_{0.978} \mathrm{O}_{4}\right)_{6} \mathrm{O}_{2}$ crystal oriented ceramic films parallel to the $c$-axis, ${ }^{102), 105)}$ (39) $\mathrm{La}_{10}\left(\mathrm{SiO}_{4}\right)_{6} \mathrm{O}_{3}$ deposited by atmospheric-plasma spray method and then annealed at $\left.1273 \mathrm{~K},{ }^{142}\right)(40) \mathrm{La}_{9.33}\left(\mathrm{SiO}_{4}\right)_{6} \mathrm{O}_{2}$ crystal oriented ceramic bulk parallel to the $c$-axis, ${ }^{144)}$ and $(41) \mathrm{La}_{9.33}\left(\mathrm{SiO}_{4}\right)_{6} \mathrm{O}_{2}$ crystal oriented ceramic bulk vertical to the $c$-axis. ${ }^{144)}$

With respect to the $\mathrm{La} / \mathrm{Si}$ ratio, the $\sigma_{\mathrm{t}}$ value is almost independent of the La/Si ratio (Fig. 12). Two explanations exist for these results. One explanation is that the $\sigma_{\mathrm{t}}$ value may be invalid

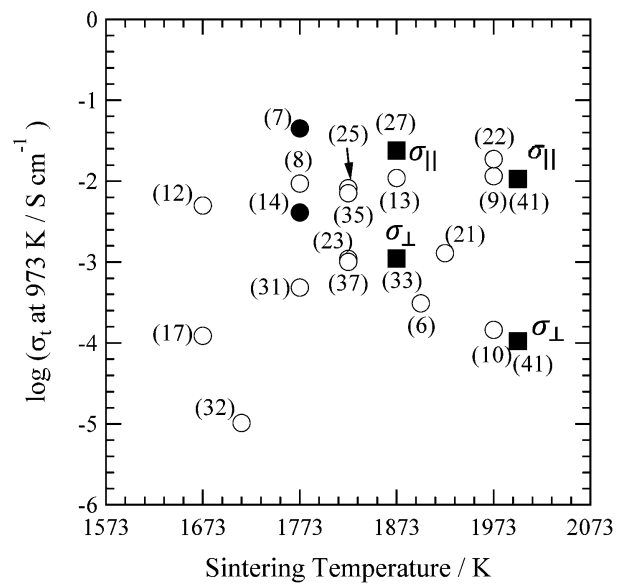

Fig. 11. Relationship between the $\sigma_{\mathrm{t}}$ of $\mathrm{La}_{9.33}\left(\mathrm{SiO}_{4}\right)_{6} \mathrm{O}_{2}$ dense ceramics at $973 \mathrm{~K}$ and the sintering temperature based on the data shown in Fig. 10. The closed circles represent the $\sigma_{\mathrm{t}}$ of SPS sintering samples. The closed squares represent the crystal-oriented ceramics data. The $\sigma_{\Pi}$ and $\sigma_{\perp}$ are the conductivity parallel to the $c$-axis and vertical to the $c$-axis, respectively. Label numbers are the same as those in Fig. 10.

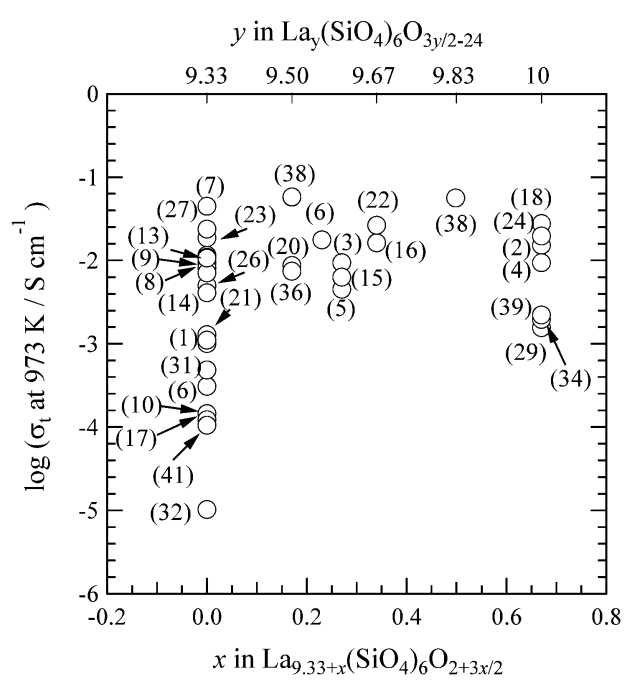

Fig. 12. Relationship between the $\sigma_{\mathrm{t}} \mathrm{La}_{9.33+x}\left(\mathrm{SiO}_{4}\right)_{6} \mathrm{O}_{2+3 x / 2}$ of dense ceramics and the chemical composition $x$ at $973 \mathrm{~K}$ shown in Fig. 10. Label numbers are the same as those in Fig. 10.

because of a misevaluation during the equivalent-circuit analysis of the impedance spectra. The second is that the $\sigma_{\mathrm{t}}$ is mainly governed by the grain morphology, distribution of the crystallographic orientation of the ceramics, and grain boundaries instead of the carrier concentration. In the former case, the bulk resistance is usually evaluated from an impedance spectrum, but only the high-frequency region is used for this purpose. However, obtaining an accurate spectrum in the high-frequency region is difficult because of spectrum distortion by the measurement instrument and stray impedance of the lead wires. If the conductivity is governed by the grain morphology and by the distribution of the crystallographic orientation, the $\sigma_{\mathrm{t}}$ value must be measured using ceramics with controlled crystal orientations. However, insufficient data exists for a discussion of the influence of the grain orientation because such ceramics are difficult to fabricate. Moreover, technological advancements are necessary from a materials engineering viewpoint to not only improve the $\sigma_{\mathrm{t}}$ value but also to enable the development of a process by 
which the $\sigma_{\mathrm{t}}$ scattering of the ceramics can be narrowed, if the lanthanum silicate oxyapatite ceramics are to be applied as solid electrolytes.

In contrast to the $\sigma_{t}$ measurement performed under air, data indicating the predominance of oxygen-ion conductivity over a wide oxygen partial-pressure range is scarce. The first studies detailing the relation between $\sigma_{\mathrm{t}}$ and normalized oxygen partial pressure, $p_{\mathrm{O}_{2}}$ from 1 to $10^{-20}$ were published by Arikawa et al. ${ }^{146)}$ and Tao et al. ${ }^{147)}$ in 2000 . However, the $\mathrm{La}_{10}\left(\mathrm{SiO}_{4}\right)_{6} \mathrm{O}_{3}$ ceramic samples in both studies contained impurity phases. Furthermore, the relative density of the sample was very low $(69 \%)$ in the latter study. Impurity phases will be discussed in the following section. Results related to the dependence of $\sigma_{\mathrm{t}}$ on $p_{\mathrm{O}_{2}}$ were different from each other. Arikawa et al. reported that the $\sigma_{\mathrm{t}}$ value was independent of $p_{\mathrm{O}_{2}}$ between 1 and $10^{-20}$ at $900^{\circ} \mathrm{C}$. However, Tao et al. reported that the $\sigma_{\mathrm{t}}$ depended on the $p_{\mathrm{O}_{2}}$ surrounding the sample because the $\sigma_{\mathrm{t}}$ values measured under air were lower than those measured under an $\mathrm{Ar}+5 \% \mathrm{H}_{2}$ atmosphere at $873 \mathrm{~K}$. Further investigating the dependence of $\sigma_{\mathrm{t}}$ on the water vapor pressure, they ruled out the possibility of the results being influenced by proton conductivity. They proposed that the $p_{\mathrm{O}_{2}}$ dependence of the $\sigma_{\mathrm{t}}$ was governed by the grain-boundary conductivity.

Although Gorshkov et al. reported that the $\sigma_{\mathrm{t}}$ of $\mathrm{La}_{10}\left(\mathrm{SiO}_{4}\right)_{6} \mathrm{O}_{3}$ was independent of $p_{\mathrm{O}_{2}}$ in the range of $1-10^{-18},{ }^{117)}$ no information could be found related to the temperature dependence. A comparison of the $\sigma_{\mathrm{t}}$ values in the Arrhenius plot reveals that the $\sigma_{\mathrm{t}}$ exhibited a $p_{\mathrm{O}_{2}}$ dependence at $1273 \mathrm{~K}$. With respect to the oxygen-ion transport number, they measured the $E M F$ value using only the following oxygen concentration cell:

$$
p_{\mathrm{O}_{2}}=1, \mathrm{Pt}\left|\mathrm{La}_{10}\left(\mathrm{SiO}_{4}\right)_{6} \mathrm{O}_{3}\right| \mathrm{Pt} \text {, Air. }
$$

Although the $E M F$ measurement conditions were very limited, they concluded that average transference number of oxygen ions was close to 1 at temperatures between 873 and $1273 \mathrm{~K}$. In 2008, they reported the $p_{\mathrm{O}_{2}}$ dependence of $\sigma_{\mathrm{t}}$ for $\mathrm{La}_{9.33+x}\left(\mathrm{SiO}_{4}\right)_{6} \mathrm{O}_{2+3 x / 2}$ $(x=0,0.22,0.67$, and 0.89$)$ at $1073 \mathrm{~K}$ and in the normalized oxygen partial pressure range from 1 to $10^{-20}$. However, the relative density of all samples used in their study was $87 \%$. They concluded that $\sigma_{\mathrm{t}}$ for all samples was almost independent of $p_{\mathrm{O}_{2}}$.

In 2008, Chefi et al. reported the $p_{\mathrm{O}_{2}}$ dependence of the $\sigma_{\mathrm{t}}$ of $\mathrm{La}_{9.33}\left(\mathrm{SiO}_{4}\right)_{6} \mathrm{O}_{2}$ for $p_{\mathrm{O}_{2}}$ values between 0.67 and $10^{-21}$ at $973 \mathrm{~K}^{123)}$ However, they did not conduct $E M F$ measurements.

In the same year, Mineshige et al. reported the dependence of $\sigma_{\mathrm{t}}$ on $p_{\mathrm{O}_{2}}$ and temperature for $\mathrm{La}_{9.69}\left(\mathrm{SiO}_{4}\right)_{6} \mathrm{O}_{2.535}$ [nominal composition: $\left.\mathrm{La}_{10}\left(\mathrm{SiO}_{4}\right)_{6} \mathrm{O}_{3}\right]$ in the $p_{\mathrm{O}_{2}}$ range from 1 to $10^{-28}$ and between 1273 and $873 \mathrm{~K} .{ }^{125}$ ) They reported that contributions of hole conductivity were observed for $p_{\mathrm{O}_{2}}$ levels between 1 and $10^{-3}$ at 1273 and $1173 \mathrm{~K}$, because the $\sigma_{\mathrm{t}}$ increased with increasing $p_{\mathrm{O}_{2}}$.

In 2009, Kobayashi and Nishimura reported the dependence of $\sigma_{\mathrm{t}}$ on $p_{\mathrm{O}_{2}}$ and the $E M F$ of $\mathrm{La}_{9.50}\left(\mathrm{SiO}_{4}\right)_{6} \mathrm{O}_{2.25}$ in the $p_{\mathrm{O}_{2}}$ range from 1 to $10^{-27}$ at temperatures from 1273 to $773 \mathrm{~K} .{ }^{128)}$ The $E M F$ was measured using a double electrochemical cell. The sample $E M F$ was measured using the following cell construction:

$$
\text { Sample gas }\left(p_{\mathrm{O}_{2}}^{\text {sample }}\right), \mathrm{Pt}\left|\mathrm{La}_{9.50}\left(\mathrm{SiO}_{4}\right)_{6} \mathrm{O}_{2.25}\right| \mathrm{Pt} \text {, } \operatorname{Air}\left(p_{\mathrm{O}_{2}}^{\text {ref }}\right) \text {. }
$$

$p_{\mathrm{O}_{2}}^{\text {sample }}$ is the normalized oxygen partial pressure of sample gas; $p_{\mathrm{O}_{2}}^{\text {sample }}$ was changed using gas mixtures of $\mathrm{O}_{2}+$ air and $\mathrm{Ar}+$ $\mathrm{H}_{2}+\mathrm{H}_{2} \mathrm{O}$. $p_{\mathrm{O}_{2}}^{\text {sample }}$ was monitored using a zirconia oxygen sensor positioned near the sample cell. They clarified that the EMF measured using the $\mathrm{La}_{9.50}\left(\mathrm{SiO}_{4}\right)_{6} \mathrm{O}_{2.25}$ ceramics showed good agreement with the $E M F$ measured using the zirconia sensor.
With combined $\sigma_{\mathrm{t}}$ and $E M F$ data, they concluded that oxygen-ion conductivity was predominant over a wide temperature and $p_{\mathrm{O}_{2}}$ range.

Mineshige et al. measured the average transference number of oxygen ions in $\mathrm{La}_{9.67}\left(\mathrm{SiO}_{4}\right)_{6} \mathrm{O}_{2.535}$ ceramics using an oxygen concentration cell over the $p_{\mathrm{O}_{2}}$ range of $10^{-2}-10^{-24}$ at 873 and $1073 \mathrm{~K}^{148)}$ They concluded that the average transference number of oxygen ions was greater than 0.99 under the aforementioned conditions. However, measurement of the transference number at temperatures above $1173 \mathrm{~K}$ would be necessary to allow a comparison with the results reported in their previous study, ${ }^{125}$ ) because hole conductivity may have influenced the results. On the other hand, they gave no data at temperatures above $1173 \mathrm{~K}$.

In the case of Nd-containing oxyapatites, significant contributions to the electronic conductivities were reported by Kobayashi et al. for $\left(\mathrm{La}_{0.46} \mathrm{Nd}_{0.54}\right)_{9.33}\left(\mathrm{SiO}_{4}\right)_{6} \mathrm{O}_{2}$ and $\mathrm{Nd}_{9.2}\left(\mathrm{SiO}_{4}\right)_{6} \mathrm{O}_{1.8}{ }^{103)} \mathrm{In}$ the case of $\left(\mathrm{La}_{0.46} \mathrm{Nd}_{0.54}\right)_{9.33}\left(\mathrm{SiO}_{4}\right)_{6} \mathrm{O}_{2}$, the partial conductivity of free electrons was observed to contribute to the total conductivity at 1173 and $1273 \mathrm{~K}$ in the $p_{\mathrm{O}_{2}}$ range of $10^{-15}-10^{-20} \mathrm{~atm}$. In the case of $\mathrm{Nd}_{9.2}\left(\mathrm{SiO}_{4}\right)_{6} \mathrm{O}_{1.8}$, the influence of the partial conductivity of holes and the partial conductivity of free electrons was observed in the low- $p_{\mathrm{O}_{2}}$ region and high- $p_{\mathrm{O}_{2}}$ region, respectively. However, the authors did not report $E M F$ measurements in this study.

Although the literature contains numerous studies related to the $\sigma_{\mathrm{t}}$ of lanthanum silicate oxyapatites, clear proof of whether this material is an ideal oxygen-ion conductor, on the basis of experimental data sets, is still limited. Further reports of basic data related to solid-state electrochemical properties are necessary to enable the use of lanthanum silicate oxyapatites as solid electrolytes.

\section{Problems related to the single-phase composition and unknown impurity phase of nondoped lanthanum silicate oxyapatite}

Although the composition region where the lanthanum silicate oxyapatite single phase is formed represents important and fundamental data, the single-phase compositions reported by various authors differ. As previously described, Nakayama et al. used a molecular formula of $\mathrm{RE}_{10}\left(\mathrm{SiO}_{4}\right)_{6} \mathrm{O}_{3}$ in their literature titles from 1995 to $1998 .{ }^{1)-3)}$ However, they explained in the literature that the sample with a nominal composition of $\mathrm{RE}_{10^{-}}$ $\left(\mathrm{SiO}_{4}\right)_{6} \mathrm{O}_{3}$ was not the oxyapatite single phase but a two-phase mixture of oxyapatite and $\mathrm{RE}_{2} \mathrm{SiO}_{5}$ phases synthesized between 1773 and $1873 \mathrm{~K}$. Higuchi et al. later successfully grew single crystals of $\mathrm{RE}_{9.33}\left(\mathrm{SiO}_{4}\right)_{6} \mathrm{O}_{2}(\mathrm{RE}=\mathrm{Nd}, \mathrm{Sm}$, and $\mathrm{Pr}) .{ }^{18), 30), 33)-35), 37)}$ Through careful analysis of the chemical compositions of $\mathrm{Nd}_{9.33}\left(\mathrm{SiO}_{4}\right)_{6} \mathrm{O}_{2}$ single crystals, they proposed that cation nonstoichiometry exists in $\mathrm{Nd}_{9.33}\left(\mathrm{SiO}_{4}\right)_{6} \mathrm{O}_{2}$ and presented a generalized neodymium silicate oxyapatite chemical composition of $\mathrm{Nd}_{9.33-x}\left(\mathrm{SiO}_{4}\right)_{6} \mathrm{O}_{2-3 x / 2}(0 \leq x \leq 0.7) .{ }^{35)}$ This nonstoichiometry is an unlikely tendency of $\mathrm{Nd}_{10}\left(\mathrm{SiO}_{4}\right)_{6} \mathrm{O}_{3}$. Notably, Nakayama et al. used the molecular formula of $\mathrm{RE}_{10}\left(\mathrm{SiO}_{4}\right)_{6} \mathrm{O}_{3}$ to represent a nominal composition, not a single-phase composition. $^{1)-3), 18), 30), 33)-37), 144), 149 \text { ) }}$

The preparation of single-phase $\mathrm{La}_{10}\left(\mathrm{SiO}_{4}\right)_{6} \mathrm{O}_{3}$ was reported in $2000^{146)}$ and $2001 .{ }^{150}$ In the case of the 2000 report, $\mathrm{La}_{10^{-}}$ $\left(\mathrm{SiO}_{4}\right)_{6} \mathrm{O}_{3}$ ceramics were synthesized by a conventional solidstate reaction method involving heating at $1923 \mathrm{~K}$. In the 2001 study, the sample was synthesized by the sol-gel method and heated at $1673 \mathrm{~K}$. However, a careful comparison of the XRD pattern with that reported in the literature, which is the most important proof of phase purity, indicated the presence of an 
impurity phase, as indicated by the peak at $2 \theta=28.5^{\circ}$ in the 2000 study. ${ }^{146)}$ In addition, a determination of whether the sample is a single-phase or multiple-phase mixture is difficult because of the low $\mathrm{S} / \mathrm{N}$ ratio of the XRD pattern in the 2001 study. ${ }^{150}$ ) Interestingly, the XRD peak from the impurity phase is completely different from the XRD peaks of $\mathrm{La}_{2} \mathrm{SiO}_{5}$ and $\mathrm{La}_{2} \mathrm{Si}_{2} \mathrm{O}_{7}$ but is close to the maximum peak position of $\mathrm{La}_{2} \mathrm{Zr}_{2} \mathrm{O}_{7}$. However, zirconia might not be used during the synthesis process. ${ }^{146)}$ Meanwhile, in the case of the 2001 study Tao et al. apparently considered that $\mathrm{La}_{10}\left(\mathrm{SiO}_{4}\right)_{6} \mathrm{O}_{3}$ and $\mathrm{La}_{9.33}\left(\mathrm{SiO}_{4}\right)_{6} \mathrm{O}_{2}$ were the different phases present in the compound. ${ }^{150)}$

In 2003, Slater and Sansom reported the successful singlephase formation of $\mathrm{La}_{9.33}\left(\mathrm{SiO}_{4}\right)_{6} \mathrm{O}_{2}$ and $\mathrm{La}_{9.67}\left(\mathrm{SiO}_{4}\right)_{6} \mathrm{O}_{2.505}$. $\left.{ }^{112}\right)$ The samples were synthesized by heating between 1873 and $1973 \mathrm{~K}$. In this study, we could not find any evidence to conclusively determine whether these two samples were the single-phase or multiple-phase.

The first suggestion that lanthanum silicate oxyapatite has a cationic nonstoichiometry and that its molecular formula should be represented as $\mathrm{La}_{10-x}\left(\mathrm{SiO}_{4}\right)_{6} \mathrm{O}_{3-3 x / 2}$ was reported by ReónLeina et al. in 2004. ${ }^{45}$ ) In this study, single-phase oxyapatite was obtained at $x$ values between $0.67\left[\mathrm{La}_{9.33}\left(\mathrm{SiO}_{4}\right)_{6} \mathrm{O}_{2}\right]$ and $0.4\left[\mathrm{La}_{9.60}\left(\mathrm{SiO}_{4}\right)_{6} \mathrm{O}_{2.4}\right]$ by heating at $1573 \mathrm{~K}$; a continuous solid solution was formed in this composition region. In particular, the samples with compositions of $\mathrm{La}_{9.66}\left(\mathrm{SiO}_{4}\right)_{6} \mathrm{O}_{2.49}$ and $\mathrm{La}_{9.73^{-}}$ $\left(\mathrm{SiO}_{4}\right)_{6} \mathrm{O}_{2.595}$ were not single phases but dual phases comprising oxyapatite phase and $\mathrm{La}_{2} \mathrm{SiO}_{5}$.

In the same year, single-phase formation of $\mathrm{La}_{10}\left(\mathrm{SiO}_{4}\right)_{6} \mathrm{O}_{3}$ was reported by Yoshioka. ${ }^{115)}$ He synthesized the sample by the sol-gel method and heated it at 1973 and $2023 \mathrm{~K}$. At both temperatures, the $\mathrm{La}_{10}\left(\mathrm{SiO}_{4}\right)_{6} \mathrm{O}_{3}$ became single-phase oxyapatite. However, Yoshioka changed the composition region related to the oxyapatite single phase in his second study. ${ }^{72)}$ The oxyapatite single phase region was revised to $\mathrm{La}_{9.33+x}\left(\mathrm{SiO}_{4}\right)_{6} \mathrm{O}_{2+3 x / 2}$ $(-0.04 \leq x \leq 0.27)$ synthesized at $2023 \mathrm{~K}$. In this study, samples with compositions of $\mathrm{La}_{8.96}\left(\mathrm{SiO}_{4}\right)_{6} \mathrm{O}_{1.44}$ and $\mathrm{La}_{9.92}\left(\mathrm{SiO}_{4}\right)_{6} \mathrm{O}_{2.88}$ were two-phase mixtures of oxyapatite and $\mathrm{La}_{2} \mathrm{Si}_{2} \mathrm{O}_{7}$ and oxyapatite and $\mathrm{La}_{2} \mathrm{SiO}_{5}$, respectively. In the case of the sample with composition $\mathrm{La}_{10.25}\left(\mathrm{SiO}_{4}\right)_{6} \mathrm{O}_{3.375}$, the formation of three phases was confirmed; the formed phases were oxyapatite, $\mathrm{La}_{2} \mathrm{SiO}_{5}$, and an unknown phase. When we compare this work to that of Arikawa, ${ }^{146)}$ we note that the peak position of the unknown phase shows good agreement with the impurity phase in Arikawa's data; the peak position is close to the (2 2 2) peak of $\mathrm{La}_{2} \mathrm{Zr}_{2} \mathrm{O}_{7}$. With respect to the sample preparation procedures, ${ }^{115)}$ magnesiastabilized zirconia was used as setter material during the sintering process, similar to that used by Nakayama. ${ }^{3)}$ Hence, the zirconia contamination might have occurred during the sintering process. However, whether the difference in the single-phase regions reported in 2004 and 2006 was due to the influence of the zirconia contamination was not clear. In addition, at least six studies were published reporting the successful fabrication of oxyapatite single phases with composition $\mathrm{La}_{10^{-}}$ $\left(\mathrm{SiO}_{4}\right)_{6} \mathrm{O}_{3}{ }^{89), 117), 127), 136), 140), 142)}$ According to these results, a detectable composition width of the lanthanum silicate oxyapatite single phase should exist in the $\mathrm{La}_{2} \mathrm{O}_{3}-\mathrm{SiO}_{2}$ quasi-binary system. However, different results also indicated that the single-phase composition of oxyapatite should be located between $\mathrm{La}_{9.21^{-}}$ $\left(\mathrm{SiO}_{4}\right)_{6} \mathrm{O}_{1.81}$ and $\mathrm{La}_{9.33}\left(\mathrm{SiO}_{4}\right)_{6} \mathrm{O}_{2}$ at $\left.\left.1773 \mathrm{~K}^{77}\right), 81\right)$ This discrepancy cannot be explained on the basis of the published results. Hence, the accurate composition region of lanthanum silicate oxyapatite remains unclear.

\section{Summary}

Oxygen-ion conductivity of rare-earth silicate oxyapatites was discovered accidentally during the development of new lithiumion conductors. However, strong consensus of the oxygenion conductivity was not achieved on the basis of the initial studies published prior to 1998 because of insufficient data and inadequate explanations. Furthermore, very high temperatures (greater than $1873 \mathrm{~K}$ ) were reported to be necessary for fabrication of dense ceramics with $\mathrm{RE}_{10}\left(\mathrm{SiO}_{4}\right)_{6} \mathrm{O}_{3}$ composition. However, the researchers who discovered oxygen-ion conductivity in $\mathrm{RE}_{10}\left(\mathrm{SiO}_{4}\right)_{6} \mathrm{O}_{3}$ also explained that oxyapatites with this composition were not single-phase. After $\mathrm{Nd}_{9.33}\left(\mathrm{SiO}_{4}\right)_{6} \mathrm{O}_{2}$, $\mathrm{Pr}_{9.33}\left(\mathrm{SiO}_{4}\right)_{6} \mathrm{O}_{2}$, and $\mathrm{Sm}_{9.33}\left(\mathrm{SiO}_{4}\right)_{6} \mathrm{O}_{2}$ single crystals were successfully grown, very high oxygen-ion conductivity was discovered in the direction parallel to the $c$-axis. Consequently, the strong potential of rare-earth silicate oxyapatites as solid electrolytes was widely recognized.

After the discovery of oxygen-ion conductivity in rare-earth silicate oxyapatites, the research trends of crystal-structure analysis shifted from the crystal-structure refinement to the determination of the atomic position of the interstitial oxygen ion. Although powder X-ray diffraction and powder neutron diffraction analyses were conducted and many studies related to the interstitial oxygen position were published, complete and consistent data were not obtained because of the very low site occupancy of the interstitial oxygen site. Instead, models involving point-defect species showed a tendency to result in better diffraction-data refinements.

With respect to the total conductivity of lanthanum silicate oxyapatite ceramics, we could not discern any correlation between the sintering temperature and the cation nonstoichiometry $x$ in $\mathrm{La}_{9.33+x}\left(\mathrm{SiO}_{4}\right)_{6} \mathrm{O}_{2+3 x / 2}$ because of scattered conductivity data. Moreover, only a small number of studies have reported $E M F$ measurements using oxygen concentration cells in wide temperature and oxygen partial pressure ranges. This lack of fundamental data about the electrolytic properties lanthanum silicate oxyapatite exists even at present.

\section{Appendix A}

Based on Wagner's theory, ${ }^{4)}$ the electromotive force $(E M F)$ of a cell with $p_{\mathrm{O}_{2}}^{\text {sample }}, \mathrm{Pt}(-) \mid$ Oxygen-ion Conductor $\mid \mathrm{Pt}(+), p_{\mathrm{O}_{2}}^{\text {ref }}$ is given by the following relationship:

$$
E M F=-\frac{R T}{4 F} \int_{\ln p_{\mathrm{O}_{2}}^{\text {ref }}}^{\ln p_{\mathrm{O}_{2}}^{\text {sample }}} t_{\mathrm{O}^{2-}} d \ln p_{\mathrm{O}_{2}} .
$$

where $p_{\mathrm{O}_{2}}^{\text {sample }}$ and $p_{\mathrm{O}_{2}}^{\text {ref }}$ are the oxygen partial pressure of the sample gas and the reference gas, respectively, and $R, F$, and $T$ are the gas constant, Faraday constant, and absolute temperature, respectively. Variable $t_{\mathrm{O}^{2-}}$ is the transference number of the oxygen ion, which can be represented using the total conductivity $\left(\sigma_{t}\right)$ and partial conductivity of the oxygen ion $\left(\sigma_{\mathrm{O}^{2-}}\right)$ by

$$
t_{\mathrm{O}^{2-}}=\frac{\sigma_{\mathrm{O}^{2-}}}{\sigma_{\mathrm{t}}}
$$

On the basis of this relationship, the slope on the $E M F$ vs. $\ln p_{\mathrm{O}_{2}}$ plot corresponds to the $t_{\mathrm{O}^{2-}}$.

\section{Appendix B}

Although Sansom and Slater described that the crystal with space group $P \overline{3}$ was hexagonal, the accurate crystal symmetry and lattice symmetry of $P \overline{3}$ are trigonal and rhombohedral, respectively, according to the International Tables for Crystallography, Vol. A (Ed. Hahn T H, Springer 2002). 


\section{Appendix C}

Referring to the monograph written by Kofstad (P. Kofstad, Nonstoichiometry, diffusion, and electrical conductivity in binary metal oxides, Wiley-Interscience, New York, 1972), an anion Frenkel defect pair is often referred to as an anti-Frenkel defect pair to distinguish it from the Frenkel defect pair formed by interstitial cations and cation vacancies. Given this categorization, the term "Frenkel-like defects" by Sansom and Slater indicated anti-Frenkel defects.

Acknowledgement Authors thank Dr. Takuji Ikeda at the National Institute of Advanced Industrial Science and Technology for consultations related to crystallography.

\section{References}

1) S. Nakayama, H. Aono and Y. Sadaoka, Chem. Lett., 24, 431432 (1995).

2) S. Nakayama, T. Kageyama, H. Aono and Y. Sadaoka, J. Mater. Chem., 5, 1801-1805 (1995).

3) S. Nakayama and M. Sakamoto, J. Eur. Ceram. Soc., 18, 1413-1418 (1998).

4) T. Kudo and K. Fueki, Solid State Ionics, Kohdansha Ltd. Tokyo, Japan (1990).

5) K. Kobayashi and Y. Sakka, J. Ceram. Soc. Japan, 122, 649663 (2014).

6) S. Nakayama and M. Sakamoto, J. Ceram. Soc. Japan, 100, 867-871 (1992)

7) PDF-2, http://www.icdd.com/index.htm.

8) G. Blasse and A. Bril, J. Inorg. Nucl. Chem., 29, 2231-2241 (1967).

9) G. Blasse and J. Devries, J. Inorg. Nucl. Chem., 29, 15411542 (1967)

10) W. W. Pillars and D. R. Peacor, Am. Mineral., 58, 681-690 (1973).

11) M. Sato, Y. Kono and K. Uematsu, Chem. Lett., 23, 14251428 (1994).

12) M. Sato, Y. Kono, H. Ueda, K. Uematsu and K. Toda, Solid State Ionics, 83, 249-256 (1996).

13) K. Kobayashi and Y. Sakka, Sci. Technol. Adv. Mater., 13, 045006 (2012).

14) ACerS-NIST Phase Equilibria Database. Standard Reference Database SRD 31. See http://www.nist.gov/srd/nist31.cfm.

15) S. Nakayama and Y. Sadaoka, Electrochim. Acta, 40, 25412546 (1995).

16) S. Nakayama and Y. Sadaoka, J. Mater. Chem., 3, 1251-1257 (1993).

17) N. A. Toropov and M. V. Kougiya, Izv. Akad. Nauk Sssr, Neorg. Mater., 7, 1220-1223 (1971) [Eng. Transl: Inorg. Mater., 7, 1082-1084 (1971)].

18) M. Higuchi, K. Kodaira and S. Nakayama, J. Cryst. Growth, 216, 317-321 (2000)

19) N. A. Toropov, F. Y. Galakhov and S. F. Konovalova, Izv. Akad. Nauk. SSSR. Otd. Khim., 539-543 (1961) [Engl. Transl: Bull. Acad. Sci. USSR, Div. Chem. Sci., 10, 497-501 (1961)].

20) N. A. Toropov and I. A. Bondar, Izv. Akad. Nauk. SSSR. Otd. Khim., 544-550 (1961) [Engl. Transl: Bull. Acad. Sci. USSR, Div. Chem. Sci., 10, 502-508 (1961)].

21) N. A. Toropov and I. A. Bondar, Izv. Akad. Nauk. SSSR. Otd. Khim., 739-744 (1961) [Engl. Transl: Bull. Acad. Sci. USSR, Div. Chem. Sci., 10, 682-687 (1961)].

22) N. A. Toropov, F. Y. Galakhov and I. A. Bondar, Izv. Akad. Nauk. SSSR. Otd. Khim., 1365-1371 (1961) [Engl. Transl: Bull. Acad. Sci. USSR, Div. Chem. Sci., 10, 1271-1277 (1961)].

23) N. A. Toropov and I. A. Bondar, Izv. Akad. Nauk. SSSR. Otd. Khim., 1372-1379 (1961) [Engl. Transl: Bull. Acad. Sci. USSR, Div. Chem. Sci., 10, 1278-1285 (1961)].

24) N. Toropov, A., Trans. 7th Internatl. Ceram. Congr., Internl.
Ceram. Congr., Paris, France (1961) pp. 435-442.

25) M. Montorsi, J. Less-Common Met., 84, 25-32 (1982).

26) J. Felsche, J. Solid State Chem., 5, 266-275 (1972).

27) O. L. Anderson and D. A. Stuart, J. Am. Ceram. Soc., 37, 573-580 (1954).

28) I. A. Bondar, Ceram. Internl, 8, 83-89 (1982).

29) E. R. Cohen, T. Cvitaš, J. G. Frey, B. Holmström, K Kuchitsu, R. Marquardt, I. Mills, I. Pavesa, M. Quack, J. Stohner, H. L. Strauss, M. Takami and A. J. Thor, Quantities, Units and Symbols in Physical Chemistry, 3rd edition (2007).

30) M. Higuchi, K. Kodaira and S. Nakayama, J. Cryst. Growth, 207, 298-302 (1999).

31) R. H. Hopkins, G. W. Roland, K. B. Steinbruegge and W. D. Partlow, J. Electrochem. Soc., 118, 637-639 (1971).

32) G. F. de la Fuente, L. R. Black, D. M. Andrauskas and H. R. Verdún, Solid State Ionics, 32-3, 494-505 (1989).

33) S. Nakayama, M. Sakamoto, M. Higuchi, K. Kodaira, M. Sato, S. Kakita, T. Suzuki and K. Itoh, J. Eur. Ceram. Soc., 19, 507-510 (1999).

34) M. Higuchi, H. Katase, K. Kodaira and S. Nakayama, J. Cryst. Growth, 218, 282-286 (2000).

35) S. Nakayama, M. Higuchi and K. Uematsu, Nippon Kagaku Kaishi, 2002, 243-245 (2002).

36) S. Nakayama and M. Highchi, J. Mater. Sci. Lett., 20, 913915 (2001).

37) S. Nakayama, M. Sakamoto, M. Highchi and K. Kodaira, J. Mater. Sci. Lett., 19, 91-93 (2000).

38 D. C. Noe, J. M. Hughes, A. N. Mariano, J. W. Drexler and A. Kato, Z. Kristallogr., 206, 233-246 (1993).

39) T. An, T. Baikie, F. X. Wei, H. N. Li, F. Brink, J. Wei, S. L. Ngoh, T. J. White and C. Kloc, J. Cryst. Growth, 333, 70-73 (2011).

$40)$ T. An, T. Baikie, F. X. Wei, S. S. Pramana, M. K. Schreyer, R. O. Piltz, J. F. Shin, J. Wei, P. R. Slater and T. J. White, Chem. Mater, 25, 1109-1120 (2013).

41) Y. Masubuchi, M. Higuchi, H. Katase, T. Takeda, S. Kikkawa, K. Kodaira and S. Nakayama, Solid State Ionics, 166, 213217 (2004).

42) H. Okudera, Y. Masubuchi, S. Kikkawa and A. Yoshiasa, Solid State Ionics, 176, 1473-1478 (2005).

43) D. I. Pushcharovskii, G. I. Dorokhova, E. A. Pobedimskaia and N. V. Belov, Dokl. Akad. Nauk SSSR, 242, 835-838 (1978) [Eng. Transl: Sov. Phys. Dokl., 23, 694-696 (1978)].

44) J. M. Hughes, A. N. Mariano and J. W. Drexler, Neu. Jahrb. Mineral.-Monatsh., 311-319 (1992).

45) L. León-Reina, E. R. Losilla, M. Martínez-Lara, S. Bruque and M. A. G. Aranda, J. Mater. Chem., 14, 1142-1149 (2004).

46) J. R. Tolchard and P. R. Slater, J. Phys. Chem. Solids, 69, 2433-2439 (2008).

47) K. Momma and F. Izumi, J. Appl. Cryst., 44, 1272-1276 (2011).

48) J. E. H. Sansom, D. Richings and P. R. Slater, Solid State Ionics, 139, 205-210 (2001).

49) T. J. White and Z. L. Dong, Acta Crystallogr., Sect. B: Struct. Crystallogr. Cryst. Chem., 59, 1-16 (2003).

50) F. Izumi and K. Momma, Solid State Phenomena, 130, 15-20 (2007).

51) W. J. A. Peterse and J. H. Palm, Acta Crystallogr., 20, 147150 (1966).

52) G. R. Redhammer and G. Roth, Acta Crystallogr., Sect. C: Cryst. Struct. Commun., 59, i120-i124 (2003).

53) J. Felsche, Rare Earths Struct. Bond., 13, 99-197 (1973).

54) M. Higuchi, Y. Masubuchi, S. Nakayama, S. Kikkawa and K. Kodaira, Solid State Ionics, 174, 73-80 (2004).

55) H. Okudera, A. Yoshiasa, Y. Masubuchi, M. Higuchi and S. Kikkawa, J. Solid State Chem., 177, 4451-4458 (2004).

56) H. Okudera, A. Yoshiasa, Y. Masubuchi, M. Higuchi and S. Kikkawa, Z. Kristallogr., 219, 27-31 (2004). 
57) P. M. Sidorov, E. L. Belokoneva, N. F. Fedorov, T. A. Tunik, M. A. Simonov and N. V. Belov, Zur. Struk. Khimi., 18, 397399 (1977) [Engl. Transl: J. Struct. Chem., 18, 319-321 (1977)].

58) A. C. Larson and R. B. von Dreele, Los Alamos National Lab. Rep, LA-UR-86748 (1994).

59) J. R. Tolchard, M. S. Islam and P. R. Slater, J. Mater. Chem., 13, 1956-1961 (2003).

$60)$ S. T. Misture, S. P. Harvey, R. T. Francy, Y. Gao, Y. G. S. DeCarr and S. C. Bancheri, J. Mater. Res., 19, 2330-2335 (2004).

61) I. Hartenbach and T. Schleid, Z. Kristallogr., 220, 206-210 (2005).

62) F. Werner and F. Kubel, Mater. Lett., 59, 3660-3665 (2005).

63) J. Felsche, Naturwissenschaften, 56, 325-326 (1969).

64) L. León-Reina, E. R. Losilla, M. Martínez-Lara, S. Bruque, A. Llobet, D. V. Sheptyakov and M. A. G. Aranda, J. Mater. Chem., 15, 2489-2498 (2005).

65) M. S. Islam, J. R. Tolchard and P. R. Slater, Chem. Comm., 1486-1487 (2003).

66) M. E. Fleet and X. Y. Liu, J. Solid State Chem., 178, 32753283 (2005)

67) Y. Masubuchi, M. Higuchi, T. Takeda and S. Kikkawa, J. Alloys Compd., 408, 641-644 (2006).

68) F. Izumi and R. A. Dilanian, Recent Res. Devel. Phy., 3, 669726 (2002).

69) F. Izumi and T. Ikeda, Mater. Sci. Forum, 198, 321-324 (2000).

70) L. León-Reina, J. M. Porras-Vázquez, E. R. Losilla and M. A. G. Aranda, Solid State Ionics, 177, 1307-1315 (2006).

71) S. Lambert, A. Vincent, E. Bruneton, S. Beaudet-Savignat, F. Guillet, B. Minot and F. Bouree, J. Solid State Chem., 179, 2602-2608 (2006).

72) H. Yoshioka, J. Alloys Compd., 408, 649-652 (2006).

73) S. Ferdov, R. A. S. Ferreira and Z. Lin, Chem. Mater, 18, 5958-5964 (2006).

74) C. Wang, X. Y. Liu, M. E. Fleet, S. H. Feng and R. R. Xu, J. Solid State Chem., 179, 2245-2250 (2006).

75) E. Rodríguez-Reyna, A. F. Fuentes, M. Maczka, J. Hanuza, K. Boulahya and U. Amador, J. Solid State Chem., 179, 522-531 (2006).

76) L. León-Reina, J. M. Porras-Vázquez, E. R. Losilla, D. V. Sheptyakov, A. Llobet and M. A. G. Aranda, Dalton Trans., 2058-2064 (2007).

77) T. Iwata, K. Fukuda, E. Béchade, O. Masson, I. Julien, E. Champion and P. Thomas, Solid State Ionics, 178, 1523-1529 (2007).

78) H. Yoshioka, J. Am. Ceram. Soc., 90, 3099-3105 (2007).

79) H. Zhang, Z. C. Li, B. Bergman and X. D. Zou, J. Mater. Sci. Technol., 23, 629-632 (2007).

80) R. Ali, M. Yashima, Y. Matsushita, H. Yoshioka, K. Ohoyama and F. Izumi, Chem. Mater., 20, 5203-5208 (2008).

81) T. Iwata, E. Béchade, K. Fukuda, O. Masson, I. Julien, E. Champion and P. Thomas, J. Am. Ceram. Soc., 91, 37143720 (2008).

82) W. Gibbs 1993(reprinted) The scientific papers of J Willard Gibbs. Vol. 1 (OX Bow Press. Connecticut, USA) pp. 55349: Original Papers were published between 1875 and 1878.

83) K. Kobayashi, Y. Matsushita, N. Igawa, F. Izumi, C. Nishimura, S. Miyoshi, Y. Oyama and S. Yamaguchi, Solid State Ionics, 179, 2209-2215 (2008).

84) H. Yoshioka, Y. Nojiri and S. Tanase, Solid State Ionics, 179, 2165-2169 (2008).

85) R. Ali, M. Yashima, Y. Matsushita, H. Yoshioka and F. Izumi, J. Solid State Chem., 182, 2846-2851 (2009).

86) Y. Matsushita, F. Izumi, K. Kobayashi, N. Igawa, H. Kitazawa, Y. Oyama, S. Miyoshi and S. Yamaguchi, Nucl. Instr. Methods. Phys. Res. Sect. A., 600, 319-321 (2009).

87) S. Guillot, S. Beaudet-Savignat, S. Lambert, R. N. Vannier, P.
Rousse and F. Porcher, J. Solid State Chem., 182, 3358-3364 (2009).

88) T. Kinoshita, T. Iwata, E. Béchade, O. Masson, I. Julien, E. Champion, P. Thomas, H. Yoshida, N. Ishizawa and K. Fukuda, Solid State Ionics, 181, 1024-1032 (2010).

89) Y. Nojiri, S. Tanase, M. Iwasa, H. Yoshioka, Y. Matsumura and T. Sakai, J. Power Sources, 195, 4059-4064 (2010).

90) T. Sakakura, M. Kamoshita, H. Iguchi, J. Wang and N. Ishizawa, Acta Crystallogr., Sect. E: Struct. Rep. Online, 66, i68 (2010).

91) Y. Q. Shen, R. Chen, F. Xiao, H. D. Sun, A. Tok and Z. L. Dong, J. Solid State Chem., 183, 3093-3099 (2010).

92) Y. Q. Shen, A. Tok and Z. L. Dong, J. Am. Ceram. Soc., 93, 1176-1182 (2010).

93) V. Uvarov, S. Shenawi-Khalil and I. Popov, J. Solid State Chem., 183, 1484-1489 (2010).

94) T. Baikie, S. S. Pramana, C. Ferraris, Y. Z. Huang, E. Kendrick, K. S. Knight, Z. Ahmad and T. J. White, Acta Crystallogr., Sect. B: Struct. Crystallogr. Cryst. Chem., 66, 1$16(2010)$

$95)$ J. E. H. Sansom, J. R. Tolchard, M. S. Islam, D. Apperley and P. R. Slater, J. Mater. Chem., 16, 1410-1413 (2006).

96) A. Orera, E. Kendrick, D. C. Apperley, V. M. Orera and P. R. Slater, Dalton Trans., 5296-5301 (2008).

97) N. Takeda, Y. Itagaki and Y. Sadaoka, J. Ceram. Soc. Japan, 115, 643-647 (2007).

98) S. Guillot, S. Beaudet-Savignat, S. Lambert, P. Roussel and R. N. Vannier, Solid State Ionics, 185, 18-26 (2011).

99) L. C. Leu, S. Thomas, M. T. Sebastian, S. Zdzieszynski, S. Misture and R. Ubic, J. Am. Ceram. Soc., 94, 2625-2632 (2011).

100) K. Fukuda, T. Asaka, N. Ishizawa, H. Mino, D. Urushihara, A. Berghout, E. Béchade, O. Masson, I. Julien and P. Thomas, Chem. Mater., 24, 2611-2618 (2012).

101) K. Fukuda, T. Asaka, R. Hamaguchi, T. Suzuki, H. Oka, A. Berghout, E. Béchade, O. Masson, I. Julien, E. Champion and P. Thomas, Chem. Mater., 23, 5474-5483 (2011).

102) K. Fukuda, T. Asaka, M. Oyabu, D. Urushihara, A. Berghout, E. Béchade, O. Masson, I. Julien and P. Thomas, Chem. Mater., 24, 4623-4631 (2012).

103) K. Kobayashi, Y. Matsushita, M. Tanaka, Y. Katsuya, C. Nishimura and Y. Sakka, Solid State Ionics, 225, 443-447 (2012).

104) C. H. Hsu, S. Das and C. H. Lu, J. Electrochem. Soc., 159, J193-J99 (2012).

105) K. Fukuda, T. Asaka, S. Hara, M. Oyabu, A. Berghout, E. Béchade, O. Masson, I. Julien and P. Thomas, Chem. Mater., 25, 2154-2162 (2013).

106) F. X. Zhang, H. Y. Xiao, M. Lang, J. M. Zhang, Y. W. Zhang, W. J. Weber and R. C. Ewing, Phys. Chem. Miner., 40, 817825 (2013).

107) G. C. Yin, H. Yin, H. Y. Zhu, X. X. Wu, L. H. Zhong, M. L. Sun, R. D. Cong, J. Zhang, W. Gao and Q. L. Cui, J. Alloys Compd., 586, 279-284 (2014).

108) K. M. Manu, C. Karthik, L. C. Leu, K. A. Lazar, R. Ubic and M. T. Sebastian, J. Am. Ceram. Soc., 96, 1504-1511 (2013).

109) E. I. Get'man, E. V. Borisova, S. N. Loboda and A. V. Ignatov, Russ. J. Inorg. Chem., 58, 265-268 (2013).

110) J. Mizusaki, S. Tsuchiya, K. Waragai, H. Tagawa, Y. Arai and Y. Kuwayama, J. Am. Ceram. Soc., 79, 109-113 (1996).

111) J. E. H. Sansom and P. R. Slater, Solid State Phenomena, vol. 90-91, Eds. P. Sajgalik, M. Drabik, and S. Varga, Trans. Tech. Pub., Switzerland (2003) pp. 189-194.

112) P. R. Slater and J. E. H. Sansam, Solid State Phenomena, vol. 90-91, Eds. P. Sajgalik, M. Drabik, and S. Varga, Trans. Tech. Pub., Switzerland (2003) p. 195-200.

113) J. E. H. Sansom and P. R. Slater, Solid State Ionics, 167, 2327 (2004).

114) J. E. H. Sansom, J. R. Tolchard, P. R. Slater and M. S. Islam, 
Solid State Ionics, 167, 17-22 (2004).

115) H. Yoshioka, Chem. Lett., 33, 392-393 (2004).

116) H. Yoshioka and S. Tanase, Solid State Ionics, 176, 23952398 (2005).

117) M. Y. Gorshkov, A. D. Neuimin, N. M. Bogdanovich and D. I. Bronin, Russ. J. Electrochem., 42, 737-743 (2006).

118) M. Y. Gorshkov, A. D. Neuimin, N. M. Bogdanovich, Y. V. Danilov and L. A. Dunyushkina, Russ. J. Electrochem., 43, 721-728 (2007).

119) S. Beaudet-Savignat, A. Vincent, S. Lambert and F. Gervais, J. Mater. Chem., 17, 2078-2087 (2007).

120) A. Chesnaud, C. Bogicevic, F. Karolak, C. Estournes and G. Dezanneau, Chem. Comm., 1550-1552 (2007).

121) A. Vincent, S. B. Savignat and F. Gervais, J. Eur. Ceram. Soc., 27, 1187-1192 (2007).

122) E. Béchade, I. Julien, T. Iwata, O. Masson, P. Thomas, E. Champion and K. Fukuda, J. Eur. Ceram. Soc., 28, $2717-$ 2724 (2008).

123) S. Chefi, A. Madani, H. Boussetta, C. Roux and A. Hammou, J. Power Sources, 177, 464-469 (2008).

124) A. Chesnaud, G. Dezanneau, C. Estournès, C. Bogicevic, F. Karolak, S. Geiger and G. Geneste, Solid State Ionics, 179, 1929-1939 (2008).

125) A. Mineshige, T. Nakao, M. Kobune, T. Yazawa and H. Yoshioka, Solid State Ionics, 179, 1009-1012 (2008).

126) P. J. Panteix, I. Julien, P. Abelard and D. Bernache-Assollant, Ceram. Internl., 34, 1579-1586 (2008).

127) S. H. Jo, P. Muralidharan and D. K. Kim, J. Mater. Res., 24, 237-244 (2009)

128) K. Kobayashi and C. Nishimura, ESC Trans., 25, 1785-1790 (2009).

129) J. M. Porras-Vázquez, E. R. Losilla, L. León-Reina, D. Marrero-López and M. A. G. Aranda, J. Am. Ceram. Soc., 92, 1062-1068 (2009).

130) Y. Higuchi, M. Sugawara, K. Onishi, M. Sakamoto and S. Nakayama, Ceram. Internl, 36, 955-959 (2010).

131) Z. X. Huang, B. Y. Li and J. Liu, Phys. Status Solidi., A Appl. Mater. Sci., 207, 2247-2251 (2010).

132) H. C. Yao, J. S. Wang, D. G. Hu, J. F. Li, X. R. Lu and Z. J. Li, Solid State Ionics, 181, 41-47 (2010).

133) T. Kharlamova, S. Pavlova, V. Sadykov, M. Chaikina, T. Krieger, A. Ishchenko, Y. Pavlyukhin, S. Petrov and C.
Argirusis, Eur. J. Inorg. Chem., 589-601 (2010).

134) J. Yu, H. Wang, J. Q. Li, X. K. Cheng, C. L. Chen and Z. L. Huang, Inorg. Mater., 46, 1212-1219 (2010).

135) P. Briois, C. Mazataud, S. Fourcade, F. Mauvy, J. C. Grenier and A. Billard, J. Electrochem. Soc., 158, B1479-B1484 (2011).

136) W. Gao, W. Y. Li, H. L. Liao and C. Coddet, J. Therm. Spray Tech., 20, 888-891 (2011).

137) B. Y. Li, J. Liu, Y. X. Hu and Z. X. Huang, J. Alloys Compd., 509, 3172-3176 (2011).

$138)$ V. A. Sadykov, T. S. Kharlamova, N. V. Mezentseva, S. N. Pavlova, E. M. Sadovskaya, V. S. Muzykantov, Y. N. Bespalko, V. V. Usoltsev, E. G. Zevak, T. A. Kriger, A. V. Ishchenko, N. F. Uvarov, A. S. Ulikhin, M. V. Chaikina and C. Argirusis, Russ. J. Electrochem., 47, 427-441 (2011).

139) K. Fukuda, T. Asaka, M. Okino, A. Berghout, E. Béchade, O. Masson, I. Julien and P. Thomas, Solid State Ionics, 217, 4045 (2012).

140) Y. L. Kuo and Y. Y. Liang, Ceram. Internl., 38, 3955-3961 (2012).

141) Q. L. Shi, L. H. Lu, Y. W. Zeng and H. Zhang, J. Wuhan Univ. Tech. Mater. Sci. Ed., 27, 841-846 (2012).

142) W. Gao, H. L. Liao and C. Coddet, J. Therm. Spray Tech., 22, 1103-1108 (2013).

143) W. Liu, S. Yamaguchi, T. Tsuchiya, S. Miyoshi, K. Kobayashi and W. Pan, J. Power Sources, 235, 62-66 (2013).

144) S. Nakayama, A. Ikesue, Y. Higuchi, M. Sugawara and M. Sakamoto, J. Eur. Ceram. Soc., 33, 207-210 (2013).

145) T. R. Yang, H. L. Zhao, J. H. Han, N. S. Xu, Y. N. Shen, Z. H. Du and J. Wang, J. Eur. Ceram. Soc., 34, 1563-1569 (2014).

146) H. Arikawa, H. Nishiguchi, T. Ishihara and Y. Takita, Solid State Ionics, 136, 31-37 (2000).

147) S. W. Tao and J. T. S. Irvine, Ionics, 6, 389-396 (2000).

148) A. Mineshige, T. Nakao, Y. Ohnishi, R. Sakamoto, Y. Daiko, M. Kobune, T. Yazawa, H. Yoshioka, T. Fukutsuka and Y. Uchimoto, J. Electrochem. Soc., 157, B1465-B1470 (2010).

149) S. Nakayama, Y. Higuchi, M. Sugawara, A. Makiya, K. Uematsu and M. Sakamoto, Ceram. Internl., 40, 1221-1224 (2014).

150) S. W. Tao and J. T. S. Irvine, Mater. Res. Bull., 36, 1245-1258 (2001). 